NBER WORKING PAPER SERIES

THE REAL EXCHANGE RATE, INNOVATION AND PRODUCTIVITY: HETEROGENEITY, ASYMMETRIES AND HYSTERESIS

\author{
Laura Alfaro \\ Alejandro Cuñat \\ Harald Fadinger \\ Yanping Liu
}

Working Paper 24633

http://www.nber.org/papers/w24633

\author{
NATIONAL BUREAU OF ECONOMIC RESEARCH \\ 1050 Massachusetts Avenue \\ Cambridge, MA 02138 \\ May 2018
}

We thank participants at NBER Summer Institute, AEA meetings, ESSIM, Barcelona GSE Summer Forum, Princeton JRCPPF Conference, IMF Macro-Financial Research Conference, SED, EAE-ESEM Lisbon and Cologne, Econometric Society North American Summer Meeting and China Meeting, CEBRA, CompNet 7th Annual Conference, Workshop on International Economic Networks (WIEN), Verein fuer Socialpolitik, XIX Conference in International Economics, Central Bank Macro Modeling Workshop, IMF 19th Jacques Polak Annual Research Conference and seminar participants at Aarhus, Bank of Canada, Central Bank of Chile, CERGE-EI, CREI, ETH, Frankfurt, IADB, IFN, Iowa, Indiana, Mannheim, Nottingham, NES Moscow, Notre Dame, Oslo, The Graduate Institute Geneva, Universidad Catolica de Chile, Queen Mary University of London, and Ufuk Akcigit, Pol Antras, Antoine Berthou, Kamran Bilir, Richard Brauer, Alberto Cavallo, Anusha Chari, Fabrice Defever, Jonathan Eaton, Jeff Frieden, Julian di Giovanni, Manuel Garcia-Santana, Steve Redding, Mark Roberts, Jesse Schreger, Stefano Schiavo, Monika Schnitzer, Bent Sorensen, Jim Tybout, Van Anh Vuong, and Shang-Jin Wei for helpful comments. We particularly thank Andy Powell, Julian Caballero, and the researchers at the IADB's Red de Centros project on the structure of firms' balance sheets. The views do not necessarily represent the views of Cornerstone Research nor the National Bureau of Economic Research.

NBER working papers are circulated for discussion and comment purposes. They have not been peerreviewed or been subject to the review by the NBER Board of Directors that accompanies official NBER publications.

(C) 2018 by Laura Alfaro, Alejandro Cuñat, Harald Fadinger, and Yanping Liu. All rights reserved. Short sections of text, not to exceed two paragraphs, may be quoted without explicit permission provided that full credit, including $\odot$ notice, is given to the source. 
The Real Exchange Rate, Innovation and Productivity: Heterogeneity, Asymmetries and Hysteresis Laura Alfaro, Alejandro Cuñat, Harald Fadinger, and Yanping Liu

NBER Working Paper No. 24633

May 2018, Revised April 2020

JEL No. F0,O1

\begin{abstract}
We evaluate manufacturing firms' responses to changes in the real exchange rate (RER) using detailed firm-level data for a large set of countries for the period 2001-2010. We uncover the following stylized facts about regional variation of manufacturing firms' integration into global value chains: firms in emerging Asia are very export oriented relative to their dependence on imported intermediates; firms from Latin America and Eastern Europe depend heavily on imported intermediates compared to their export orientation; firms from high-income countries export on average as much as they import. Motivated by these facts, we build a dynamic model in which real depreciations raise the cost of importing intermediates, affect export demand, borrowing-constraints and the profitability of engaging in innovation (R\&D). We decompose the effects of RER changes on average firm-level productivity growth across regions into these channels. We then structurally estimate the model and quantitatively evaluate the different mechanisms by providing counterfactual simulations of temporary RER movements. In export-oriented emerging Asia, real depreciations are on average associated with higher firm-level probabilities to engage in $\mathrm{R} \& \mathrm{D}$, faster growth of firm-level productivity and cash-flow and higher export entry rates. We find negative average effects for firms in other emerging economies, which are relatively more import dependent, and no significant average effects for firms in industrialized economies. Effects on physical TFP growth, while different across regions, are non-linear and asymmetric.
\end{abstract}

Laura Alfaro

Harvard Business School

Morgan Hall 263

Soldiers Field

Boston, MA 02163

and NBER

lalfaro@hbs.edu

Alejandro Cuñat

Department of Economics

University of Vienna

Oskar Morgenstern Platz 1

A-1090 Vienna

Austria

alejandro.cunat@univie.ac.at

\author{
Harald Fadinger \\ University of Mannheim \\ Department of Economics \\ L7 3-5, D-68131 Mannheim, Germany \\ and CEPR \\ harald.fadinger@uni-mannheim.de \\ Yanping Liu \\ University of Mannheim \\ Department of Economics \\ L7, 3-5, 68131 Mannheim, Germany \\ yanping.liu@uni-mannheim.de
}




\title{
The Real Exchange Rate, Innovation and Productivity*
}

\author{
Laura Alfaro ${ }^{\dagger}$
}

HBS and NBER

\author{
Alejandro Cuñat
}

U. Vienna and CES-ifo

\author{
Harald Fadinger ${ }^{\S}$
}

U. Mannheim and CEPR
Yanping Liu

Cornerstone Research

April 2020

\begin{abstract}
We evaluate manufacturing firms' responses to changes in the real exchange rate (RER) using detailed firm-level data for a large set of countries for the period 2001-2010. We uncover the following stylized facts about regional variation of manufacturing firms' integration into global value chains: firms in emerging Asia are very export oriented relative to their dependence on imported intermediates; firms from Latin America and Eastern Europe depend heavily on imported intermediates compared to their export orientation; firms from high-income countries export on average as much as they import. Motivated by these facts, we build a dynamic model in which real depreciations raise the cost of importing intermediates, affect export demand, borrowing-constraints and the profitability of engaging in innovation (R\&D). We decompose the effects of RER changes on average firm-level productivity growth across regions into these channels. We then structurally estimate the model and quantitatively evaluate the different mechanisms by providing counterfactual simulations of temporary RER movements. In export-oriented emerging Asia, real depreciations are on average associated with higher firm-level probabilities to engage in $R \& D$, faster growth of firm-level productivity and cash-flow and higher export entry rates. We find negative average effects for firms in other emerging economies, which are relatively more import dependent, and no significant average effects for firms in industrialized economies. Effects on physical TFP growth, while different across regions, are non-linear and asymmetric.
\end{abstract}

JEL Codes: F, O.

Key Words: real exchange rate, innovation, productivity, exporting, importing, financial constraints, firm-level data

*We thank participants at NBER Summer Institute, AEA meetings, ESSIM, Barcelona GSE Summer Forum, Princeton JRCPPF Conference, IMF Macro-Financial Research Conference, SED, EAE-ESEM Lisbon and Cologne, Econometric Society North American Summer Meeting and China Meeting, CEBRA, CompNet 7th Annual Conference, Workshop on International Economic Networks (WIEN), Verein fuer Socialpolitik, XIX Conference in International Economics, Central Bank Macro Modeling Workshop, IMF 19th Jacques Polak Annual Research Conference and seminar participants at Aarhus, Bank of Canada, Central Bank of Chile, CERGE-EI, CREI, ETH, Frankfurt, IADB, IFN, Iowa, Indiana, Mannheim, Nottingham, NES Moscow, Notre Dame, Oslo, The Graduate Institute Geneva, Universidad Católica de Chile, Queen Mary University of London, and Ufuk Akcigit, Pol Antràs, Antoine Berthou, Kamran Bilir, Richard Brauer, Alberto Cavallo, Anusha Chari, Fabrice Defever, Jonathan Eaton, Jeff Frieden, Julian di Giovanni, Manuel García-Santana, Steve Redding, Mark Roberts, Jesse Schreger, Stefano Schiavo, Monika Schnitzer, Bent Sorensen, Jim Tybout, Van Anh Vuong, and Shang-Jin Wei for helpful comments. We particularly thank Andy Powell, Julian Caballero, and the researchers at the IADB's Red de Centros project on the structure of firms' balance sheets. Hayley Pallan, Haviland Sheldahl-Thomason, George Chao, Daniel Ramos, Sang Hyu Hahn and Harald Kerschhofer provided great research assistance. Cuñat and Fadinger gratefully acknowledge the hospitality of CREI. Fadinger and Liu gratefully acknowledge financial support by the DFG (grant FA 1411/1-1 and CRC TR 224). Liu also gratefully acknowledges financial support from the European Research Council through grant no. 313623. Liu coauthored this paper before joining Cornerstone Research. The views expressed herein are solely those of the authors who are responsible for the content, and do not necessarily represent the views of Cornerstone Research.

† Email: lalfaro@hbs.edu

‡Email: alejandro.cunat@univie.ac.at

$\S$ Email: harald.fadinger@uni-mannheim.de Address: Department of Economics, University of Mannheim, L7 3-5, 68131 Mannheim, Germany.

『Email: yaliu@cornerstone.com 


\section{Introduction}

This paper looks into the link between real exchange rate (hereafter RER) changes and firm-level productivity growth. A number of policy debates have renewed the interest in the effects of RER movements on manufacturing activity (e.g. the experience of China's export-led industrialization strategy is often regarded as based on an undervalued real exchange rate). ${ }^{1}$ Real appreciations and their effects are also at the center stage of concerns over the effects of large capital inflows associated with the quantitative-easing policies implemented in the aftermath of the global financial crisis. ${ }^{2}$ Finally, the idea of governments defining interventionist industrial policies has ceased to be taboo even in the political debate of market-friendly countries. RER changes, for example, can produce effects comparable to those of the combination of import tariffs and export subsidies and are not constrained by the WTO. ${ }^{3}$

On the academic side, the empirical evidence regarding the effects of RER changes on economic activity is far from conclusive. On the one hand, there is some evidence that RER depreciations are associated with more manufacturing activity and faster economic growth in developing countries. This has been rationalized theoretically with sizable market imperfections specific to traded goods, in particular manufacturing exports. ${ }^{4}$ However, precise evidence on the channels through which this positive effect operates remains elusive and is hard to obtain. ${ }^{5}$ On the other hand, there is ample microlevel evidence of substantial productivity gains from importing intermediate goods (Halpern, Koren and Szeidl, 2015). RER depreciations increase the cost of importing them and are associated with aggregate productivity losses (Gopinath and Neiman, 2014). Finally, nowadays manufacturing production is based to a great extent on global value chains, which imply that firms simultaneously import intermediates and export their output; at the same time, the degree of firms' integration into these global value chains varies across regions (Baldwin, 2016). All of this suggests a more nuanced view of the impact of RER fluctuations on manufacturing activity and productivity.

We revisit this question by studying the effects of medium-term fluctuations in the RER on firm-level export and import decisions, innovation, and productivity growth using a dynamic heterogenous-firm model and micro data for many countries. We view changes in productivity as the result of firms' deliberate decisions and not as the outcome of externalities and develop a dynamic model of R\&D investment by heterogeneous firms that can also choose to export their output and import intermediate inputs. $^{6}$

\footnotetext{
${ }^{1} \mathrm{~S}$. Korea's industrialization is understood as partly based on an undervalued real exchange rate (Eichengreen, 2008).

${ }^{2}$ Policymakers in emerging markets have expressed concerns that large capital inflows can bring about the appreciation of their RERs and a corresponding loss of competitiveness in manufacturing. The use of reserve accumulation and capital controls has been suggested to limit exchange rate appreciations. (See Alfaro et al., 2017, Benigno et al., 2016, and Magud et al., 2018, for a discussion.) In rich countries, worries about appreciated RERs and their impact on economic activity, mainly in the manufacturing industry, have made recent headlines.

${ }^{3}$ Barattieri et al., 2018, for example, analyze macro-level effects of recent trade policy, in particular anti-dumping.

${ }^{4}$ See Rodrik, 2008, and Benigno and Fornaro, 2012. In the latter, given the traded nature of manufactures, a RER depreciation can be understood as a subsidy that remedies the under-provision of manufacturing output through an increase in exports.

${ }^{5}$ Henry, 2008, and Woodford, 2008, raise a number of empirical issues regarding this macro-level evidence (omitted variables, reverse causality, etc.).

${ }^{6}$ A related literature on the link between trade liberalization and innovation has highlighted general-equilibrium aspects as potentially important channels. For example, Atkeson and Burstein, 2010, emphasize the role of free entry.
} 
Our model implies that RER depreciations have different effects on firms' sales, profits and cash flow according to their trade status: they rise for exporters as these gain market shares abroad; and fall for importers as their costs rise. ${ }^{7}$ For firms engaging in both activities, the net effect on profits and cash flow depends on their export intensity relative to their import intensity. If RER fluctuations are persistent, they affect both current and future profits and thus the net present value of innovation. Subsequently, exporting firms' R\&D activities and thereby TFP growth are enhanced by RER depreciations, whereas importing firms reduce their $\mathrm{R} \& \mathrm{D}$ during depreciations. Whether changes in cash flow or expected future profits drive the response of R\&D activity to RER fluctuations depends on the importance of credit constraints, which may matter particularly in the case of emerging economies. We therefore allow for the potential presence of credit constraints in the model. Due to sunk innovation costs, the model yields asymmetric effects of real depreciations and appreciations, as first discussed by the hysteresis literature. Firms tend to respond less to a negative profitability shock compared to a positive one because they try to avoid having to repay the R\&D start-up cost in case they stop doing innovation. ${ }^{8}$

We then evaluate the model's quantitative performance by structurally estimating its key parameters using firm-level micro data for many countries. Since to our knowledge no single available dataset contains all the information we need, we combine firm-level data from a series of sources (Orbis, Wordbase, World Bank's Exporter Dynamics Database, representative micro data for several countries) ${ }^{9}$ for around 70 emerging economies and 20 industrialized countries for the period 2001-2010 to evaluate manufacturing firms' responses to changes in the RER. ${ }^{10}$

In our analysis, we group countries into three macro regions that display substantial differences as far as their firms' integration into the global economy is concerned: emerging Asia; other emerging markets (Latin America and Eastern Europe); industrialized countries. In comparison with firms from other emerging countries, firms from emerging Asia display a larger export orientation (in terms of both the probability to export and the ratio of exports to sales) relative to their import orientation (in terms of both the probability to import and the ratio of imports to sales). Industrial-country firms lie in between these two groups in this regard. These differences characterize the heterogeneous responses of manufacturing firms to RER changes.

Table 1 provides evidence for differences in export and import orientation of manufacturing firms. It reports firm-level import and export probabilities and intensities (imports/sales for importers; exports/sales for exporters) based on representative micro data sets for four countries for which we have detailed administrative firm-level data available: China, Colombia, Hungary, and France. ${ }^{11}$ Firms in China, representative for emerging Asia, have a high relative export orientation compared to firms from

\footnotetext{
${ }^{7}$ RER changes are taken as exogenous by firms and are passed on one-to-one to prices of exports and imports. See Burstein et al, 2005, on the responsiveness of export and import prices to exchange-rate changes.

${ }^{8}$ See Baldwin, 1988, Baldwin and Krugman, 1989, and Dixit, 1989.

${ }^{9}$ A detailed description of the data sources can be found in Section 4.1.

${ }^{10}$ Previous evidence based on firm-level studies, discussed below, is relatively scarce. Here, data availability for a wide range of countries including emerging economies has been an obvious constraint, limiting the analysis of firm-level mechanisms and their aggregate implications, as well as their external validity.

${ }^{11}$ The numbers for China have been computed by the authors from representative plant-level administrative data; information for Colombia is also from administrative data (we thank Norbert Czinkan for sharing this information with us); data for Hungary are from Halpern et al., 2015; data for France are from Blaum et al., 2018. The analysis considers that many firms are exporters and importers.
} 
the other countries (for Chinese firms the export probability divided by the import probability is 1.53 , whereas the firms' average export intensity divided by the corresponding import intensity is 4.62) while firms from Colombia (0.82 and 0.71) and Hungary (0.90 and 0.42), representative for the other emerging economies, have a low relative export orientation. Firms in France (1.15 and 1.64), representative for industrialized countries, have intermediate relative export propensities and intensities. ${ }^{12}$ In Appendix Table B-2 we compute the same statistics for emerging Asia and other emerging economies from the Worldbank's 2016 Enterprise Survey. This dataset includes a much larger sample of countries in these regions. We find similar numbers, thus confirming the representativeness of the four countries for their respective regions. ${ }^{13}$

Table 1: Evidence on import and export propensity/intensity of manufacturing firms

(Computed from representative micro data)

\begin{tabular}{rrrrr}
\hline \hline & China & Colombia & Hungary & France \\
\hline Export prob. & 0.26 & 0.37 & 0.35 & 0.23 \\
Import prob. & 0.17 & 0.45 & 0.39 & 0.20 \\
Relative export prob. & 1.53 & 0.82 & 0.90 & 1.15 \\
Avg. export intensity & 0.6 & 0.10 & 0.10 & 0.23 \\
$\begin{array}{r}\text { (exporters) } \\
\text { Avg. import intensity }\end{array}$ & 0.13 & 0.14 & 0.24 & 0.14 \\
$\begin{array}{r}\text { (importers) } \\
\text { Relative export intensity }\end{array}$ & 4.62 & 0.71 & 0.42 & 1.64 \\
\hline \hline
\end{tabular}

Data Sources: China: computed from administrative data; Colombia: computed from administrative data; Hungary: Halpern et al., 2015; France: Blaum et al., 2015.

With these stylized facts in mind, we then estimate the model's structural parameters separately for each region using an indirect-inference procedure. We match reduced-form regression coefficients of the impact of RER changes on firm-level outcomes such as TFP growth ${ }^{14}$ and the sensitivity of firms' R\&D activity to cash flow, as well as a number of additional firm-level statistics, such as crossregional differences in firms' average export and import orientation, innovation decisions and the firmsize distribution. To evaluate the fit of the estimated model, we show that it can reproduce a number of non-targeted moments, such as the sensitivity of firm-level R\&D, cash flow and the aggregate export entry rate to RER changes. The model also fits well moments conditional on trade participation: it can quantitatively replicate the positive effect of RER depreciations on exporting firms and the negative one on importing firms in terms of their R\&D decisions and cash flow.

\footnotetext{
${ }^{12}$ Defever and Riaño, 2017, document similar evidence for a broader sample of countries.

${ }^{13}$ The Enterprise Survey does not cover most industrialized countries. We also performed complementary analysis on regional differences in import and export propensity for the full set of countries in each region using information from Worldbase, which reports export and import status by plant. This evidence confirms the results presented above.

${ }^{14}$ The reduced-form regressions net out confounding factors that may impact on firm-level outcomes, such as aggregate supply or demand shocks to the manufacturing sector other than RER shocks, which are absent from the structural model. We thus match conditional correlations that are fully consistent with our structural model.
} 
Due to the regional heterogeneity in relative export orientation, the model predicts qualitatively different effects of RER depreciations on average firm outcomes: (i) manufacturing firms from emerging Asia experience positive average effects of real depreciations on their revenue productivity (TFPR) growth and R\&D activity; (ii) firms from other emerging countries (Eastern Europe and Latin America) experience instead negative average effects on these outcomes; (iii) industrial-country firms do not react much to real depreciations. ${ }^{15}$ In this context, we use our structural model to disentangle the different effects of RER depreciations that contribute to growth in firm-level TFPR that we can observe in the micro data: (i) transitory export demand effects; (ii) transitory productivity effects due to changes in firm-level imports; and (iii) persistent physical productivity effects due to innovation. ${ }^{16}$

We find that real depreciations have the largest positive effects on average firm-level physical productivity growth in emerging Asia, where firms display a high relative export orientation. In this region, the additional demand for exports dominates the negative effect on TFPR operating via the higher costs of imported intermediates. Thus, firm-level profitability increases on average. This induces additional firms to engage in R\&D and leads to faster physical TFP growth. By contrast, negative average effects are found for other emerging markets (Latin America and Eastern Europe), which are not particularly export oriented and rely heavily on imported intermediates. Finally, negative and positive effects of real depreciations tend to offset each other in industrialized economies.

These facts are consistent with different productivity channels - seemingly contradictory - stressed in different strands of the literature. In line with the "development" tradition our paper shows that RER depreciations increase exports and solve a market failure by enabling certain firms to relax financial constraints that prevent them from investing in innovation (R\&D activity). As argued by the "international" literature, depending on their (trade/financial) integration into the world economy, different firms and regions can experience disparate gains, in magnitude and sign, from similar changes in the RER. $^{17}$

Finally, we quantitatively evaluate the different mechanisms by providing counterfactual simulations of temporary RER movements. Several key results emerge here. First, even relatively short-lived (temporary) real depreciations can trigger sizable (positive or negative) long-run impacts on innovation and productivity growth because the evolution of physical TFP is very persistent. In emerging Asia, a 25-percent real depreciation over a five-year period (corresponding to one standard deviation of RER changes) raises average firm-level TFPR growth by up to 7 and physical TFP growth by up to 0.5 percentage points. By contrast, in the other emerging economies, the same depreciation reduces average firm-level TFPR growth by around 3 and physical TFP growth by up to 0.3 percentage points. Finally, the average industrialized-country firm does not react significantly to such a shock.

Second, the effects of real depreciations and appreciations are asymmetric due to hysteresis. In

\footnotetext{
${ }^{15}$ These predictions are corroborated by the reduced-form evidence that we present in the Appendix.

${ }^{16}$ In our model RER movements are triggered by productivity shocks to the outside sector. We do not provide a welfare analysis weighing benefits and costs of RER depreciations. Among the latter, for example, one should consider the costs of reserve accumulation, inflation, financial repression, tensions among countries, etc. (See Woodford, 2008, and Henry, 2008.)

${ }^{17}$ Negative effects are consistent with Diaz Alejandro's (1965) early characterization of those due to RER movements in Latin America, where "the existing manufacturing sector generally takes a dim view of exchange rate devaluations and fears such policy."
} 
the case of emerging Asia, for example, the negative impact of a real appreciation on TFPR and physical TFP growth is roughly a third of the size of the positive effect of a real depreciation of the same magnitude. In other emerging markets, the positive impact of an appreciation on productivity is instead more than twice as large as the negative impact of a depreciation of identical magnitude. These regional asymmetries are due to the heterogeneous impact of depreciations on average firm-level profitability and the corresponding changes in the option value of engaging in R\&D: firms' innovation responses to a positive profitability shock are larger than to a negative one because of sunk costs. These differences across regions also find support in our reduced-form evidence.

Third, the quantitative effects of depreciations are non-linear: for emerging Asia, doubling the magnitude of a depreciation leads to (positive) effects on firm-level outcomes that are more than double in magnitude. In other emerging markets instead, the (negative) impact of a larger depreciation is comparatively smaller in proportional terms than the impact of a depreciation of half the size. These non-linearities are explained by the substitution effects between domestic and imported inputs. These cushion the impact of larger depreciations on import costs in emerging Asia and boost the impact of larger appreciations in other emerging economies.

We conduct several robustness checks. First, we evaluate the role of credit constraints. Since R\&D investments are large, sunk, and intangible, they may be hard to finance from external sources. Therefore, in our benchmark model we allow for credit-constraints, so that firms' innovation decisions are not necessarily based exclusively on net-present-value considerations, but also on the availability of sufficient cash flow to fund them. We thus compare our benchmark model against one with no credit constraints. Not surprisingly, the latter model delivers larger effects of RER fluctuations on physical TFP growth, as innovation responds more to changes in future profit expectations. However, this comes at the price of the model's inability to match key data moments. In particular, the tight link between R\&D and cash flow that we observe in the data is lost without credit constraints.

Second, we introduce export sunk costs into the model, which have been shown to be quantitatively important for export responses to RER fluctuations (see, e.g., Alessandria and Choi, 2007). We find that our results are robust to this feature and that the firm-level effects of RER changes are qualitatively unchanged. In comparison with our baseline model, the impact of a depreciation on firm outcomes is a bit less positive for emerging Asia and more negative for the other emerging economies because in the presence of export sunk costs exports are less responsive to changes in the RER.

Third, we look into the valuation effects associated with changes in the RER. This "balance-sheet channel" may be relevant as devaluations raise the domestic value of debt for firms that issue unhedged foreign-denominated liabilities. ${ }^{18}$ In terms of foreign currency debt, data on currency composition and hedging for a wide range of countries is not easily available. We complement our analysis with information on currency denomination of foreign debt from the World Bank Enterprise survey and

\footnotetext{
${ }^{18} \mathrm{~A}$ vast literature has analyzed the effects of the balance-sheet channel. For theoretical work, see Céspedes et al., 2004, and references therein; Salomão and Varela, 2018, develop a firm-dynamics model with endogenous currency-debt composition using data for Hungary. Kohn et al., 2019, study the impact of financial frictions and balance-sheet effects on exports.
} 
national sources. ${ }^{19}$ We uncover that Eastern European and Latin American firms are more exposed to foreign-currency debt than firms from emerging Asia. Moreover, exporters borrow more in foreign currency compared to other firms. We then extend our structural model to account for a simple form of valuation effects. We show that for the empirically observed foreign-debt shares and the magnitude of RER fluctuations in the data, the qualitative and quantitative implications of our simulated model are similar: exporting and importing continue to be the dominating factors through which RER movements affect firm-level innovation decisions and TFP growth.

The rest of the paper is structured as follows. The next section presents a short review of the related literature. In Section 3 we lay out our theoretical framework. Section 4 presents our data and discusses our structural estimation strategy. In Section 5 we use our estimated model to run a number of counterfactual experiments and in Section 6 we report a number of extensions and robustness checks. Section 7 presents some concluding remarks.

\section{Related Literature}

Our findings relate to structural research based on firm-level data studying the link between trade, innovation, and productivity growth. Aw et al., 2011, estimate a dynamic framework to study the joint incentive to innovate and export for Taiwanese electronics manufacturers.Kasahara and Lapham, 2013, study the export and import choices of heterogeneous firms in a structurally estimated model for Chilean manufacturers that abstracts from $R \& D$ decisions. As far as the relationship between imports and innovation is concerned, Bøler et al., 2015, provide evidence for complementarities between these decisions using a panel of Norwegian firms. Regarding the link between imports and productivity, Halpern et al., 2015, structurally estimate these gains for Hungarian manufacturing firms, while Gopinath and Neimann, 2014, uncover large productivity losses due to reductions in imports at the product and firm level during the Argentine crisis that followed the collapse of the currency board. The role of imperfect substitution between foreign and domestic inputs has also been shown to be quantitatively important in explaining productivity losses in sovereign default episodes and, more generally, in explaining effects of large financial shocks. See Mendoza and Yue, 2012, and references therein. Large devaluations in emerging markets have also been used to study exporting behavior. See Alessandria et al., 2010, and Burstein and Gopinath, 2014, for an overview of the effects of large devaluations. A contemporaneous paper by Blaum, 2019, based exclusively on Mexican detailed micro data, considers the reaction of firms' joint export and import behavior in the face of large devaluations. He studies the resulting effects on aggregate productivity through within-industry reallocations, but does not look into firms' innovation activity. None of these papers uses cross-country firm-level data to identify changes in the incentives for innovation; furthermore, none takes into account the joint impact of exporting, imported intermediate inputs and financial constraints and none highlights the heterogeneous aggregate impact a given shock may have across countries due to differences in countries' integration into global value chains.

While our model is very rich, it still abstracts from a number of theoretical channels through which

\footnotetext{
${ }^{19}$ We cross-check the data with additional sources, as explained in the next section.
} 
trade may affect innovation. (Shu and Steinwender, 2018, provide a systematic review of the related empirical evidence.) In particular, we disregard a number of general-equilibrium effects, such as free entry (Atkison and Burstein, 2010) and import competition in firms' domestic market. In this regard, we do not find much evidence in support of an import-competition channel: firms that neither export nor import intermediates do not seem to respond to RER changes with changes in their R\&D activity or their productivity. We do not look into the free-entry channel due to data limitations.

Turning to the role of credit constraints, Bond et al., 2015, use Colombian firm-level data to study the negative implications of financial constraints for entrepreneurial decisions in the presence of high fixed costs to entry. The relation between financial constraints and trade is explored by Manova, 2013. ${ }^{20}$ She develops a static model of financial constraints and exporting in which fixed and variable costs of exporting have to be financed with internal cash flows. These financial constraints reduce exports at the extensive and the intensive margins. The link between trade, financial constraints, and innovation is studied in Gorodnichenko and Schnitzer, 2013, who produce a static model in which exports and innovation are complementary activities for financially unconstrained firms, but might become substitutes when financial constraints are binding. Our model avoids this feature by assuming that exporting is not subject to financial constraints. Finally, Midrigan and $\mathrm{Xu}, 2014$, use Korean producer-level data to evaluate the role of financial frictions in determining total factor productivity (TFP): they find that financial frictions distort entry and technology adoption decisions and generate dispersion in the returns to capital across existing producers, and thus productivity losses from misallocation. In line with this literature, our paper shows that RER fluctuations affect financial constraints that prevent firms from investing in R\&D activity subject to sizable fixed costs.

\section{Theoretical Framework}

We build a model with heterogeneous firms that choose whether or not to invest in R\&D, which in turn affects their future productivity, disciplined by the empirical evidence. The model focuses on the manufacturing sector, which is our object of empirical analysis. We adopt a small-open-economy approach in which foreign prices and expenditure are given. Free capital mobility keeps the interest rate constant. ${ }^{21}$ Since R\&D is an intangible investment that cannot be used as collateral easily, borrowing constraints are key: only firms with sufficiently large cash flow can finance the fixed and sunk costs involved in R\&D activity. Domestic firms self-select into exporting their output and/or importing materials. RER fluctuations change the profitability of these activities, as well as cash flow and the net present value of innovation and affect thereby firms' behavior.

\subsection{The Real Exchange Rate}

We think of the RER as the price of a country's consumption basket relative to that of the rest of the world. In the Appendix, we model its fluctuations in a Balassa-Samuelson way: productivity increases

\footnotetext{
${ }^{20}$ Chaney, 2016, also considers the role of financial constraints in determining firm export export behavior.

${ }^{21}$ The interest rate may still vary across regions due to differences in risk premia.
} 
in a freely traded numéraire sector lead to a higher wage and thereby higher prices in manufacturing and non-tradables; ${ }^{22}$ this brings about an RER appreciation, making exportables more expensive and importables cheaper. The logarithm of the cost-shifter (inverse of productivity) in the numéraire sector follows an $\mathrm{AR}(1)$ process:

$$
\log \left(e_{t}\right)=\gamma_{0}+\gamma_{1} \log \left(e_{t-1}\right)+\nu_{t}, \quad \nu_{t} \sim N\left(0, \sigma_{\nu}^{2}\right)
$$

We impose enough structure so that the $(\log )$ real exchange rate $\log \left(P_{t}^{*} / P_{t}\right) \approx \log \left(e_{t}\right)$ : a higher $e_{t}$ leads to lower factor prices and thereby a real depreciation.

\subsection{Preferences and Technologies}

There is a continuum of differentiated varieties of manufacturing goods. Consumers have the following preferences over manufacturing varieties $i$,

$$
D_{T, t}=\left(\int_{i \in \Omega_{T}} d_{i, t}^{\frac{\sigma-1}{\sigma}} d i+\int_{i \in \Omega_{T}^{*}} d_{i, t}^{\frac{\sigma-1}{\sigma}} d i\right)^{\frac{\sigma}{\sigma-1}} .
$$

$\Omega_{T}$ and $\Omega_{T}^{*}$ denote the sets of domestically produced and imported varieties, respectively, which are given ${ }^{23}$ and $d_{i t}$ is consumption of individual varieties. Since each variety is associated with a different producer, the number of firms equals the number of varieties. Firms are infinitely lived and heterogeneous in terms of log-productivity $\omega_{i t}$, which follows a Markov process defined below and is realized before firms make decisions in each period.

Each firm $i$ produces a single variety of the manufacturing good using technology:

$$
Y_{i, t}=\exp \left(\omega_{i, t}\right) K_{i, t}^{\beta_{k}} L_{i, t}^{\beta_{l}} M_{i, t}^{\beta_{m}}
$$

$K_{i, t}, L_{i, t}$, and $M_{i, t}$ denote the amounts of capital, labor and materials, respectively, employed by $i$.

\section{$3.3 \quad$ Imports}

Manufacturing firms can use domestic and imported intermediates, which are imperfect substitutes with elasticity of substitution $\varepsilon$ :

$$
M_{i, t}=\left[\left(B^{*} X_{i, t}^{*}\right)^{\frac{\varepsilon}{\varepsilon-1}}+X_{i, t}^{\frac{\varepsilon}{\varepsilon-1}}\right]^{\frac{\varepsilon-1}{\varepsilon}} .
$$

$X_{i, t}$ is the quantity of domestically produced intermediates used by firm $i ; X_{i, t}^{*}$ is the quantity of imported intermediate inputs (see Halpern et al., 2015). $B^{*}$ is a quality shifter that allows imported intermediates to be of a quality different from that of domestic intermediates. In case a firm decides to

\footnotetext{
${ }^{22}$ The rental rate of capital, which equals the interest rate, is assumed constant due to international capital mobility.

${ }^{23}$ We do not allow firms to enter or exit the manufacturing sector since in our data we do not observe these decisions.
} 
import foreign inputs, the price index of intermediates is

$$
P_{M, t}=P_{X, t} \exp \left[-\tilde{a}_{t}\left(e_{t}\right)\right] .
$$

$P_{X, t}$ is the price of domestically produced intermediates and $\tilde{a}_{t}\left(e_{t}\right)=(\varepsilon-1)^{-1} \ln \left[1+\left(A_{t} e_{t}^{-1}\right)^{\varepsilon-1}\right]$ is the cost reduction from importing that results from a combination of relative price, quality and imperfect substitution. ( $A_{t} \equiv B^{*} / P_{X, t}^{*}$ is the price-adjusted quality of imported intermediates. $)^{24}$ It is easy to show that the elasticity of $\exp [-\tilde{a}(e)]$ with respect to $e$ is positive: a depreciation raises the relative price of imported intermediates $P_{X, t}^{*} / P_{X, t}$ and the price of materials for importing relative to nonimporting firms, for which $P_{M, t}=P_{X, t}$. Moreover, this elasticity depends negatively on $e$ : substitution of domestic intermediates for foreign intermediates makes the response of $P_{M, t} / P_{X, t}$ to depreciations more muted the larger these are. Our assumptions thus imply that all importers have the same import intensity and that import intensity decreases in $e$.

Materials expenditure $\tilde{M}_{t} \equiv P_{M, t} M_{t}$ can be written as $\tilde{M}_{t}=P_{X, t} \exp \left[-\tilde{a}_{t}\left(e_{t}\right)\right] M_{t}$. Substituting this into the production function and taking $\operatorname{logs}$, and using $z \equiv \log Z, Z=K, L, \tilde{M}$,

$$
y_{i, t}=\beta_{0}+\beta_{k} k_{i, t}+\beta_{l} l_{i, t}+\beta_{m} \tilde{m}_{i, t}-\beta_{m} \log \left(P_{X, t}\right)+I_{m i, t} \beta_{m} \tilde{a}_{t}\left(e_{t}\right)+\omega_{i, t}
$$

$I_{m i, t}$ is an indicator that equals one if firm $i$ imports in period $t$. The term $I_{m i, t} \beta_{m} \tilde{a}_{t}\left(e_{t}\right)$ captures the productivity gains from importing intermediates. In case the firm does not import, this term disappears from the corresponding expression for the production function. We discuss the choice to import intermediates below.

\subsection{Demand}

Given preferences (2), demand faced by firm $i$ is

$$
d_{i, t}=\left(p_{i, t} / P_{T, t}\right)^{-\sigma} D_{T, t} \text { and } d_{i, t}^{*}=\left(p_{i, t} / P_{T, t}^{*}\right)^{-\sigma} D_{T, t}^{*}
$$

Here, $d_{i, t}$ is the domestic demand and $d_{i, t}^{*}$ is foreign demand faced by firm $i ; p_{i, t}$ is the price charged by firm $i$. $P_{T, t}$ is the price index of the manufacturing sector; $D_{T, t}$ is demand for the CES aggregate by domestic consumers. Both are taken as given by firms. The mass of foreign firms $\Omega_{T}^{*}$, foreign demand $D_{T, t}^{*}$ and the foreign price level $P_{T, t}^{*}$ are also given. Firms behave as monopolists and charge a constant mark-up over their marginal production costs. ${ }^{25}$ Firm $i$ 's domestic revenue is

$$
R_{i, t}^{d}=p_{i, t}^{1-\sigma} P_{T, t}^{\sigma-1}\left(E_{T, t}\right)
$$

\footnotetext{
${ }^{24}$ Note that $A_{t}$ includes anything affecting $P_{X, t}^{*}$, such as transport costs and tariffs on imports of intermediates.

${ }^{25} \mathrm{As}$ we show in the Appendix, due to the endogenous response of the wage to the change in $e$, the price charged by non-importing firms is $p_{i, t}\left(\omega_{i, t}, e_{t}\right)=e_{t}^{-1} \frac{\sigma}{\sigma-1} \exp \left(-\omega_{i, t}\right)$. Importing firms charge $p_{i, t}\left(\omega_{i, t}, e_{t}\right)=$ $e_{t}^{-1} \exp \left[-\tilde{a}_{t}\left(e_{t}\right)\right]^{\beta_{m}} \frac{\sigma}{\sigma-1} \exp \left(-\omega_{i, t}\right)$.
} 
where $E_{T, t}=P_{T, t} D_{T, t}$. As shown in the Appendix, non-importing $(N I)$ firms face factor costs proportional to $e^{-1}$. By substituting the optimal price into (8) we get:

$$
R_{i, t}^{d}\left(\omega_{i, t}\right)=\left(\frac{\sigma}{\sigma-1}\right)^{1-\sigma} \exp \left[(\sigma-1) \omega_{i, t}\right] e_{t}^{\sigma-1} P_{T, t}^{\sigma-1}\left(E_{T, t}\right)
$$

Variable domestic profits are given by $\Pi_{i, t}^{d}=R_{i, t}^{d} / \sigma$. Notice that $e_{t}$ affects $R_{i, t}^{d}$ by (i) impacting on the marginal cost faced by the firm and thereby the price $p_{i, t}$ it charges, and (ii) by shifting the domestic aggregate price level in manufacturing $P_{T, t}$. Both effects are proportional to $e_{t}^{-1}$ and cancel out. (See the Appendix). Thus, conditional on aggregate expenditure on manufacturing $E_{T, t}, e_{t}$ has no effect on $R_{i, t}^{d}$ and $\Pi_{i, t}^{d}$. By contrast, in the case of importing $(I)$ firms, $e_{t}$ has an additional negative effect on revenue (and profits) through the effect of the price of imported intermediates on the price these firms charge:

$$
R_{i, t}^{d}\left(\omega_{i, t}\right)=\left(\frac{\sigma}{\sigma-1}\right)^{1-\sigma} \exp \left[(\sigma-1) \omega_{i, t}\right] e_{t}^{\sigma-1} \exp \left[-\tilde{a}_{t}\left(e_{t}\right)\right]^{(1-\sigma) \beta_{m}} P_{T, t}^{\sigma-1}\left(E_{T, t}\right)
$$

Hence, a real depreciation reduces the domestic revenue and profits of importers. These profit reductions are proportionally smaller for larger depreciations, due to the fact that the elasticity of $\exp [-\tilde{a}(e)]$ with respect to $e$ depends negatively on $e$ : substitution of domestic for foreign intermediates makes the response of $P_{M, t} / P_{X, t}$ to depreciations more muted the larger these are.

\subsection{Exports}

If a firm with log-productivity level $\omega_{i t}$ chooses to export, its export revenue is

$$
R_{i, t}^{x}=p_{i, t}^{1-\sigma}\left(P_{T, t}^{*}\right)^{\sigma-1}\left(E_{T, t}^{*}\right)
$$

For non-importing $(N I)$ firms,

$$
R_{i, t}^{x}\left(\omega_{i, t}\right)=\left(\frac{\sigma}{\sigma-1}\right)^{1-\sigma} \exp \left[(\sigma-1) \omega_{i, t}\right] e_{t}^{\sigma-1}\left(P_{T, t}^{*}\right)^{\sigma-1}\left(E_{T, t}^{*}\right)
$$

Variable export profits are $\Pi_{i, t}^{x}=R_{i, t}^{x} / \sigma$. Changes in $e_{t}$ affect export revenues and profits by impacting on a firm's marginal cost. A real depreciation reduces domestic factor costs, thereby reducing export prices and increasing sales and profits in the export market. ${ }^{26}$ (The foreign price level $P_{T, t}^{*}$ is unaffected by the shift in $e_{t}$.) This effect is smaller for exporters that also import $(I)$, since a real depreciation makes imports of intermediate inputs more expensive. ${ }^{27}$

\footnotetext{
${ }^{26}$ Our model assumes that exports are invoiced in the exporting country's currency. If they were invoiced in a foreign currency, a depreciation would still lead to a larger amount of profits in domestic currency for the exporting firm by increasing the domestic-currency value of export revenue for a given amount of export revenue. Qualitatively, this leads to the same impact of RER movements on export decisions and the dynamic choice of R\&D.

${ }^{27} \mathrm{As}$ in the case of domestic sales, export revenues and profits of importers and non-importers differ by term $\exp \left[-\tilde{a}_{t}\left(e_{t}\right)\right]^{(1-\sigma) \beta_{m}}$. Because the elasticity of $\exp [-\tilde{a}(e)]$ with respect to $e$ depends negatively on $e$, the difference in importing and non-importing exporters performance becomes proportionally smaller with larger depreciations.
} 


\subsection{Exporter and Importer Status}

Importing and exporting decisions involve per-period fixed costs $f_{m}$ and $f_{x}$, respectively. ${ }^{28}$ Each firm's fixed costs are i.i.d. random draws from an exponential distribution. More productive firms self-select into one or both of these activities. The resulting decisions are static choices. Moreover, they are complements: each activity raises the gain from the other. Export and import decisions are made after $\omega_{i, t}$ is realized. Firm $i$ chooses one among four different "regimes", which characterize the following per-period profit function:

$$
\Pi_{i, t}\left(\omega_{i, t}\right)=\max \left[\Pi_{i, t}^{(x, m)}\left(\omega_{i, t}\right)-f_{x}-f_{m}, \Pi_{i, t}^{(x, 0)}\left(\omega_{i, t}\right)-f_{x}, \Pi_{i, t}^{(0, m)}\left(\omega_{i, t}\right)-f_{m}, \Pi_{i, t}^{(0,0)}\left(\omega_{i, t}\right)\right],
$$

where $\Pi_{i, t}^{x, m}\left(\omega_{i, t}\right)=\Pi_{i, t}^{d}\left[\omega_{i, t}, \exp \left[-\tilde{a}_{t}\left(e_{t}\right)\right]\right]+\Pi_{i, t}^{x}\left[\omega_{i, t}, e_{t}, \exp \left[-\tilde{a}_{t}\left(e_{t}\right)\right]\right]$ are the profits of a firm that both exports and imports; $\Pi_{i, t}^{(x, 0)}\left(\omega_{i, t}\right)=\Pi_{i, t}^{d}\left(\omega_{i, t}\right)+\Pi_{i, t}^{x}\left(\omega_{i, t}, e_{t}\right)$ are the profits of an exporting firm that does not import materials; $\Pi_{i, t}^{(0, m)}\left(\omega_{i, t}\right)=\Pi_{i, t}^{d}\left[\omega_{i, t}, \exp \left[-\tilde{a}_{t}\left(e_{t}\right)\right]\right]$ are the profits of an importing non-exporter; and $\Pi_{i, t}^{(0,0)}\left(\omega_{i, t}\right)=\Pi_{i, t}^{d}\left(\omega_{i, t}\right)>0$ are the profits of a firm that neither exports nor imports. Notice that firms that choose to export and/or import can always finance the corresponding fixed costs with their profits.

\subsection{Dynamic Choice of R\&D}

Unlike the static export and import choices, the R\&D choice is dynamic due to both the existence of stochastic fixed and sunk costs and its impact on productivity, which is persistent. Innovation increases productivity, but is subject to an i.i.d sunk cost $f_{R D, 0}$ in the period the firm starts innovating and i.i.d. fixed costs $f_{R D}$ in other periods in which it innovates. Both costs are drawn from exponential distributions. We follow Aw et al., 2011, and assume that log-productivity $\omega_{i, t}$ follows the following Markov process

$$
\omega_{i, t}=\alpha_{0}+\alpha_{1} \omega_{i, t-1}+\alpha_{2} I_{i R D, t-1}+u_{i, t}, \quad u_{i, t} \sim N\left(0, \sigma_{u}^{2}\right)
$$

$I_{i R D, t-1}$ is an indicator variable for innovation in $t-1$ and $\alpha_{2}$ is the short-run log-productivity return to innovation. Under $\left|\alpha_{1}\right|<1$, the stochastic process is stationary and the model does not produce any long-run productivity trends. A firm that always engages in $R \& D$ has expected logproductivity $E\left(\omega_{i, t} \mid I_{i R D, t}=1 \quad \forall t\right)=\frac{\alpha_{0}+\alpha_{2}}{1-\alpha_{1}}$; a firm that never does R\&D has expected log-productivity $E\left(\omega_{i, t} \mid I_{i R D, t}=0 \quad \forall t\right)=\frac{\alpha_{0}}{1-\alpha_{1}}$.

We model credit constraints by assuming that in each period the sum of all sunk and fixed costs cannot go beyond a proportion $\theta$ of current period's cash flow:

$$
I_{i R D, t}\left[f_{R D, 0}\left(1-I_{i R D, t-1}\right)+f_{R D} I_{i R D, t-1}\right] \leq \theta \epsilon_{i, t} \Pi_{i, t}\left(\omega_{i, t}, e_{t}\right) .
$$

Parameter $\theta \in[1, \bar{\theta}]$ reflects the quality of the financial system: the lower $\theta$, the more financially constrained the firms. $\epsilon_{i, t}$ is an i.i.d. shock that affects cash flow and thereby the amount that can

\footnotetext{
${ }^{28}$ Unlike with the R\&D decision, we assume no one-time sunk cost is required for either of these two activities. We consider a model with export sunk costs in an extension, discussed in Section 6 below.
} 
be borrowed to finance $\mathrm{R} \& \mathrm{D}$, but not the profit and value of doing $\mathrm{R} \& \mathrm{D}$. It is distributed lognormal: $\ln (\epsilon) \sim N(0,1) .{ }^{29}$

As in Manova, 2013, firms do not have any savings from past cash flows or profits and they rent whatever physical capital they use. Therefore they cannot pledge any assets as collateral. ${ }^{30}$ In order to avoid moral-hazard problems, lenders expect borrowing firms to have some "skin in the game" by financing a fraction of the investment themselves (that is, a down-payment). ${ }^{31}$ The more important the moral-hazard problems, the lower $\theta$, which implies that a larger fraction of the project must be financed out of firm's cash flow.

To sum up, firms maximize

$$
\mathbb{E}_{0} \sum_{t=0}^{\infty}(1+r)^{-t}\left\{\Pi_{i, t}-I_{i R D, t}\left[f_{R D, 0}\left(1-I_{i R D, t-1}\right)+f_{R D} I_{i R D, t-1}\right]\right\}
$$

s.t. (1), (13), (14), (15). $r$ denotes the interest rate, which is constant due to capital mobility and our small-open-economy assumption. ${ }^{32}$ This objective function can be derived by maximizing the value of the firm given an initial debt level $B_{i, 0}$, the budget constraint:

$$
\begin{aligned}
& B_{i, t+1}+\Pi_{i, t}=I_{i R D, t}\left[f_{R D, 0}\left(1-I_{i R D, t-1}\right)+f_{R D} I_{i R D, t-1}\right]+(1+r) B_{i, t}, \quad \text { for } B_{i, t}>0, \\
& \Pi_{i, t}-I_{i R D, t}\left[f_{R D, 0}\left(1-I_{i R D, t-1}\right)+f_{R D} I_{i R D, t-1}\right]=\text { dividends } s_{i, t}, \quad \text { for } B_{i, t}=0,
\end{aligned}
$$

the credit constraint $(15)$ and $\lim _{t \rightarrow \infty} B_{i, t} /(1+r)^{t} \leq 0$. The current state for firm $i$ in year $t$ is given by the vector $s_{i, t}=\left(\omega_{i, t}, e_{t}, I_{i R D, t-1}\right)$. The firm's value function is then,

$$
\begin{aligned}
& V_{i, t}\left(s_{i, t}\right)= \\
& \quad \mathbb{E}_{R D}\left[\operatorname { m a x } _ { I _ { i R D , t } } \left\{\Pi_{i, t}\left(\omega_{i, t}, e_{t}\right)-\left[f_{R D, 0}\left(1-I_{i R D, t-1}\right)+f_{R D} I_{i R D, t-1}\right]+\beta \mathbb{E}_{t} V_{i, t+1}\left(s_{i, t+1} \mid I_{i R D, t}=1, s_{i, t}\right),\right.\right. \\
& \left.\left.\quad \Pi_{i, t}\left(\omega_{i, t}, e_{t}\right)+\beta \mathbb{E}_{t} V_{i, t+1}\left(s_{i, t+1} \mid I_{i R D, t}=0, s_{i, t}\right)\right\}\right]
\end{aligned}
$$

where $\beta=(1+r)^{-1}$ and $\mathbb{E}_{R D}$ indicates expectations with respect to the R\&D fixed and sunk costs, $f_{R D}$ and $f_{R D, 0}$. The firm then chooses an infinite sequence of R\&D decisions $I_{i R D, t}$ that maximizes the value function subject to the financial constraint for R\&D. ${ }^{33}$

\footnotetext{
${ }^{29}$ This shock breaks the perfect correlation between profits and cash flow in the model. This feature enables us to match some data moments better further below.

${ }^{30}$ In Manova, 2013, firms cannot use profits from past periods to finance future operations: in the absence of debt they have to distribute all profits to shareholders due to (unmodeled) principal-agent problems; in the presence of outstanding debt they use all profits for repayment.

${ }^{31}$ Alternatively, one could assume that a constant fraction of profits goes to dividends and the rest to debt repayment.

${ }^{32}$ Discounting with the constant interest rate $r$ implicitly assumes that firm owners are risk neutral or able to diversify away the firm's idiosyncratic risk.

${ }^{33}$ This way of modeling R\&D choice helps us understand the economics of the results we report in Section 4.5 below. Small (i.e. low-productivity) firms are unlikely to carry out any R\&D activity: for sufficiently large sunk costs, these firms have no incentive whatsoever to invest in R\&D even in the absence of credit constraints; since they barely make any profits, the net present value of such a decision is negative. For higher-productivity firms, the net present value of investing in $R \& D$ is positive, but the credit constraint limits such activity to the amount of current cash flow corrected by the tightness of the constraint. The looser the constraint, the less current profits matter for R\&D decisions. Finally, for very highly productive firms, current profits are large enough for them to finance R\&D regardless of the credit constraint. Their investment activity is guided exclusively by the net present value of R\&D activity.
} 
To summarize, the timing of decision making in period $t$ is the following:

1. Observe $s_{i, t}=\left(\omega_{i, t}, e_{t}, I_{i R D, t-1}\right)$.

2. Observe the realizations of $f_{x}$ and $f_{m}$.

3. Choose variables inputs $\left(M_{i, t}, L_{i, t}, K_{i, t}\right)$, export status $I_{i x, t}$ and import status $I_{i m, t}$.

4. Observe realization of cash-flow shock $\epsilon_{i, t}$ and R\&D fixed costs $f_{R D, 0}$, and $f_{R D}$.

5. Make R\&D decision $I_{i R D, t}$.

Having set up the model, we now discuss how to connect it to the data. According to our model, changes in innovation and import behavior induced by RER fluctuations should impact on firm-level productivity growth. Thus, we next show how to obtain an empirical measure of (revenue-based) productivity growth; how the empirical measure of productivity growth responds to changes in the RER; and how to relate it to its theoretical counterpart in the model.

\subsection{Revenue-based Productivity}

We follow de Loecker, 2011, Halpern et al., 2015 and Aw et al., 2011, to obtain consistent estimates of the short-run return to $\mathrm{R} \& \mathrm{D} \alpha_{2}$ and the output elasticities $\beta_{i}$ from firm-level data on revenue, capital and labor inputs, material expenditure and R\&D status. ${ }^{34}$ Substituting the demand function (7) into the definition of total revenue, the latter can be expressed as: ${ }^{35}$

$$
R_{i, t}=p_{i, t} d_{i, t}+I_{i X, t} p_{i, t} d_{i, t}^{*}=\left(Y_{i, t}\right)^{\frac{\sigma-1}{\sigma}} G_{i, t}\left(D_{T, t}, D_{T, t}^{*}, e_{t}\right)
$$

where $Y_{i, t}$ is physical output and $G_{i, t}$ captures the state of aggregate demand, which depends on the RER $e_{t} . G_{i, t}$ varies by firm only through $I_{i X, t}$, an indicator variable that equals one if the firm exports and thus allows the firm to also attract foreign demand. ${ }^{36}$ Note that, conditional on exporting, export intensity is the same for all firms and depends positively on $e_{t}$. Taking logs and plugging in production function (6), we obtain a log-linear expression of firm revenue in terms of physical output and aggregate demand faced by each firm:

$$
r_{i, t}=\left[\tilde{\beta}_{0}+\tilde{\beta}_{k} k_{i, t}+\tilde{\beta}_{l} l_{i, t}+\tilde{\beta}_{m} \tilde{m}_{i, t}-\tilde{\beta}_{m} \log \left(P_{X, t}\right)+I_{i m, t} \tilde{\beta}_{m} \tilde{a}_{t}\left(e_{t}\right)+\tilde{\omega}_{i t}\right]+g_{i, t}\left(D_{T, t}, D_{T, t}^{*}, e_{t}\right),
$$

where $x$ indicates the natural $\log$ of the variable and $\tilde{x}$ indicates multiplication by $\frac{\sigma-1}{\sigma}$. In the Appendix, we show how to combine (20) with the Markov process for log productivity (14) in order to consistently estimate output elasticities $\tilde{\beta}_{i}$ and the short-run return to R\&D $\tilde{\alpha}_{2}$.

Having recovered the output elasticities, we can construct an empirical measure of the log of firmlevel revenue-based productivity (TFPR) as

$$
t f p r_{i, t} \equiv r_{i, t}-\tilde{\beta}_{l} l_{i, t}-\tilde{\beta}_{k} k_{i, t}-\tilde{\beta}_{m} m_{i, t}=\left[\tilde{\beta}_{0}+\tilde{\omega}_{i, t}+I_{i m, t} \tilde{\beta}_{m} \tilde{a}_{t}-\tilde{\beta}_{m} \log P_{X, t}\right]+g_{i, t}\left(D_{T, t}, D_{T, t}^{*}, e_{t}\right) .
$$

\footnotetext{
${ }^{34}$ Like the vast majority of studies, we do not have information on firm-level prices of outputs and materials available. ${ }^{35}$ Details of the derivation can be found in Appendix A-1.4.

${ }^{36} G_{i, t}\left(D_{T}, D_{T}^{*}, e_{t}\right) \equiv D_{T}^{\frac{1}{\sigma}} P_{T}$ if $I_{i X, t}=0$ and $G_{i, t}\left(D_{T}, D_{T}^{*}, e_{t}\right) \equiv\left[\nu_{t}\left(e_{t}\right)^{\frac{\sigma-1}{\sigma}} D_{T}^{\frac{1}{\sigma}} P_{T}+\left(1-\nu_{t}\left(e_{t}\right)\right)^{\frac{\sigma-1}{\sigma}}\left(D_{T}^{*}\right)^{\frac{1}{\sigma}}\left(P_{T}^{*}\right)\right]$ if $I_{i X, t}=1$, where $1-\nu_{t}\left(e_{t}\right)$ is the (common) export intensity.
} 
Notice that this empirical measure of TFPR is a combination of physical productivity $\tilde{\beta}_{0}+\tilde{\omega}_{i, t}$, import effects on TFPR $I_{i m, t} \tilde{\beta}_{m} \tilde{a}_{i, t}\left(e_{t}\right)$ and export demand $g_{i, t}\left(D_{T, t}, D_{T, t}^{*}, e_{t}\right)$. We do not control for the effect of exporting and importing when constructing the empirical measure of TFPR because in our micro data we neither observe time variation in firms' export and import indicators (just a constant trade status) nor their import and export intensities. We thus need to use our structural model to decompose it into these three components. ${ }^{37}$

\subsection{Decomposing the Revenue-based Productivity Effects of RER Changes}

We now use our structural model to derive a decomposition that splits the revenue-based productivity elasticity with respect to the RER into physical TFP growth due to changes in innovation, an import channel and an export-demand channel.

In the structural estimation procedure discussed below, we match the empirical average firm-level RER elasticity of TFPR with the one generated by our model. In the regression we run on the data, we model the conditional expectation of the $\log$ of TFPR as $\mathbb{E}\left(\operatorname{tfpr}_{i c, t} \mid X_{i c, t}\right)=\beta_{0}+\beta_{1} \log e_{c, t}+\beta_{2} X_{s c, t}+$ $\delta_{i}+\delta_{t}$, where $\delta_{i}$ and $\delta_{t}$ are respectively firm and time fixed effects, and $X_{s c, t}$ is a vector of control variables. Taking time differences to eliminate $\delta_{i}$, we obtain the empirical regression specification

$$
\Delta \operatorname{tfpr}_{i c, t}=\beta_{1} \Delta \log e_{c t}+\beta_{2} \Delta X_{s c, t}+\Delta \delta_{t}+u_{i c t},
$$

where $\beta_{1}=\frac{\mathbb{E}\left(t f p r_{i c, t} \mid X_{s c, t}\right)}{\log t_{c t}}$ is the short-run elasticity of firm-level TFPR with respect to the RER conditional on $X_{s c, t}$. In our empirical specification, $X_{s c, t}$ includes business cycle controls (the growth rate of real GDP and the inflation rate), as well as country-sector fixed effects that absorb the average growth rate of TFPR in each 3-digit sector in a given country. Therefore, this estimate corresponds to a partial-equilibrium elasticity net of general equilibrium effects.

Taking expectations of (21) and derivatives with respect to RER, we can compute the model counterpart to regression coefficient $\beta_{1}$ :

$$
\beta_{1} \equiv \frac{\partial \mathbb{E}\left(t f p r_{i, t}\right)}{\partial \log e_{t}}=\underbrace{\tilde{\alpha}_{2} \frac{\partial \operatorname{Prob}\left(I_{i R D, t-1}=1\right)}{\partial \log e_{t}}}_{\text {innovation }}+\underbrace{\tilde{\beta}_{m} \frac{\partial \mathbb{E}\left(I_{i m, t} \tilde{a}_{t}\right)}{\partial \log e_{t}}}_{\text {imports }}+\underbrace{\frac{\partial \mathbb{E}\left(g_{i, t}\left(D_{T, t}, D_{T, t}^{*}, e_{t}\right)\right)}{\partial \log e_{t}}}_{\text {export demand }}
$$

Note that $\tilde{\alpha}_{2} \frac{\partial \operatorname{Prob}\left(I_{R D, t-1}=1\right)}{\partial \log e_{t}}=\frac{\tilde{\alpha}_{2}}{\gamma_{1}} \frac{\partial \operatorname{Prob}\left(I_{R D, t-1}=1\right)}{\partial \log e_{t-1}}$. This is the innovation channel of the elasticity of TFPR with respect to RER. The magnitude of the innovation channel depends on the product of the short-run TFP return to R\&D and the sensitivity of firms' innovation status to changes in the RER. This depends both on (i) a market-size effect and (ii) a financial-constraints effect. The former affects $\mathrm{R} \& \mathrm{D}$ activity through changes in export market profits and, subsequently, in the net present value of future profits. The latter operates through a change of current cash flow and, subsequently, of the

\footnotetext{
${ }^{37}$ In the construction of the empirical measure of TFPR, we do not adjust for the markup term (i.e., we do not multiply the output elasticities by $\sigma /(\sigma-1))$. As we show in Appendix Table A-3 adjusting output elasticities for this term makes no substantial difference for the empirical results. Consistently, when computing the decomposition of tfpr from the structural model, we also multiply coefficients by $(\sigma-1) / \sigma$ (see below).
} 
borrowing constraint. Below we decompose the innovation channel into these two effects.

The second term is the import channel of the elasticity of TFPR with respect to the RER, which affects the elasticity of TFPR negatively. It operates through changes in marginal costs due to changes in the imports of intermediate inputs. These changes in importing of intermediates imply transitory changes in TFPR. They can be further divided into two terms: an extensive margin, which measures the change in the probability to import weighted by the average import intensity; and an intensive margin, which measures the change in import intensity weighted by the average probability to import. ${ }^{38}$ The import channel is more relevant in the presence of a larger fraction of importers and a higher import intensity.

Finally, the third term is the export-demand channel of the elasticity of TFPR. An increase in the RER increases demand and revenue for exporters. Again, this term can be further decomposed into two terms: an extensive margin, which represents the change in the probability of exporting weighted by average export sales; and an intensive margin, which measures the average change in export sales weighted by the probability of exporting. ${ }^{39}$ The export-demand channel is more important in the presence of a larger fraction of exporters and a higher export intensity.

\section{Structural Estimation}

In this section, we first provide a detailed description of the different datasets we use and how we combine them before discussing the structural estimation procedure and the estimation results.

\subsection{Data and Sources}

We combine several data sources to obtain information on firm-level outcomes, such as TFPR growth, cash flow, R\&D status and export and import status for manufacturing firms located in each of the regions; representative information on export and import participation of manufacturing firms in each region; and macro variables, such as the RER. ${ }^{40}$ Of course, one cannot expect the same level of data quality as in high-quality micro datasets available for individual countries. However, the use of crosscountry firm-level data (i) guarantees much better external validity of our findings without the need to extrapolate results for a single country to other economies and (ii) allows us to exploit the structural differences across regions that we have highlighted in the introduction.

Regarding firm-level data, our first data source is Orbis (Bureau Van Dijk), which provides information for listed and unlisted firms on sales, materials, capital stock (measured as total fixed assets), cash flow (all measured in domestic currency), ${ }^{41}$ employees, and R\&D participation. Our sample spans the period 2001-2010: we have an unbalanced annual panel of firms in 76 emerging economies and 23 industrialized countries. Data coverage varies a lot across countries and the sample is not necessarily

\footnotetext{
${ }^{38} \tilde{\beta}_{m} \frac{\partial \mathbb{E}\left(I_{i m, t} \tilde{a}_{t}\right)}{\partial \log e_{t}}=\tilde{\beta}_{m}\left[\frac{\partial \operatorname{Prob}\left(I_{i m, t}>0\right)}{\partial \log e_{t}} \mathbb{E}\left(\tilde{a}_{t} \mid I_{i m, t}>0\right)+\operatorname{Prob}\left(I_{i m, t}>0\right) \frac{\partial \mathbb{E}\left(\tilde{a}_{t} \mid I_{i m, t}>0\right)}{\partial \log e_{t}}\right]$.

$39 \frac{\partial \mathbb{E}\left(g_{i, t}\left(D_{T, t}, D_{T, t}^{*}, e_{t}\right)\right)}{\partial \log e_{t}}=\left[\frac{\partial \operatorname{Prob}\left(I_{i x, t}=1\right)}{\partial \log e_{t}} \mathbb{E}\left(g_{t}\left(D_{T, t}, D_{T, t}^{*}, e_{t}\right) \mid I_{i x, t}=1\right)+\operatorname{Prob}\left(I_{i x, t}=1\right) \frac{\partial \mathbb{E}\left(g_{t}\left(D_{T, t}, D_{T, t}^{*}, e_{t}\right) \mid I_{i x, t}=1\right)}{\partial \log e_{t}}\right]$.

${ }^{40} \mathrm{~A}$ detailed explanation of the datasets we use can be found in the Appendix.

${ }^{41}$ Cash flow is the difference in the amount of cash available at the beginning and end of a period.
} 
representative in all countries (see Appendix Table B-1, Panel A). ${ }^{42}$ We focus on manufacturing firms (US-SIC codes 200-399). The sample is selected according to the availability of the data necessary to construct TFPR (gross output, materials, capital stock and employees). It includes around 1,333,000 firm-year observations corresponding to around 495,000 firms (see Appendix Table B-1, Panel B for descriptive statistics). Our second data source is Worldbase (Dun and Bradstreet), which provides plant-level information of production activities, export and import status and plant ownership for the same set of countries as Orbis. ${ }^{43}$ We use an algorithm to match firms in the two data sets based on company names. We use the export and import status in the first year the firm reports this information and are able to match around 177,000 firms. We also construct a dummy for the multinational status of a company for the same set of firms. ${ }^{44}$

In terms of representative firm-level data that we use to match aggregate statistics, we also draw on data from several sources. The World Bank's Exporter Dynamics Database reports entry rates into exporting by country and year for a large set of countries for our sample period. This variable is computed from underlying customs micro data covering all export transactions (see Fernandes et al., 2016 for more details). We also use detailed administrative firm-level data on sales, exports and imports for China, Colombia, Hungary and France to compute representative statistics on export and import probabilities and intensities for these countries. As an alternative source for this information for emerging economies, we use representative firm-level data from the Worldbank's 2016 version of the World Enterprise Survey. In addition, we take advantage of information on the fraction of manufacturing firms performing R\&D by region from the OECD's Science, Technology and Innovation Scoreboard, which is based on representative survey data.

We obtain data on the exposure of firms to foreign-currency borrowing from various sources. First, we use the 2002-2006 version of the World Enterprise Survey. This vintage of the dataset has the advantage that it provides information for a wide range of countries included in our sample. Second, for a subset of countries, we have more detailed data collected from Central Banks and the IADB research department. ${ }^{45}$

We define the real exchange rate (RER) as $\log \left(e_{c, t}\right)=\log \left(1 / P_{c, t}\right)$, where $P_{c, t}$ is the price level of GDP in PPP (expenditure-based) from PWT 8.0 in country $c$ in year $t .{ }^{46}$ This RER measure is defined relative to the U.S. and is our main empirical measure of the RER since its definition is consistent with our structural model. An increase indicates a real depreciation of the currency (making exports cheaper

\footnotetext{
${ }^{42}$ Since data coverage varies substantially across countries within each macro region, we prefer to look at macro regions, rather than exploiting heterogeneity across individual countries.

${ }^{43}$ This data set is more comprehensive in terms of coverage than Orbis. It provides the 4-digit SIC code of the primary industry in which each establishment operates; SIC codes of as many as five secondary industries; basic operational information (sales, employment, export and import status); and ownership information to link plants within the same firm. But it does not include the balance-sheet variables to construct TFPR nor information on plants' R\&D status.

${ }^{44}$ The set of countries in each region and the corresponding numbers of firm-level observations in Orbis, the descriptive statistics for firm-level variables and for the growth rate of the RER are listed in Table B-1, panels A-D.

${ }^{45}$ We use data provided by the IADB databases compiled as part of the Research Network project Structure and Composition of Firms' Balance Sheets. For Colombia the data comes from Barajas et al., 2016, for Brazil, Valle et al., 2017, and Chile, Alvarez and Hansen, 2017.

${ }^{46}$ We obtain similar results using PPP from PWT 7.1. We prefer using version 8.0 since the accuracy of version 7.1 has recently been questioned (see Feenstra et al., 2015). However, since we use growth rates of RER rather than levels and the measurement problems are related to levels, our results are not affected by them. See Cavallo and Rigobon, 2017, for an in-depth discussion.
} 
Table 2: Parameters needed

\begin{tabular}{ccccc}
\hline Parameter & Description & Value & Parameter & Description \\
\hline \multicolumn{2}{l}{$\left({ }^{*}\right.$ set without solving the dynamic model* $\left.{ }^{*}\right)$} & & (*estimated parameters*) \\
$\sigma$ & demand elasticity & 4 & $f_{x}$ & export fixed cost, mean \\
$\varepsilon$ & subst. elasticity intermediates & 4 & $f_{m}$ & import fixed cost, mean \\
$r$ & interest rate (emerging) & 0.10 & $f_{R D, 0}$ & R\&D sunk cost, mean \\
$r$ & interest rate (industrialized) & 0.05 & $f_{R D}$ & R\&D fixed cost, mean \\
$\alpha_{2}$ & return to R\&D & 0.06 & $\theta$ & coefficient for credit constraint \\
$\gamma_{1}$ & persistence, log RER & 0.93 & $\alpha_{1}$ & persistence, log productivity \\
$\sigma_{\nu}$ & s.d., log RER & 0.1 & $\sigma_{u}$ & s.d., innovation of log productivity \\
& & & $\log \left(E_{T}\right)$ & $\log$ domestic demand \\
\end{tabular}

and imports more expensive). ${ }^{47}$

In terms of other macro data, we draw on the real GDP growth rate from the Penn World Tables 8.0 (PWT 8.0); compute inflation rates from GDP deflators as reported by the IMF; and take information on private credit/GDP by country from the World Bank's Global Financial Development Database.

\subsection{Calibration}

We now identify the structural model parameters of the model and estimate them separately for each of the three macro regions (emerging Asia, other emerging economices, industrialized countries).

First, we calibrate a few model parameters $(r, \sigma, \varepsilon)$ that we cannot identify from the data. Table 2 reports our preferred values for these parameters. For industrialized economies, we choose a real interest rate of $5 \%$. For emerging markets, we set the annual real interest rate to $10 \%$. These numbers are obtained from the World Development Indicators and correspond to the average annual real interest rates for firm bonds in these regions during the sample period. We set the elasticity of demand $\sigma$ equal to 4 (see Costinot and Rodriguez-Clare, 2014). We set the elasticity of substitution between domestic and imported intermediates equal to 4, which is in the range estimated by Halpern et al., 2015, for Hungarian firms. We provide robustness checks for all of these parameter choices in Section 6.

\subsection{Estimates of the RER Process}

The parameters of the RER process can be estimated without simulating the model. We estimate a single $\operatorname{AR}(1)$ process of $\log \left(e_{t}\right)$ (see equation (1)) for the period 2001-2010. We pool all countries in the sample because we do not want variation in outcomes to be driven by regional differences in the stochastic process governing RER fluctuations. ${ }^{48}$ Table B-3 in the Appendix reports the corresponding

\footnotetext{
${ }^{47}$ Alternatively, we also construct export-weighted and import-weighted country-sector-specific RERs by combining country-level PPP deflators with bilateral sectoral export and import shares at the 3-digit US-SIC level (164 manufacturing sectors) from UN COMTRADE database. We define $\log \left(e_{s c, t}^{E X P}\right) \equiv \sum_{c^{\prime}} w_{c c^{\prime} s 0}^{E X} \log \left(P_{c^{\prime}, t} / P_{c, t}\right)$ and $\log \left(e_{s c, t}^{I M P}\right) \equiv \sum_{c^{\prime}} w_{c c^{\prime} s 0}^{I M P} \log \left(P_{c^{\prime}, t} / P_{c, t}\right) . \quad w_{c c^{\prime} s 0}^{E X P}$ and $w_{c c^{\prime} s 0}^{I M P}$ are the sector-s export share of country $c$ to country $c^{\prime}$ and the import share of country $c$ from country $c^{\prime}$, respectively. Both shares are calculated for the first period of the sample. This measure of the RER is used in robustness checks.

${ }^{48}$ Moreover, we do not find much evidence that the RER process varies systematically across regions.
} 
results. The point estimate for the auto-correlation of the $\log \operatorname{RER} \gamma_{1}$ is 0.93 : swings in the RER are very persistent and can thus potentially have a significant effect on firms' dynamic R\&D investment decisions. The estimated standard deviation of the RER shock $\sigma_{v}$ is 0.1 .

\subsection{Estimates of the Return to R\&D and Output Elasticities}

Also the short-run physical TFP return to R\&D and the production function coefficients can be structurally estimated without simulating the full model. Table B-4 in the Appendix reports the point estimates of both the production-function parameters (equation (6)) and the parameters of the stochastic process for log-productivity (equation (14)). Again, we do not want to allow for heterogeneity in these coefficients across regions and thus estimate a single value for these parameters in the pooled sample. In columns (1) and (2) of Table B-4 we report unconstrained estimates of the output elasticities of factor inputs for the gross-output and value-added production functions, while in columns (3) and (4) we report estimates imposing constant returns to scale. Depending on the specification, the estimate for the R\&D coefficient $\tilde{\alpha}_{2}$ is in the interval [0.033, 0.078], which, given a value of $\sigma$ of 4 , corresponds to a short-run TFP return to R\&D $\alpha_{2}$ of 4.4 to 10.4 percent. Given an auto-correlation of TFP of around 0.85 , this implies a steady-state TFP difference between a firm that never engages in R\&D and one that always performs R\&D of 30 to 70 percent. These numbers are broadly in line with the literature (see, e.g., Aw et al., 2010). To be conservative, we set $\alpha_{2}$ equal to 6 percent in the model simulation, and provide robustness checks for an even lower value.

The estimates for the output elasticities suggest increasing returns to scale for the case of the grossoutput-based production function and constant returns for the value-added production function. ${ }^{49}$ In the model simulations, we use gross-output-based production functions and TFPR and scale output elasticities to add up to unity (constant returns).

\subsection{Estimation of Model Parameters using Indirect Inference}

The remaining model parameters are estimated structurally by matching model-generated statistics with the data. The structural estimation method employed is Indirect Inference (Gouriéroux and Monfort, 1993). We first choose a set of auxiliary statistics that provide a rich statistical description of the data and then try to find parameter values such that the model generates similar values for these auxiliary statistics. More formally, let $\nu$ be the $p \times 1$ vector of data statistics and let $\nu(\Theta)$ denote the synthetic counterpart of $\nu$ with the same statistics computed from artificial data generated by the structural model. Then the indirect-inference estimator of the $q \times 1$ vector $\Theta, \tilde{\Theta}$ is the value that solves

$$
\min _{\Theta}(\nu-\nu(\Theta))^{\prime} V(\nu-\nu(\Theta))
$$

\footnotetext{
${ }^{49}$ The coefficients on labor, capital and materials in column (1) are 0.336, 0.097 and 0.681 and correspond to $\beta_{L}=0.448$, $\beta_{K}=0.129$ and $\beta_{M}=0.899$, which suggests increasing returns to scale. By contrast, the estimates for the value-addedbased output elasticities in column (2) are $\tilde{\beta}_{L}=0.533$, and $\tilde{\beta}_{K}=0.208\left(\beta_{L}=0.71\right.$ and $\left.\beta_{K}=0.28\right)$, suggesting constant returns. The estimates for the constrained coefficients in column (3) are $0.336,0.051$ and 0.363 and imply $\beta_{L}=0.448$, $\beta_{K}=0.068$ and $\beta_{M}=0.484$.
} 
where $V$ is the $p \times p$ optimal weighting matrix (the inverse of the variance-covariance matrix of the data statistics $\nu$ ). The following parameters $\tilde{\Theta}$ are estimated within the structural model: the mean export fixed cost $f_{x}$, the mean import fixed cost $f_{m}$, the mean R\&D sunk cost $f_{R D, 0}$, the mean R\&D fixed $\operatorname{cost} f_{R D}$, the credit-constraint parameter $\theta$ and the domestic and foreign (log) aggregate demand levels $\log \left(E_{T}\right)$ and $\log \left(E_{T}^{*}\right) .{ }^{50}$ We also estimate within the model the auto-correlation coefficient of TFP, $\alpha_{1}$, and the standard deviation of the TFP shocks $\sigma_{u}{ }^{51}$

We estimate these structural parameter values separately for each of the three regions. In order to identify the model parameters, we choose to match a number of cross-sectional statistics and dynamic moments. In terms of cross-sectional statistics, crucial moments are each region's firms' export and import orientation. We thus match the model's implied export probability, import probability, export/sales ratio for exporters, import/sales ratio for importers, with the ones reported in Table 1 . We target statistics for China for emerging Asia, statistics for Hungary for other emerging economies and statistics for France for industrialized economies. We also match the model's implied R\&D probability to the R\&D probability for firms of each region using information from the OECD's innovation score board, and we match the model's implied mean and standard deviation of the firm-size distribution (in terms of log sales) to the corresponding moments for each region in the Orbis data. The values of the targeted statistics for each region can be found in Tables 4-6.

In addition, we target a number of dynamic moments. The first key dynamic statistic that we target is the elasticity of firm-level TFPR with respect to the RER for each region, as estimated from regression (22). This moment is informative about the average firm-level response of the observable productivity measure TFPR with respect to the RER. The point estimates for these elasticities for each region are reported in Tables 4-6 and the full regression specifications can be found in Appendix Table A-1. For manufacturing firms from emerging Asia, there is a significant positive association between real depreciations and TFPR growth (elasticity 0.12 , s.d. 0.02 ), whereas for firms from other emerging economies the relationship is significantly negative (elasticity -0.11, s.d. 0.04). Finally, for industrialcountry firms there is no significant correlation between the growth rate of the RER and firm-level TFPR growth (elasticity -0.03 , s.d. 0.03). Note that these elasticity estimates are conceptually consistent with our model, since they partial out potential general equilibrium effects of RER movements. See the Appendix for a detailed discussion of the econometric identification.

The second important dynamic moment that we target is informative about the relationship between R\&D status and credit constraints. To obtain reduced-form estimates for the sensitivity of R\&D to firmlevel cash flow, we regress the firm-level R\&D status on log cash flow, allowing the relationship to vary both by the level of financial development and by firm size bins. We run the following regression for

\footnotetext{
${ }^{50}$ Since $E_{T}$ is treated as a parameter, the model is effectively identified in partial equilibrium. This is consistent with the theory where $w_{t}$ fluctuates exogenously with shocks to $e_{t}$ and there are no general-equilibrium feedback effects of firms' innovation decisions on factor prices. Since we control for general-equilibrium effects in the reduced-form regressions from which we take a number of targeted moments, the empirical moments are conceptually consistent with the model-generated moments.

${ }^{51}$ In principle, these parameters can be directly recovered from the production-function estimation, but there we allow for a Markov process which is a bit more general than $\mathrm{AR}(1)$. We do this because the production-function estimation works much better when we also allow for a square term in lagged productivity.
} 
firms in the Orbis dataset:

$I_{i R D, t}=\beta_{0} \sum_{i=1}^{4} \beta_{1 i} \log (\text { cashflow })_{i, t} \times$ size $_{i}+\sum_{i=1}^{4} \beta_{2 i} \log \left(\right.$ cashflow $_{i, t} \times$ size $_{i} \times$ fin.dev $\cdot c_{c}+\beta_{4} X_{i c, t}+\nu_{i, t}$,

where $I_{i R D, t}$ is an indicator that equals one if firm $i$ performs R\&D in year $t . \log (\text { cash flow })_{i, t}$ is the firm's cash flow (in logs), size $e_{i}$ is a dummy indicator for the firm-size quartile (measured in terms of $\log ($ employment)), fin. dev.c is a measure of the country's financial development (private credit/GDP) and $X_{i c, t}$ is a vector of controls. ${ }^{52}$ Table 3 summarizes the estimated marginal effects for each region by firm-size bin. ${ }^{53}$ Indeed, the estimated marginal effect of cash flow on the probability to engage in innovation is positive for sufficiently large firms, but the relationship is stronger for emerging-market firms compared to firms located in industrialized economies. We thus target for each region the elasticity of $R \& D$ with respect to cash flow of the top firm-size quartile; and the ratio of this elasticity for the fourth relative to the second firm-size quartile.

Table 3: Marginal effects of cash flow on firms' R\&D probability (estimates by region)

\begin{tabular}{lccc}
\hline \hline & $\begin{array}{c}\text { emerging } \\
\text { Asia }\end{array}$ & $\begin{array}{c}\text { other } \\
\text { emerging }\end{array}$ & industrialized \\
\hline credit/GDP & 0.84 & 0.50 & 1.47 \\
\hline marginal effect of cash flow - firm-size quartile 1 & 0 & 0 & 0 \\
marginal effect of cash flow - firm-size quartile 2 & 0.017 & 0.024 & 0.003 \\
marginal effect of cash flow - firm-size quartile 3 & 0.034 & 0.041 & 0.020 \\
marginal effect of cash flow - firm-size quartile 4 & 0.039 & 0.046 & 0.026 \\
\hline \hline
\end{tabular}

Notes: Predicted marginal effects of $(\log )$ cash flow on R\&D probability by firm size quartile for each region based on the regression specifications reported in Table A-6.

We also match the model-generated start and continuation rates of $\mathrm{R} \& \mathrm{D}$ for firms in each region with the ones computed from Orbis data. Note that R\&D status is very persistent with a continuation rate of around 0.9 and a low start rate of around 0.06. Finally, we target the autocorrelation of the empirical measure of firm-level TFPR for each region, which is in the ballpark of 0.9. Overall, the model is over-identified: we estimate 10 parameters while targeting 13 statistics.

While parameters and moments are all jointly identified, some moments are much more sensitive to certain parameters than to others. The export probability mainly identifies the distribution of export fixed costs, while the export-to-sales ratio is informative about relative foreign demand. A higher mean export fixed cost reduces export participation, while higher foreign demand increases the exports-tosales ratio. The elasticity of TFPR with respect to the RER also plays a role for pinning down these parameters: ceteris paribus, the smaller the export fixed costs and the larger foreign demand, the higher the export participation and intensity. Thus, the elasticities of average export demand and TFPR with respect to the RER will be higher in this case.

\footnotetext{
${ }^{52}$ The controls account for additional heterogeneity absent in our model and business-cycle controls. They consist of firm-size-bin dummies, capital stock (in logs), the inflation rate, the real growth rate of GDP and country-sector fixed effects.

${ }^{53}$ The corresponding point estimates are reported in Appendix Table A-6.
} 
The import probability and the import-to-sales ratio are most sensitive to import fixed costs and the relative quality of imported intermediates. A larger mean import fixed cost reduces import participation, while a larger price-adjusted quality of imported intermediates increases import intensity. Higher import participation and import intensity also reduce the average elasticity of TFPR with respect to the RER: for importers, TFPR contains the import component which is affected negatively by an RER depreciation.

The elasticity of $R \& D$ with respect to cash flow is informative about the credit-constraint parameter, as it governs the extent to which R\&D decisions are determined by current profits rather than by the net present value of future profits. Moreover, comparing the elasticities of $R \& D$ with respect to cash flow for the fourth and second firm-size quartiles is informative about how this statistic varies with firm size, which in turn depends on the level of credit constraints (see Table 3). In the presence of sufficiently large start-up costs of $R \& D$, low-productivity firms never find it worthwhile to engage in $\mathrm{R} \& \mathrm{D}$, independently of the level of credit constraints (so their decision not to invest in $\mathrm{R} \& \mathrm{D}$ is insensitive to cash flow). When credit constraints are tight, medium to high-productivity firms in principle would find it profitable to do R\&D but they are credit constrained. Thus, the R\&D decisions are very sensitive to current profits for sufficiently productive firms. By contrast, with loose credit constraints, high-productivity firms' decisions are determined by net-present-value considerations. Consequently, the $R \& D$ choices of sufficiently productive firms are not very sensitive to changes in the level of current cash flow. Thus, when credit constraints are relaxed, the relationship between the elasticity of R\&D with respect to cash flow and firm size becomes looser.

The identification of the parameters related to $\mathrm{R} \& \mathrm{D}$ is more complicated, since individual parameters affect several moments simultaneously. Given the TFP-return to R\&D, $\alpha_{2}$, and the process for the RER, the $R \& D$ probability, the $R \& D$ start rate, the $R \& D$ continuation rate, the auto-correlation of TFPR and the firm-size distribution together identify the R\&D sunk and fixed costs, the auto-correlation and the standard deviation of TFP. Other things equal, a higher R\&D sunk cost reduces the R\&D participation and start rates, and raises the $\mathrm{R} \& \mathrm{D}$ continuation rate; it also affects the auto-correlation of TFPR and the elasticity of TFPR with respect to the RER by making R\&D less sensitive to fluctuations in the RER. A higher R\&D fixed cost mainly reduces the R\&D participation rate. Finally, the auto-correlation and standard deviation of TFP affect the firm-size distribution, export and import participation, the net present value of $R \& D$ and its option value, thereby influencing the $R \& D$ participation, start and continuation rates.

The indirect-inference procedure is implemented as follows. For a given set of parameter values, we solve the value function and the corresponding policy function with a value-function iteration procedure: we first draw a set of productivity and RER shocks; we then simulate a set of firms for multiple countries with different realizations of the RER and compute the statistics of interest. We compare the simulated and data statistics and update the parameter values to minimize the weighted distance between them. We iterate these steps (keeping the draws of the shocks fixed) until convergence. See the Appendix for details. 


\subsection{Indirect Inference - Estimation Results}

Tables 4-6 report the parameter values estimated using the indirect-inference procedure for the three regions and a comparison between the data and the simulated statistics. We report standard errors in parentheses. In general, the model performs well in terms of fitting both cross-sectional moments as well as dynamic statistics. The firm-size distribution and the import and export probabilities and intensities are always very precisely matched, while the model slightly under-predicts R\&D participation rates. $\mathrm{R} \& \mathrm{D}$ start and continuation rates are also quite closely matched in all regions. The model also matches the difference in signs of the elasticity of firm-level TFPR with respect to the RER across regions. The predicted RER elasticities are slightly larger in absolute magnitudes ( 0.21 vs. 0.12 for emerging Asia; -0.15 vs. -0.10 for other emerging economies) and the elasticities of $R \& D$ with respect to cash flow for the top firm-size quartile display slightly more variation across regions in the model than in the data. Overall, the discrepancies between model-generated and data moments are small.

The parameters are estimated quite precisely. The mean sunk costs incurred by R\&D starters are large for firms in all regions. The values are remarkable relative to average R\&D benefits (17.6 percent of average R\&D benefits for emerging Asia, around 28 percent for other emerging economies and 102 percent for industrialized countries). ${ }^{54}$ The mean R\&D fixed cost for continuous R\&D performers is much smaller than R\&D start-up costs: these costs correspond to roughly 0.24 to 1 percent of mean $\mathrm{R} \& \mathrm{D}$ benefits. The mean fixed cost for importing is relatively low in relation to importers' sales (corresponding to the 4th-5th percentile of importers' sales). The mean fixed cost for exporting is more sizable and corresponds to the 10-12th percentile of exporters' sales. The high export intensity of firms in emerging Asia is due to large foreign demand relative to domestic demand as shown by the values of $\log \left(E_{T}^{*}\right)$ and $\log \left(E_{T}\right)$.

The value of $A$, the price-adjusted relative quality of imported intermediates, is significantly lower than one for emerging Asia and the industrialized countries (0.72 and 0.69, respectively), whereas it takes on a larger value for other emerging economies (0.97). Credit constraints are substantial in emerging Asia and other emerging economies (firms in these regions are estimated to be able to borrow up to 15 and 11 times their current profits, respectively), and pretty much non-binding in industrialized countries (their firms can borrow up to 53 times current profits). This parameter is estimated relatively precisely, except for industrialized countries. Finally, the parameters ruling the stochastic process of $\log$-productivity $\omega$ are comparable across the three subsamples: $\alpha_{1}$ and $\sigma_{u}$ are in the ballpark of 0.85 and 0.45 , respectively.

\subsection{Non-targeted Moments}

In order to assess the model's external validity, we now report the model's performance as far as a number of non-targeted moments are concerned. We first show that the model can replicate the average firm-level elasticity of $R \& D$, cash flow and the entry rate into exporting in each region in response to

\footnotetext{
${ }^{54} \mathrm{By} R \& \mathrm{D}$ benefits we understand the net present value of the firm's expected flow of profits if R\&D takes place compared to the same variable in case no $R \& D$ occurs.
} 
a RER depreciation. These moments were not targeted in the structural estimation and thus there is no intrinsic reason why the model should perform in well in replicating them. We present the point estimates from reduced-form regressions and compare them with the estimates obtained from running the same regressions on the simulated data.

The empirical regression specification we use to estimate these elasticities in the data is the same as in equation (22), but the dependent variable is now the change in the R\&D status, the change in $\log$ cash flow and the change in the log export entry rate. ${ }^{55}$ Table 7 reports model-generated and data moments for these statistics. For emerging Asia, the model somewhat under-predicts the average firm-level elasticity of R\&D (0.05 compared to 0.19$)$; it performs extremely well in terms of replicating the average firm-level elasticity of cash flow (0.75 compared to 0.78$)$; and somewhat under-predicts the elasticity of the export entry rate (0.33 compared to 0.55$)$. In all cases, the model-generated elasticity lies within the confidence interval of the data moments. For other emerging economies, the elasticity of $\mathrm{R} \& \mathrm{D}$ is -0.04 (0.16 in the data). However, this reduced-form point estimate is very noisy and not statistically significant, so that the model-generated elasticity is within the data confidence interval. In line with our model, the model generates a negative elasticity of cash flow (-0.51 compared to -0.55$)$ and an elasticity of the export entry rate (0.21 compared to 0.06$)$ similar to the corresponding data moments. Finally, for industrialized countries, there are somewhat larger discrepancies between the model-predicted elasticities, which are basically zero for the R\&D and cash-flow elasticities, and the corresponding estimates from the data. However, in this case the data estimates are very noisy and not statistically significant; the zero elasticity of $R \& D$ is well within the confidence interval.

Table 7 also reports estimates of firm-level elasticities of R\&D status and cash flow to changes in the RER conditional on trade status. We interact the RER shock with dummies for firms' exporter and importer status and absorb the impact on domestic firms by including country-sector-year fixed effects in the regression. ${ }^{56}$ These numbers are to be interpreted as the effect of RER changes relative to the ommited baseline category (firms that neither export nor import). The model almost always captures that the effects on these outcomes are positive for exporters and negative for importers, like in the data. Moreover, the model also matches well the magnitudes of these effects in most cases. Overall, the model performs very well in terms of fitting the non-targeted moments, confirming its validity.

\subsection{Decomposing the Short-run Elasticity of Revenue-Productivity Growth}

Our model highlights very different effects of real depreciations on TFPR growth and its components across regions due to the regional differences in the underlying structure of these economies. In Table 8, we use equation (23) to decompose the short-run elasticity of TFPR with respect to the RER into its various components for each of the regions. For emerging Asia, the overall elasticity is 0.21: a one-percent depreciation leads to a 0.266 percentage-point increase in export demand growth; a 0.055 percentage-point reduction in TFPR growth due to less importing; and a 0.013 percentage-point increase

\footnotetext{
${ }^{55}$ The regression specifications are discussed in more detail in the Appendix and the results can be found in Table A-1.

${ }^{56}$ Like in the reduced-form regressions on the data, we keep the trade status fixed to the one at the beginning of the simulation and then use 10 years of simulated data to estimate the coefficients. Detailed results for this specification can be found in the Appendix and in A-5.
} 
in physical TFP growth associated to the innovation channel due to more R\&D. Thus, in the short run, even in emerging Asia physical productivity gains from innovation are outweighted by TFPR losses from reduced importing. However, we show below that this result is reversed in the medium run because the productivity gains from $\mathrm{R} \& \mathrm{D}$ are persistent, while the TFPR losses due to reduced importing are temporary. In the set of other emerging economies, a one-percent depreciation is associated with a 0.153 percentage-point loss in TFPR growth, which is composed of a 0.051 percentage-point increase in export demand growth, a 0.207 percentage-point loss in TFPR growth to reduced imports, and a 0.009 percentage-point TFP gain from increased $R \& D$. The large import dependence relative to the export orientation of these economies exacerbates the negative effects of the depreciation. Finally, the elasticity of TFPR is basically zero in industrialized countries (-0.017). It consists of a 0.051 percentage-point increase in export demand growth, a 0.069 percentage-point TFPR growth loss due to reduced imports, and a 0.013 percentage-point productivity growth gain from increased R\&D.

\section{Counterfactuals and the Long-run Response of Revenue-Productivity Growth to RER Changes}

In this section, we perform a number of counterfactual exercises (separately for each region) with the estimated model in order to understand its quantitative implications regarding the long-run response of TFPR growth to changes in the RER. As a benchmark exercise, we first simulate an unanticipated temporary depreciation of the RER. We allow for a yearly depreciation of $5 \%$ for five years with a subsequent sudden $25 \%$ appreciation back to the initial level of the RER (Figure 1). ${ }^{57}$ This magnitude corresponds roughly to a one-standard-deviation change in the RER over a five-year interval (see Appendix Table B-1 Panel D). The corresponding results show, in line with our evidence, that the effects of depreciations are heterogeneous across regions with different relative export orientation. We then simulate a similar RER depreciation of smaller magnitude (12.5\%) and show that the impact of depreciations is non-linear due to a number of mechanisms, such as the substitution of domestic intermediates with foreign ones, and the complementarities between the decisions to export and import. Finally, we simulate a $25 \%$ appreciation and find remarkable asymmetries in firms' responses: these arise due to the presence of sunk costs, which give rise to the option value of a firm continuing with its R\&D investments. ${ }^{58}$

\footnotetext{
${ }^{57}$ These yearly changes should be interpreted as unexpected shocks. In all exercises we keep firms' beliefs about the exchange-rate process the same as in the baseline case. (See equation (1)).

${ }^{58} \mathrm{We}$ take a partial-equilibrium approach here and focus on the reaction of firms to changes in the RER. While the impact of RER changes on wages is accounted for, we do not consider the feedback effect on expenditure $E_{T}$. In the Appendix we discuss potential ways to close the model in general equilibrium.
} 

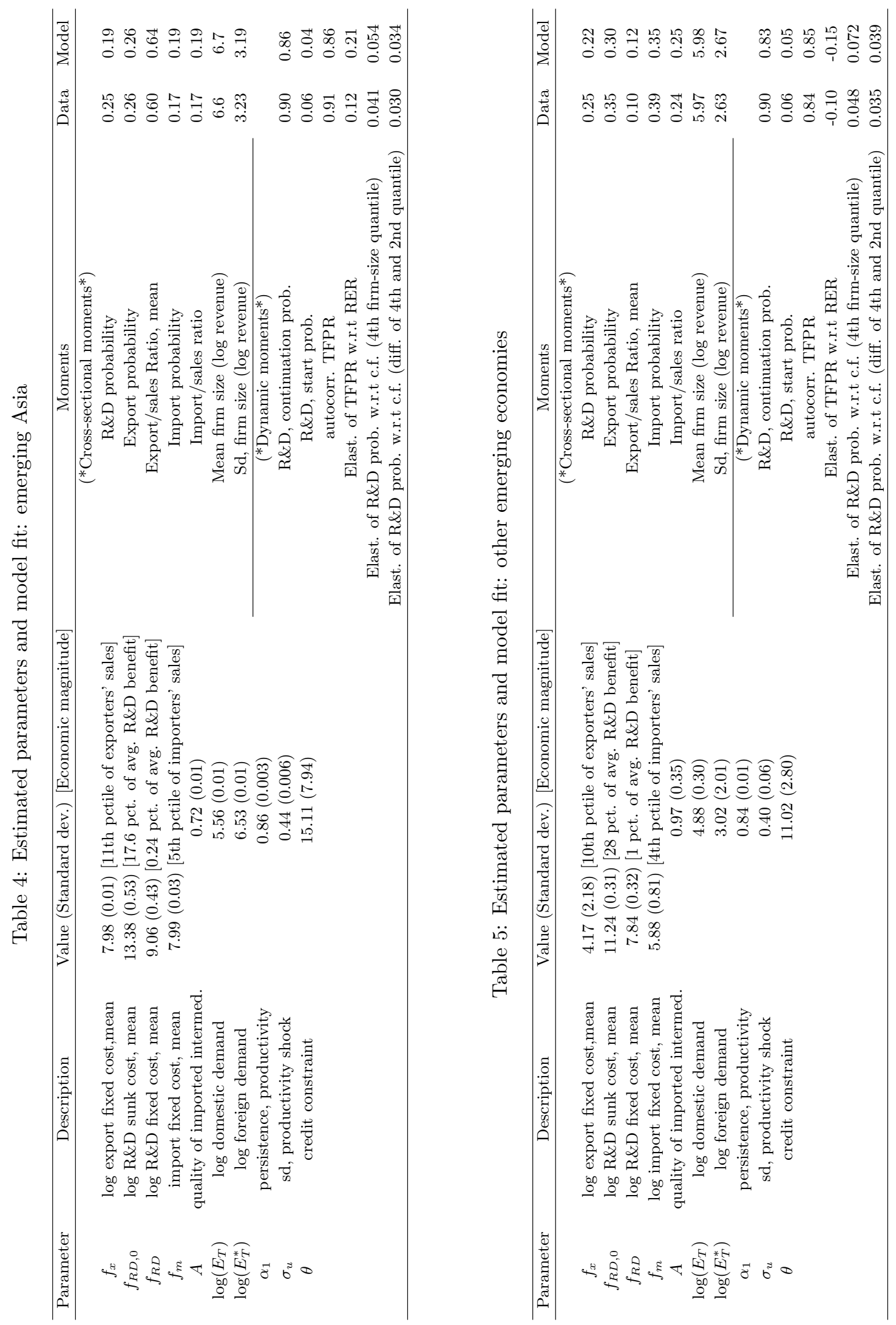


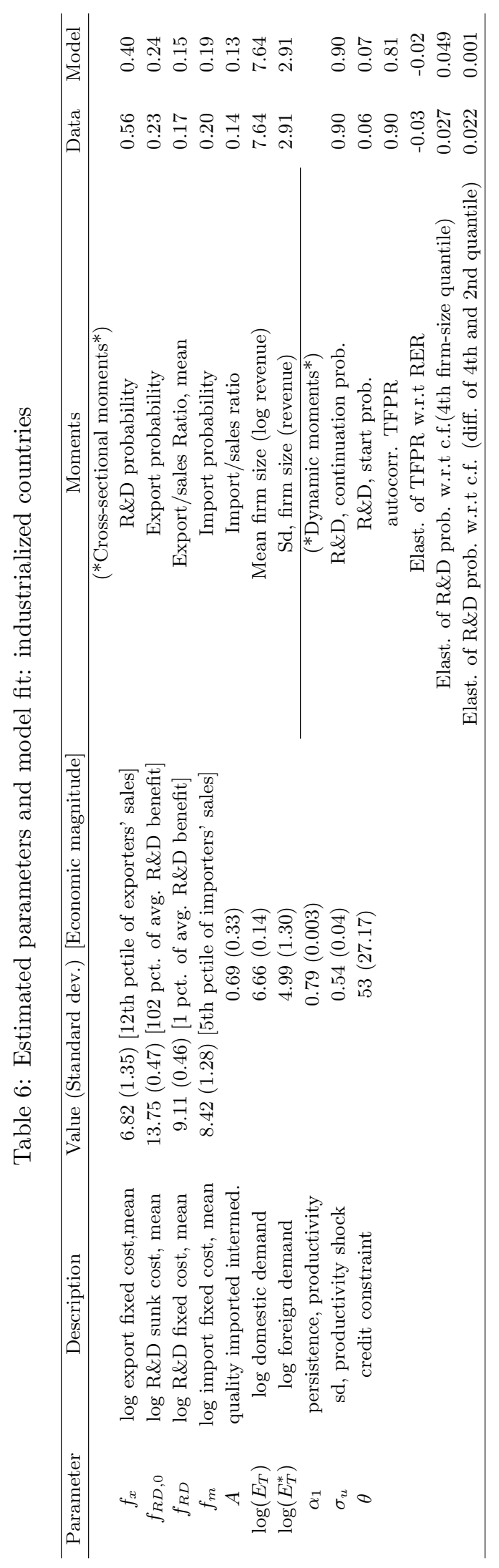


Table 7: Non-targeted moments

\begin{tabular}{lrcl}
\hline \hline & Model & Data & $\begin{array}{l}\text { Confidence interval } \\
\text { data moments }\end{array}$ \\
\hline Emerging Asia & & & \\
\hline elasticity of R\&D w.r.t RER & 0.052 & 0.190 & {$[0.004,0.376]$} \\
elasticity of cash flow w.r.t RER & 0.745 & 0.783 & {$[0.560,1.006]$} \\
elasticity of export entry rate w.r.t RER & 0.326 & 0.552 & {$[0.146,0.958]$} \\
elasticity of R\&D w.r.t RER exporters rel. domestic & 0.073 & 0.065 & {$[0.043,0.087]$} \\
elasticity of R\&D w.r.t RER importers rel. domestic & -0.003 & -0.101 & {$[-0.125,-0.077]$} \\
elasticity of cash flow w.r.t RER exporters rel. domestic & 0.568 & 0.243 & {$[0.173,0.313]$} \\
elasticity of cash flow w.r.t RER importers rel. domestic & -0.150 & -0.123 & {$[-0.221,-0.025]$} \\
\hline Other emerging & & & \\
\hline elasticity of R\&D w.r.t RER & -0.043 & 0.160 & {$[-0.085,0.405]$} \\
elasticity of cash flow w.r.t RER & -0.514 & -0.557 & {$[-0.839,-0.275]$} \\
elasticity of export entry rate w.r.t RER & 0.217 & 0.063 & {$[-0.053,0.179]$} \\
elasticity of R\&D w.r.t RER exporters rel. domestic & 0.010 & 0.167 & {$[0.109,0.225]$} \\
elasticity of R\&D w.r.t RER importers rel. domestic & -0.047 & -0.119 & {$[-0.263,0.025]$} \\
elasticity of cash flow w.r.t RER exporters rel. domestic & 0.132 & 1.162 & {$[0.600,1.724]$} \\
elasticity of cash flow w.r.t RER importers rel. domestic & -0.597 & -0.803 & {$[-1.209,-0.297]$} \\
\hline Industrialized & & & \\
\hline elasticity of R\&D w.r.t RER & -0.0002 & -0.168 & {$[-0.460,0.124]$} \\
elasticity of cash flow w.r.t RER & -0.041 & -0.319 & {$[-0.566,-0.072]$} \\
elasticity of export entry rate w.r.t RER & -0.264 & -0.275 & {$[-0.812,0.262]$} \\
elasticity of R\&D w.r.t RER exporters rel. domestic & 0.046 & -0.004 & {$[-0.04,0.032]$} \\
elasticity of R\&D w.r.t RER importers rel. domestic & -0.069 & -0.042 & {$[-0.074,-0.010]$} \\
elasticity of cash flow w.r.t RER exporters rel. domestic & 0.134 & 0.272 & {$[0.102,0.442]$} \\
elasticity of cash flow w.r.t RER importers rel. domestic & -0.052 & -0.052 & {$[-0.208,0.104]$} \\
\hline \hline
\end{tabular}

Notes: This table presents the point estimates of the elasticities of various firm-level outcomes as well as the elasticity of the export entry rate w.r.t the RER obtained from running regression (22) on the simulated data. It compares them with the point estimates obtained from running the same regression on the firm-level data from Orbis and the export entry rate from the Exporter Dynamics database.

\subsection{Regional Heterogeneity: 25\% Depreciation}

Emerging Asia Figure 2 plots the simulation results for the outcomes averaged over the firm distribution. In particular, for every period $t, t=1, \ldots, T$, we report $\Delta \mathbb{E}\left(t f p r_{i, t}\right)$, the average proportional difference between firm-level TFPR in the counterfactual and its baseline level. We think of this as the "growth rate" of firm-level TFPR in the counterfactual with respect to the baseline. We do the same for the components of TFPR: (i) physical TFP growth due to the innovation channel, (ii) TFPR growth due to the import channel and (iii) TFPR growth due to the export-demand channel. The continuous red lines plot the effects of the benchmark $25 \%$ real depreciation. ${ }^{59}$ The impact of a depreciation on TFPR growth is positive: it leads to up to a 6.5 percentage-point increase in average firm-level TFPR growth (always with respect to the baseline case). The positive export-demand effect of the depreciation on TFPR growth is even larger (up to 8 percentage points), while the negative impact on TFPR growth

\footnotetext{
${ }^{59}$ The blue dashed-dotted lines plot the effect of a $12.5 \%$ depreciation. The gray dashed lines lines correspond to the effects of a $25 \%$ appreciation. Figures 3 and 4 should be read similarly.
} 
Table 8: Decompositon of short-run elasticity of TFPR w.r.t. RER

\begin{tabular}{lcccc}
\hline \hline & $\begin{array}{c}\text { Innovation } \\
(\mathrm{R \& D})\end{array}$ & Imports & $\begin{array}{c}\text { Export } \\
\text { Demand }\end{array}$ & $\begin{array}{c}\text { Total } \\
\text { Elasticity }\end{array}$ \\
\hline Emerging Asia & 0.013 & -0.055 & 0.266 & 0.210 \\
Other emerging & 0.009 & -0.207 & 0.051 & -0.153 \\
Industrialized & 0.013 & -0.069 & 0.051 & -0.017 \\
\hline \hline
\end{tabular}

Figure 1: Unexpected real depreciation $(25 \%, 12.5 \%)$ and real appreciation $(25 \%)$.

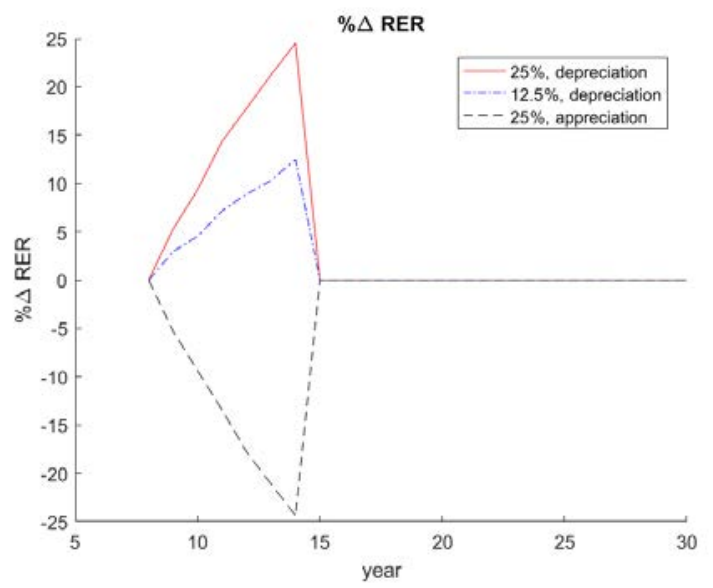

through the import channel is relatively small (with a minimum of -1 percentage point). Physical TFP growth due to innovation increases by up to 0.5 percentage points in response to the depreciation.

In a sub-sample of countries with relatively export-intensive firms, the average profit increase due to higher demand for firms' exports is larger than the decrease due to the fact that intermediate inputs become more expensive. The resulting net increase in profits leads to more R\&D investment and an increase in physical productivity. Notice that the increase in physical productivity due to more innovation persists much longer than the other effects, which disappear as soon as the RER appreciates back to its initial level: temporary RER movements can have very long-lasting effects on physical TFP growth. Finally, there is both a direct and an indirect impact of the depreciation working through the innovation channel of physical TFP growth. The direct effect comes through more R\&D participation, while the indirect impact works through the additional exporting and importing in the future (at the extensive and intensive margins) induced by the additional $\mathrm{R} \& \mathrm{D}$. These changes influence future trade participation and thus the import and demand components of TFPR. ${ }^{60}$

Other Emerging Economies The overall impact of the depreciation on average firm-level TFPR growth is negative: the depreciation leads roughly to a $3 \%$ decline in TFPR growth. (See Figure 3.) The negative effect of the depreciation on TFPR growth through the import channel ( -4.3 percentage

\footnotetext{
${ }^{60}$ Quantitatively, the indirect effect on average TFPR growth turns out to be relatively small: it accounts for at most 0.1 percentage points (around the time the RER re-appreciates back to the initial level).
} 
Figure 2: Average effect of an unexpected real depreciation $(25 \%, 12.5 \%)$ and appreciation $(25 \%)$ for emerging Asia.
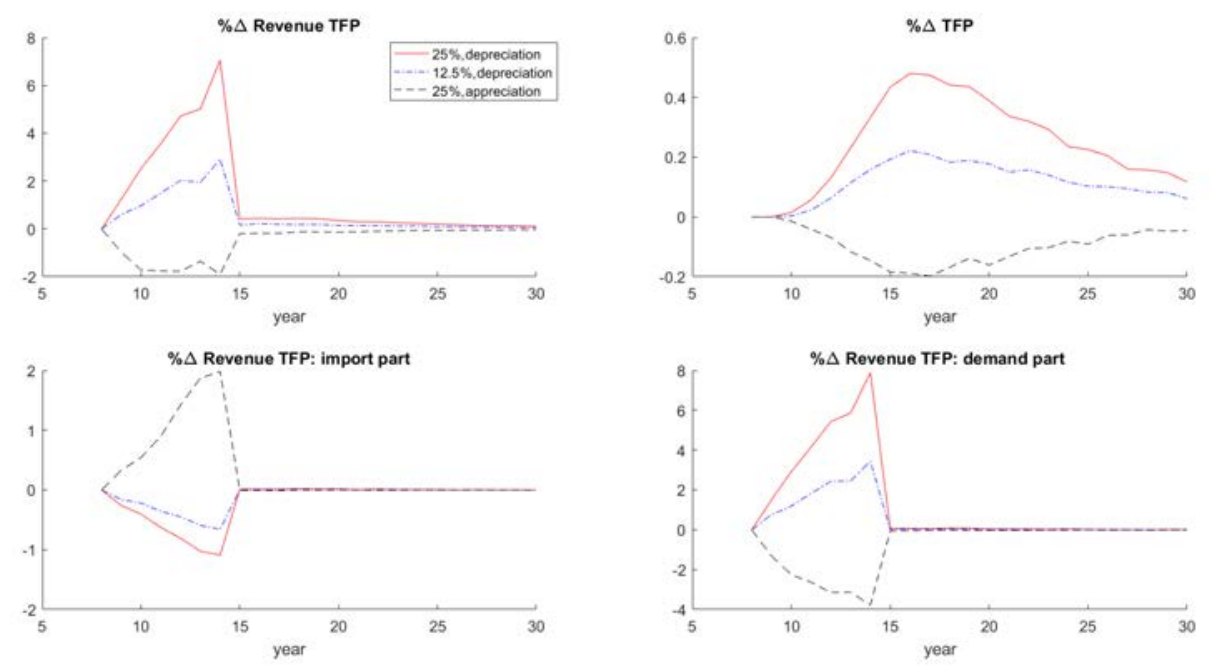

Figure 3: Average effect of an unexpected real depreciation $(25 \%, 12.5 \%)$ and appreciation $(25 \%)$ for other emerging economies.
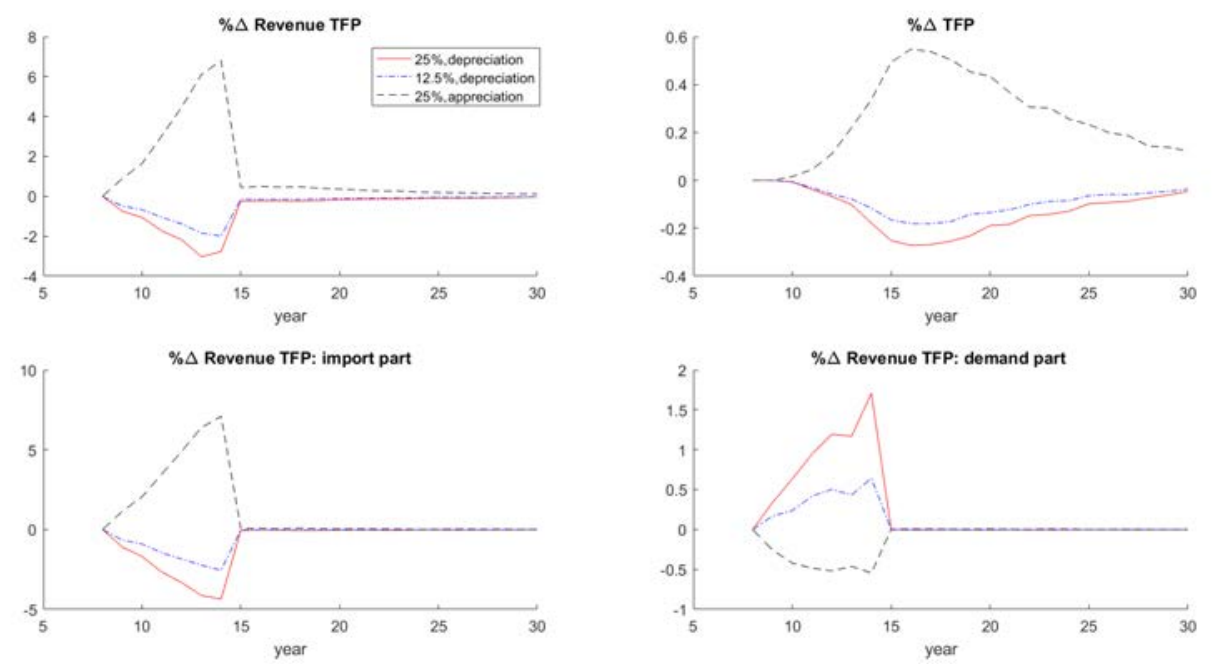
Figure 4: Average effect of an unexpected real depreciation $(25 \%, 12.5 \%)$ and appreciation $(25 \%)$ for industrialized economies.
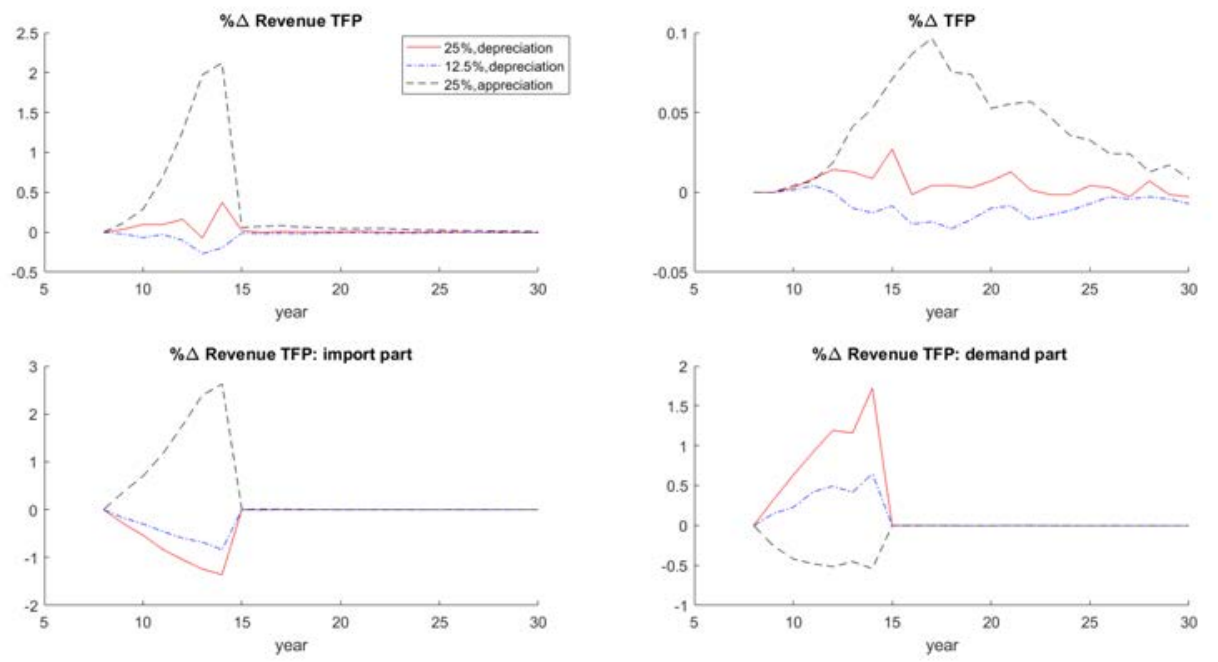

points) dominates the positive effect operating through the export-demand channel (1.6 percentage points). Physical productivity due to innovation falls by up to 0.3 percentage points. Again, changes in physical productivity due to $\mathrm{R} \& \mathrm{D}$ are much more long lasting than those of the other components of TFPR. Moreover, the direct impact of the decline in physical TFP due to less innovation explains only around $10 \%$ of the reduction in TFPR. ${ }^{61}$

In comparison with emerging Asia, firms in this sub-sample are on average relatively import intensive. This reverses the net effect of the depreciation on firms' profits, which becomes negative and induces firms to reduce their investment in R\&D and a subsequent decrease in physical TFP growth.

Industrialized Countries The pattern of long-lasting changes in physical productivity growth due to innovation and merely transitory reactions of the other two components of TFPR growth repeats itself once more. (See Figure 4.) The overall effect of the depreciation on average firm-level TFPR growth is positive but tiny in comparison with the magnitudes of the responses in emerging economies. In this case, export demand and import TFPR growth are of similar magnitude. The increase in profits induced by a larger volume of exports is compensated by the decrease in profits due to more expensive intermediate-input imports. Since the positive and negative effects of the depreciation on profits roughly cancel each other, R\&D investment hardly reacts: changes in physical TFP due to this channel are positive but very close to zero.

\subsection{Non-linearities: $12.5 \%$ Depreciation}

We now simulate a $12.5 \%$ depreciation (blue dashed-dotted lines in Figures 1-4).

\footnotetext{
${ }^{61}$ The indirect impact of changes in R\&D on TFPR via less exports and imports accounts for a TFPR reduction of $-0.05 \%$.
} 
Emerging Asia The overall impact of the 25\% depreciation on average firm-level outcomes is more than double in magnitude than that of the $12.5 \%$ depreciation: Figure 2 shows that TFPR growth increases by slightly more than 2 percentage points (compared to more than 6 percentage points for the $25 \%$ depreciation); physical TFP growth due to innovation is raised by 0.2 percentage points (compared to around 0.5 percentage points); the export-demand component of TFPR growth rises by around 3 percentage points (compared to 8 percentage points); and the import component of TFPR growth decreases by less than 0.5 percentage points (compared to more than 1 percentage point).

Why do larger depreciations in emerging Asia bring about more than proportional increases in profitability in comparison with smaller depreciations? Given the high relative export intensity of this region's firms, the losses from more expensive imported inputs are more than compensated by the profits from better access to export markets. First, holding constant import costs, firm-level variable export profits respond to changes in $e$ with a constant elasticity $\sigma-1>1$ (see Section 3.5). Therefore, disproportionately more firms find it profitable to export for larger depreciations and hence the extensive margin of exports reacts more. Second, the elasticity of $\exp [-\tilde{a}(e)]$ with respect to $e$ becomes smaller with larger depreciations (see Section 3.3), and therefore revenues for importing firms are reduced proportionally less with a larger depreciation. Third, a larger increase in exports subsequent to a larger depreciation induces more firms to import through the complementarity between these two choice variables (an increase in the extensive margin of imports); this partly compensates the negative effect of higher import costs on the use of foreign intermediates (a decrease in the intensive margin of imports). Finally, since profitability increases disproportionately more with a larger depreciation, physical TFP due to innovation also rises disproportionately more, as the number of firms that start investing in $R \& D$ is significantly higher with the larger depreciation.

Other Emerging Economies Unlike in emerging Asia, the impact of a smaller depreciation in other emerging economies is comparatively larger. The total (negative) effect of a $12.5 \%$ depreciation on TFPR growth (-2 compared to -3 percentage points), physical TFP growth due to innovation (-0.2 compared to -0.3 percentage points) and the import component of TFPR growth (-3 compared to -4.5 percentage points) is proportionally bigger in absolute magnitude than the one of a $25 \%$ depreciation. The impact on the export-demand component of TFPR growth is instead relatively larger for a depreciation of larger magnitude ( $1.8 \%$ compared to $0.6 \%$ ).

Since this region's firms feature a high relative import intensity, depreciations reduce their profitability. Since the elasticity of $\exp [-\tilde{a}(e)]$ with respect to $e$ becomes smaller with larger depreciations, the latter have less of a proportional effect on the revenues of importing firms. Thus, larger depreciations have disproportionately smaller negative effects on exports and profits. Besides, this implies that, in the presence of complementarities between export and import decisions, imports decline proportionally less with larger depreciations. Finally, since the average firm's profitability is reduced disproportionately less with the larger depreciation, innovation and thus physical TFP growth also fall disproportionately less.

Industrialized Countries The negative impact of the $12.5 \%$ depreciation is larger in absolute terms than the one of the $25 \%$ depreciation. Import and export intensities are very similar, so that the 
larger profitability induced by a depreciation through the export channel is roughly offset by higher import costs. Because of the non-linear effect of a depreciation on the import costs, import costs fall disproportionately less with a larger depreciation. It turns out that for the $12.5 \%$ depreciation the import component of TFPR dominates the export component, so that firms become slightly less profitable and thus perform slightly less innovation, reducing physical TFP growth. By contrast, with the $25 \%$ depreciation the increase in profits via the export channel dominates the import component and profitability and thus physical TFP growth increase slightly.

\subsection{Asymmetries: 25\% Appreciation}

We now simulate an unanticipated temporary yearly appreciation of $5 \%$ for five years with a subsequent sudden $25 \%$ depreciation back to the initial level of the RER (see the gray dashed lines in Figures 1-4).

Emerging Asia The effects of an appreciation on average firm-level TFPR growth and its components are opposite to those of a depreciation. (See Figure 2.) The reduction in TFPR growth through lower exports and lower physical TFP growth due to less innovation dominates the positive effect on TFPR growth through more imports. However, the quantitative impact on TFPR growth and its components (TFPR growth falls by at most 2 percentage points, which can be decomposed into a 4 percentage-point drop in export demand, a 1.8 percentage-point increase in TFPR growth due to cheaper imported inputs and a 0.2 percentage-point reduction in physical TFP growth due to less innovation) is just around a third of the size of the corresponding effects of a depreciation of the same absolute magnitude.

Due to the large magnitude of $R \& D$ sunk costs relative to that of fixed costs, firms respond more to a positive shock to the net present value of innovation than to a negative one. They try to avoid paying the sunk costs of re-starting innovation in case they stop performing R\&D. In other words, R\&D has an option value in the face of a negative shock. This effect relates to the classical hysteresis argument made by Baldwin, 1988, Baldwin and Krugman, 1989, and Dixit, 1989. For firms in this region, a depreciation corresponds to a positive shock to R\&D profitability, while an appreciation corresponds to a negative one. Thus, in this region physical TFP growth responds more to a depreciation than to an appreciation. ${ }^{62}$

Moreover, a depreciation triggers a reduction in imports that is smaller than the increase associated to an appreciation. This is the result of three feedback effects: (i) for a depreciation, the positive change in physical TFP growth due to more innovation mitigates the impact of higher import costs; (ii) the import component of TFPR growth decreases less during a depreciation than it increases for an appreciation of the same magnitude due to substitution effects; (iii) complementarities between exporting and importing activities: since emerging Asia export intensity is high compared to import intensity, the positive effect of higher exports on imports is larger than the negative effect of lower imports on exports. Finally, a depreciation triggers an increase in exports larger than the decline caused by an appreciation: the extensive margin of exports responds more to a depreciation because of

\footnotetext{
${ }^{62}$ There is an additional channel via credit constraints: credit constraints are relaxed for more firms during a depreciation than they are tightened during an appreciation because $R \& D$ continuation costs are smaller than start-up costs. This effect turns out to be quantitatively small in comparison with the asymmetries induced by the option value.
} 
the stronger selection into exporting triggered by the more sizable change in physical TFP growth.

Other Emerging Economies In stark contrast to emerging Asia, the impact of the appreciation on TFPR growth is in this case positive and more than twice as large as the negative effect of the depreciation. As seen in Figure 3, TFPR growth increases by around 6.5 percentage points, compared to the three-percentage-point decline following the depreciation. This effect is composed of a 6.5 percentage-point increase in TFPR growth through increased imports, a 0.5 percentage-point decline through reduced exports and a 0.5 percentage-point increase via larger physical TFP growth due to more innovation. A positive shock to profitability has a larger impact on innovation and thus on physical TFP growth than a negative one.

The explanation of these effects is the mirror image of the emerging-Asia case: since for other emerging economies an appreciation increases the profitability of $R \& D$, while a depreciation reduces it, an appreciation has a larger effect on physical TFP growth than a depreciation due to the optionvalue effect. Besides, due to complementarities between exporting and importing decisions, the larger import orientation and the smaller export orientation of these economies, the effects of larger imports on exports via the appreciation are more sizeable than the effects of larger exports on imports via the depreciation. Moreover, the increase in physical TFP due to the appreciation leads more firms to select into exporting and importing and thus also raises TFPR growth through these channels.

Industrialized Countries In this case, the impact of RER movements on TFPR growth is quantitatively small compared to the other regions and qualitatively similar to the case of other developing countries. (See Figure 4.) The effect of the $25 \%$ appreciation on TFPR growth is positive and larger in magnitude compared to the one of a depreciation of equal size. In the case of a depreciation, the negative impact on TFPR growth via the import channel is almost exactly offset by the positive effect through more exports, so that innovation and physical TFP growth are almost unchanged. For an appreciation, the positive effects through cheaper inputs and increased profitability of R\&D dominate the negative effects on TFPR growth through reduced exports so that the net effects on TFPR growth are positive but small (TFPR growth increases by two percent and physical TFP growth due to innovation by 0.1 ). The intuition is very similar to the case of other developing countries.

The model's predictions for the asymmetric effects of RER depreciations and appreciations are consistent with the corresponding reduced-form estimates, as we show in Appendix Table B-5. In these specifications, we allow for differential effects of RER depreciations and appreciations on firm-level outcomes for each region. In emerging Asia, the effect of RER depreciations is positive, large and highly statistically significant, while RER appreciations have no significant impact on firm-level outcomes. In the other emerging economies, the impact of RER appreciations on firm-level outcomes is instead positive, large and highly significant, while depreciations have no statistically significant effect. Finally, for industrialized countries, neither depreciations nor appreciations have significant effects. 


\subsection{Decomposition of Physical Productivity Growth: Market-size Effects versus Credit Constraints}

Finally, we decompose the effect of the $25 \%$ temporary depreciation on physical TFP growth into (i) market-size effects and (ii) relaxed credit constraints. We provide the corresponding results for the fiveyear depreciation period on Table 12. In emerging Asia, the R\&D participation rate increases by 2.6 percentage points during the depreciation. $87 \%$ of the new R\&D performers start this activity due to a relaxation of credit constraints (firms that found it profitable to do $R \& D$ in net-present-value terms, for which the credit constraint was initially binding), while only $13 \%$ of the new R\&D investment is due to an increase in market size (firms that were initially unconstrained but found it unprofitable to engage in $\mathrm{R} \& \mathrm{D}$ in net-present-value terms, for which it now becomes profitable to perform $\mathrm{R} \& \mathrm{D})$. By contrast, in the other emerging economies, the R\&D participation rate falls by 1.7 percentage points. This change can be decomposed into a $82 \%$ reduction due to a tightening of credit constraints and a $18 \%$ reduction due to reduced market-size effects. ${ }^{63}$

Table 9: Elasticity of R\&D w.r.t. RER, decomposition into market size and financial constraints (25\% depreciation over 5 -year period).

\begin{tabular}{rrrr}
\hline \hline & $\begin{array}{c}\text { Innovation Channel } \\
\text { (Change in R\&D prob.) }\end{array}$ & Market size & Financial constraints \\
\hline emerging Asia & $2.6 \%$ & $13 \%$ & $87 \%$ \\
other emerging & $-1.7 \%$ & $18 \%$ & $82 \%$ \\
\hline \hline
\end{tabular}

\subsection{Aggregate Results}

Figures B-1-B-3 in the Appendix report the aggregate results of our counterfactuals. We compute these by aggregating the time paths of firm-specific variables using as weights the firms' market shares prior to the RER depreciation/appreciation episode and holding them fixed. Qualitatively, the results are similar to the ones we discussed above: depreciations lead to higher productivity in emerging Asia and lower productivity in other emerging countries whereas appreciations induce the opposite results in the two regions; the effects of RER changes are much weaker for industrialized countries; finally, the asymmetric effects of depreciations and appreciations also apply here.

Quantitatively, the aggregate effects are stronger than the average effects (e.g, up to 10 percentage points more aggregate annual TFPR growth and 0.7 percentage points more physical TFP growth in emerging Asia due to the $25 \%$ depreciation). This is due to the fact that firms responding to RER movements in terms of exporting, importing and $\mathrm{R} \& \mathrm{D}$ tend to be relatively productive and have large market shares. The reaction of these firms to changes in the RER is not only more likely, but also carries a larger weight when aggregating firms' responses. ${ }^{64}$

\footnotetext{
${ }^{63}$ Decomposition for industrialized countries not reported as $\mathrm{R} \& \mathrm{D}$ participation rate hardly reacts to the depreciation. ${ }^{64}$ One caveat is that we hold the number of firms fixed. Atkeson and Burstein, 2010 show in a calibrated model that allowing for free entry tends to reduce the aggregate effects of changes in trade costs on innovation.
} 


\section{$6 \quad$ Extensions and Robustness}

\subsection{Model without Credit Constraints}

n our first robustness check, we assume away credit constraints, so that equation (15) never binds. In this case, firms' R\&D decisions are based purely on net present value considerations and they just maximize their value function (18). To assess the qualitative and quantitative performance of this model, we reestimate it for each region, targeting the same set of moments as in the baseline case with credit constraints. The results are reported in Appendix Tables B-6 to B-8. In general, the fit is very similar to the case with credit constraints, except for one important exception: without credit constraints the model is not able to reproduce the strong positive correlation between cash flow and R\&D that is present in the data: it predicts basically no correlation between these variables. In terms of parameter estimates, most remain quite similar to the baseline estimates except for R\&D sunk and fixed costs. Without credit constraints, these need to be larger in magnitude in order to account for the relatively low $R \& D$ participation rate in the data.

We now discuss the counterfactual simulation results for this model, reported in Figure 5. For brevity purposes we only report results for the baseline scenario of a $25 \%$ RER depreciation.

Emerging Asia Like in the model with credit constraints, a depreciation triggers a positive response of both average revenue and physical TFP, as well as export demand growth, while the import channel reacts negatively. The magnitude of the responses of the export and import channels of TFPR growth remains similar to the baseline case. However, the response of physical TFP growth is much more pronounced (up to 1.5 percentage points compared to 0.5 percentage points in the baseline case). Before the depreciation, a large fraction of firms do not find it profitable to do R\&D. With the persistent depreciation, this changes for a significant mass of them, leading to a switch in their R\&D decisions. Without credit constraints R\&D activity responds exclusively to changes in the net present value of innovation. With a persistent RER change, changes in the net present value of innovation are large. By contrast, in the presence of credit constraints - provided these are binding - R\&D activity responds only to contemporaneous relaxations of the constraint. This dampens the sensitivity of R\&D activity to RER changes.

Other Emerging Economies Also in this region firms' average response to a depreciation is similar to the baseline case in terms of sign: TFPR growth and its components respond negatively, except for exports. Again, the magnitude of the responses is also similar, with the exception of physical TFP growth, which now responds more negatively because there is a larger mass of firms that are close to the margin of changing their R\&D decisions.

Industrialized Countries In this region, the positive effect on TFPR growth operating via the export channel is more than offset by the negative import effect, leading overall to a small negative response of innovation and physical TFP growth, which, in absolute terms, is again larger than in the presence of credit constraints. Thus, overall, neglecting the role of credit constraints leads to an overestimation of the innovation response to changes in the RER. 
Figure 5: No credit constraints: average effect of an unexpected real depreciation $(25 \%)$ in the three regions.
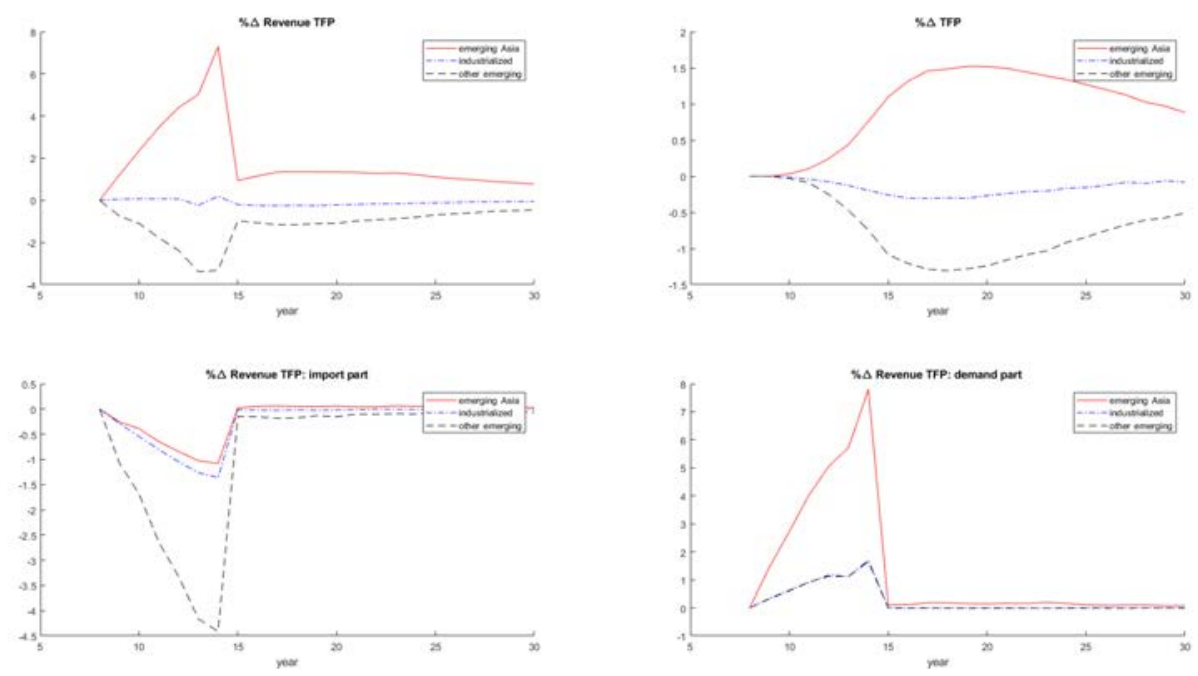

\subsection{Sunk Export Costs}

The literature suggests that sunk export costs are important for understanding the quantitative impact of real exchange rate fluctuations on export dynamics (see, e.g., Alessandria and Choi, 2007). We therefore introduce this feature into our model in order to understand whether it changes its quantitative implications. Our modelling strategy for export and R\&D decisions is inspired by Aw et al., 2011. In contrast with them, we also allow for a static import decision and introduce credit constraints exclusively for the R\&D decision, as in our baseline model. We lay out the details of this model in Appendix A-1.3 and only provide a discussion of the simulation results in the main text. Lack of good information on export entry decisions in our data prevents us from estimating the magnitude of export sunk costs within our model. ${ }^{65}$ Thus, we use the estimates from Aw et al., 2011, to calibrate this parameter. They find that mean export sunk costs are roughly 4.61 times mean export fixed costs. ${ }^{66}$ The remaining structural parameters are re-estimated following the same procedure as for our main model. Parameter estimates are generally similar to those of our main model, with the exception of per-period export fixed costs (not reported). In the presence of sunk export costs, these must be smaller to keep the export participation rate constant.

We now discuss the counterfactual simulation results for this model, reported in Figure 6. Again, we focus on the baseline scenario of a $25 \%$ RER depreciation.

Emerging Asia Like in the model without export sunk costs, a depreciation triggers a positive response

\footnotetext{
${ }^{65}$ Recall that information on firm-level export status from Worldbase is available only for a small number of years.

${ }^{66}$ Results are similar when, alternatively, setting mean export sunk costs proportional to mean R\&D sunk costs, using again estimates by Aw et al., 2011.
} 
Figure 6: Sunk export costs: average effect of an unexpected real depreciation $(25 \%)$ in the three regions.
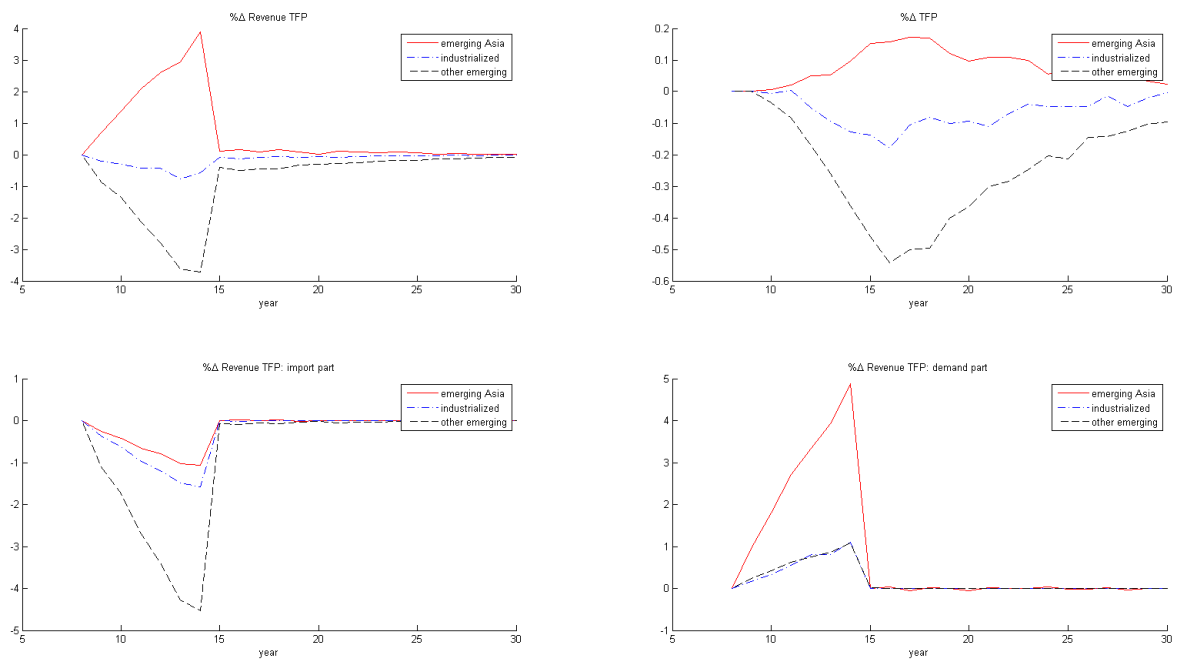

of both average revenue and physical TFP, and export demand growth, while the import channel reacts negatively. However, the magnitude of the positive responses of the individual components is smaller. This is not surprising since the export sunk cost creates an option value of waiting and makes the export decision less responsive to changes in the RER. As a consequence, the reaction of profits and cash flow is also less pronounced, which implies that less firms start doing innovation.

Other Emerging Economies Again, in this region the depreciation produces a negative profitability shock. Compared to the model without export sunk costs, export demand increases by less, while revenue and physical TFP growth decrease by more. The smaller responsiveness of exports due to the export sunk costs implies that increases in export profits compensate less for the rise in import costs. Profits therefore fall by more than without export sunk costs inducing an even larger negative response of innovation due to a more pronounced tightening of credit constraints.

Industrialized Countries Finally, in this case the magnitudes of the responses are again very small. However, while the export and the import components were exactly offsetting each other in the model without export sunk costs, exports now become less responsive to the depreciation compared to imports, making the overall impact on profitability negative. As a result, physical and revenue TFP growth decline slightly.

\subsection{Foreign-currency Borrowing}

An alternative explanation for the heterogeneity of RER effects on firm-level outcomes across regions lies in the fact that firms, in particular in emerging economies, often borrow in foreign currency. In this case, a RER depreciation makes foreign borrowing more expensive and may thus discourage R\&D investment 
for firms that finance a large share of their debt in foreign currency. While firms in industrialized countries mostly borrow in their own currency, we employ the Worldbank's World Enterprise Survey to show that firms in Latin America and Eastern Europe are far more exposed to foreign-currency borrowing than firms in emerging Asia. As explained in the data section, we cross-checked the data with several alternative local sources. ${ }^{67}$

In the first column of Table 6.3,we report the OLS regression results from running the share of manufacturing firms' foreign-currency liabilities in total liabilities on dummies for emerging Asia and other emerging economies (Latin America and Eastern Europe). The latter's average share of foreign borrowing is roughly twice as large as that of the former (around $20 \%$ compared to $10 \%$ ). In column (2) we add interactions of region dummies with exporter and importer status dummies. Not surprisingly, in both regions exporting firms exhibit a much larger average share of foreign-currency borrowing than importing firms or firms that do not engage in international trade. Still, the overall effect suggests that firms from emerging Asia are much less dependent on foreign-currency borrowing than firms from other emerging countries. Thus, it is possible that RER depreciations lead to different effects across regions not only because of differences in export and import orientation, but also because of differential exposure of firms to foreign-currency borrowing. Given their stronger reliance on such sources of financing, firms from other emerging economies experience an increase in borrowing costs in the event of a depreciation in comparison with firms from emerging Asia. ${ }^{68}$

Table 10: Foreign debt shares by region

\begin{tabular}{lcc}
\hline \hline & $(1)$ & $(2)$ \\
& foreign debt share & foreign debt share \\
\hline & & \\
emerging Asia & & $4.820^{* * *}$ \\
& $(0.338)$ & $(0.462)$ \\
emerging Asia $_{c} \times$ & & $18.21^{* * *}$ \\
exporter $_{f}$ & & $(0.876)$ \\
emerging Asia $_{c} \times$ & & 0.433 \\
importer $_{f}$ & & $(0.626)$ \\
other emerging $_{c}$ & $19.09^{* * *}$ & $14.15^{* * *}$ \\
& $(0.386)$ & $(0.581)$ \\
other emerging $_{c} \times$ & & $24.90^{* * *}$ \\
exporter $_{f}$ & & $(1.073)$ \\
other emerging $_{c} \times$ & & -0.919 \\
importer $_{f}$ & & $(0.759)$ \\
\hline Observations $_{\text {R-squared }}$ & 14,554 & 14,554 \\
Cluster & 0.201 & 0.271 \\
\hline \hline
\end{tabular}

Notes: The dependent variable in columns (1)-(5) is the foreign debt share for manufacturing firms in emerging Asia and other emerging economies (Latin America, Eastern Europe) in the 2002-2006 World Enterprise Survey. Standard errors are clustered at the firm level. ${ }^{*}, * *$ and ${ }^{* * *}$ indicate statistical significance at the $10 \%, 5 \%$ and $1 \%$ levels..

We extend our structural model to consider foreign-currency borrowing. We assume that firms contract loans for period $t$ in period $t-1$. Lenders loan a multiple $\theta$ of the firms' period- $t$ expected

\footnotetext{
${ }^{67}$ For our time period, we analyze as well foreign currency patterns in Hungary and Colombia. For France, according to BIS, most firms tend to borrow in local currency.

${ }^{68}$ The more positive effects of depreciations on exporters and the more negative effects on importers found above cannot be rationalized with differential foreign currency exposure, since exporters borrow more in foreign currency, while importers are not different from firms that do not trade.
} 
profits $E_{t-1} \Pi_{i, t}$. A share $\lambda$ is borrowed by the firm in domestic consumption units and a share $1-\lambda$ is borrowed in foreign consumption units, where $\lambda$ is an exogenous parameter that we allow to vary by region and trade status. ${ }^{69}$ In the event of a RER depreciation (that is, $e_{t-1} / e_{t}<1$ ), the corresponding credit constraint becomes tighter, as a given amount of expected profits in domestic consumption units elicits a smaller amount of credit in foreign consumption units. (Implicit is the assumption that lenders, at the moment in which $e_{t}$ is realized, do not have time to revise expectations.) The credit constraint now is as follows: ${ }^{70}$

$$
\theta \epsilon_{i, t}\left[\lambda+(1-\lambda) \frac{E_{t-1}\left(e_{t}\right)}{e_{t}}\right] E_{t-1} \Pi_{i, t} \geq I_{i R D, t}\left[f_{R D, 0}\left(1-I_{i R D, t-1}\right)+f_{R D} I_{i R D, t-1}\right] .
$$

We calibrate the model by using the baseline model's parameter estimates (see Tables 4-6) and setting the foreign debt shares for emerging markets equal to the estimated ones for each region and trade-participation status, as reported in column 2 of Table 10. We set foreign debt shares for industrialized countries to zero. ${ }^{71}$ We simulate a $25 \%$ depreciation as described above. The corresponding effects, reported in Figure 7, are qualitatively and quantitatively comparable to those of our baseline counterfactuals. TFPR growth is roughly the same for emerging Asia. The negative impact of the depreciation on TFPR in other emerging economies becomes slightly larger, but the most important channel continues to be importing. One would need to assume a foreign-debt share much higher than in the data for the tightening of the credit constraint through valuation effects to become dominant, and innovation and physical TFP to decline on impact upon a depreciation. Thus, our results are robust to introducing foreign-currency borrowing.

\subsection{Sensitivity Checks}

We now present robustness checks regarding the values of the calibrated parameters. We consider different values for the elasticity of demand $(\sigma)$, the elasticity of substitution between domestic and imported intermediates $(\varepsilon)$ and the return to $\mathrm{R} \& \mathrm{D}\left(\alpha_{1}\right)$. We vary each of these parameters one by one and re-estimate the structural model given the new parameter value. We report results for the indirect-inference parameter estimates and the simulated model statistics in Appendix Tables B6-B8.

We first consider a higher value for the elasticity of demand within the reasonable range for this parameter $(\sigma=6$ instead of $\sigma=4$ ), while leaving the other preset parameters at their baseline values. Increasing $\sigma$ makes the sales distribution more sensitive to the underlying TFP differences and thus reduces the estimate of the standard deviation of the TFP process $\sigma_{u}$ required to fit the firm-size distribution. To keep the R\&D continuation and start probabilities fixed, this then requires a lower

\footnotetext{
${ }^{69}$ We abstract from firm's endogenous choice in terms of debt's currency denomination (see Salomão and Varela, 2018.

${ }^{70}$ Under the assumption that the firm makes repayments so as to keep a fraction $\lambda$ of domestic debt and a fraction $1-\lambda$ of foreign debt, the firm's budget constraint needs to be modified as follows:

$$
B_{i, t+1}+\Pi_{i, t}-I_{i R D, t}\left[f_{R D, 0}\left(1-I_{i R D, t-1}\right)+f_{R D} I_{i R D, t-1}\right]=(1+r)\left[\lambda+(1-\lambda) e_{t} / e_{t-1}\right] B_{i, t}, B_{i, t}>0 .
$$

The term $e_{t} / e_{t-1}$ represents the effect of a RER depreciation on the value of the firm's outstanding debts in terms of domestic consumption. Notice, however, that our assumptions on the firm's behavior regarding dividends and debt repayment prevent RER changes from affecting the firm's credit constraint via the firm's stock of outstanding debt.

${ }^{71}$ Results obtained by ignoring trade status in the calibration (column 1 of Table 10) yield similar results.
} 
Figure 7: Foreign debt: average effect of an unexpected real depreciation $(25 \%)$ in the three regions.
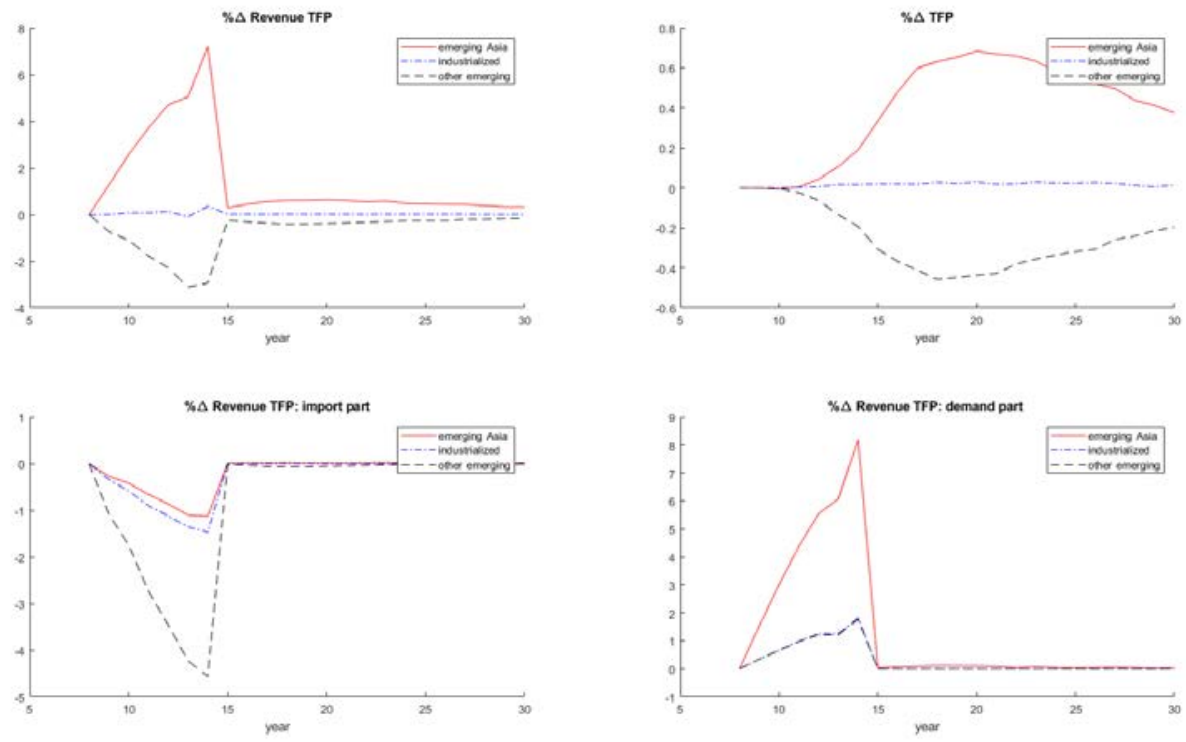

estimate of the R\&D sunk cost $f_{R D, 0}$. The remaining parameter estimates are not affected much and the fit of the model is overall similar to the baseline case.

Next, we change the elasticity of substitution between intermediates $\varepsilon$ and consider a value of 6 instead of 4, which is still within the range of values estimated by Halpern et al., 2015. Increasing $\varepsilon$ makes imports more sensitive to price-adjusted quality and thus requires us to adjust downward the estimate of the quality of imported intermediates $A$ to keep the import to sales ratio fixed. This then requires a lower estimate for the import fixed $\operatorname{cost} f_{m}$ in order to hold the import probability constant. The remaining parameter estimates are not significantly altered and the model fit is overall not changed much compared to the baseline case.

Third, we reduce the short-run return to R\&D from 6 to 4 percent (this is the lower bound of our estimates from the production-function estimation). A lower return to R\&D mainly requires a downward adjustment in the R\&D sunk cost $f_{R D, 0}$ to keep the R\&D start and continuation rates roughly similar. However, with a lower $R \& D$ sunk cost the $R \& D$ continuation rate is reduced and very low in comparison with the targeted rate.

Finally, our results are also robust to considering higher or lower real interest rates (15\% and 5\%) for discounting firm-level profits. As the estimated parameters are hardly affected, we do not report these results for brevity. The decomposition of innovation responses into credit constraints and market size slightly shifts (results available upon request).

Overall, the model fit is robust to altering the value of these calibrated parameters - alternative values give similar model fit. In addition, this robustness also implies that these parameters need to be 
set outside of the indirect-inference procedure because the targeted statistics are not very informative about their values.

\section{Conclusions}

This paper evaluates firms' responses to changes in the real exchange rate. We limit the analysis to manufacturing firms, as we exploit detailed firm-level data for a large set of countries for the period 2001-2010. Our focus on the firm level enables us to tease the micro channels through which the aggregate economic effects of changes in the real exchange rate operate. We also establish that the relative strength of these channels varies across regions and types of firms.

To motivate our analysis, we first present a number of stylized facts. Exporters are positively affected by real depreciations in terms of their cash flow and innovation decisions, while firms importing intermediates are hurt. Moreover, firms in emerging Asia are relatively more export oriented and less reliant on imported intermediates than firms in other emerging economies and industrialized countries. Our firm-level evidence also establishes that a firm's R\&D choice depends on the level of internal cash flow, and the more so the less developed local financial markets are.

We build and estimate structurally a dynamic heterogeneous-firm model in which higher current profits relax borrowing constraints and allow firms to overcome the fixed-cost hurdle for financing R\&D. Real depreciations increase the cost of importing intermediates, but raise exports. Depending on the relative export orientation of firms, the RER affects profits and thereby R\&D activity one way or another. The model enables us to decompose the effects of RER changes on observed revenue-based productivity growth into an innovation, an import and an export demand channel; explain regional heterogeneity in the effects of RER changes on average firm-level outcomes in terms of differences in export and import orientation and financial constraints; and quantitatively evaluate the different mechanisms by providing counter-factual simulations.

Regarding the latter, we obtain a number of interesting results. First, as in our reduced-form evidence, RER changes have different impacts depending on the relative export orientation of regions and the prevalence of credit constraints: while in emerging Asia a real depreciation leads to more $\mathrm{R} \& \mathrm{D}$ and an increase in physical productivity, other emerging economies experience effects with the opposite sign; finally, in industrialized economies opposing effects operating through the export and import channels largely offset each other. Second, the effects on physical productivity are rather persistent, extending far beyond the length of the real depreciation. Finally, we also show that depreciations and appreciations yield asymmetric effects due to the presence of sunk costs to R\&D.

Our analysis remains silent about welfare effects, as we take movements in the real exchange rate as given. We also take the origins of the regional differences in export and import behavior and financial constraints as the result of exogenously determined parameters. Still, the huge heterogeneity of effects

across regions for similar changes in RER suggests that some aspects of our work may be informative for policy-making. First, as opposed to conventional analysis, the effects of RER fluctuations on the manufacturing sector depend on the firms' average export and import participation. Hence, cross- 
country differences in the degree of firms' integration into global value chains are a key factor in our understanding of the implications of real depreciations. Triggering a depreciation would perhaps seem to be a reasonable policy for (export-intensive) emerging Asia but certainly not for (import-intensive) Latin America and Central and Eastern Europe, where engineering an appreciation may potentially have positive effects on productivity growth in manufacturing. Second, as global value chains evolve, or the degree of integration of a country's firms into them changes, the effects of RER fluctuations might change over time. As emerging-country firms follow the path of industrialized-country firms and become ever more integrated into global value chains, manipulating the RER will be less effective, as opposing effects will offset each other. Third, a deeper integration of firms into global value chains that makes them both export their output and import intermediates is likely to reduce the effectiveness of real exchange rate manipulation as a policy tool, as effects operating in opposite directions will cancel each other out, as is already the case for industrial-country firms. This will allow firms to become less vulnerable to exchange-rate shocks. Finally, the non-linearities and asymmetries in the effects of RER appreciations and depreciations we have uncovered suggest that the link between RER changes and macroeconomic performance might be much more nuanced than usually thought.

We limited the analysis to manufacturing firms due to data restrictions. Future work should aim to study the response of firms in the services industry, too, as it is becoming the most important sector both in industrialized and many emerging markets.

\section{References}

[1] Alessandria, George and Horag Choi, 2007, "Do Sunk Costs for Exporting Matter for Net Export Dynamics?," Quarterly Journal of Economics, 122 (1), 289-336, 2007.

[2] Alessandria, George, Joseph P. Kaboski and Virgiliu Midrigan, 2010, "Inventories, Lumpy Trade, and Large Devaluations," American Economic Review, 100(5), 2304-2339.

[3] Alfaro, Laura, Anusha Chari and Fabio Kanczuk, 2017, "The Real Effects of Capital Controls: Firm-Level Evidence from a Policy Experiment," Journal of International Economics, 108,191-210.

[4] Alfaro, Laura, Paola Conconi, Harald Fadinger, and Andrew Newman, 2016, "Do Price Determine Vertical Integration?" Review of Economic Studies, 83(3), 855-888.

[5] Alfaro, Laura, Alejandro Cuñat, Harald Fadinger, and Yanping Liu, 2018, "The Real Exchange Rate, Innovation and Productivity: Regional Heterogeneity, Asymmetries and Hysteresis," NBER $\mathrm{WP} \# 24633$

[6] Alfaro, Laura, and Maggie X. Chen, 2018, "Selection and Market Reallocation: Productivity Gains from Multinational Production," American Economic Journal: Economic Policy, 10(2), 1-38.

[7] Alvarez and Hansen, Erwin, 2017, "Corporate Currency Risk and Hedging in Chile: Real and Financial Effects," Inter-American Development Bank Working Paper Series IDB-WP-769. Washington DC, February.

[8] Aw, Bee, Mark Roberts and Daniel Xu, 2011, "R\&D Investment, Exporting and Productivity Dynamics," American Economic Review, 101(4), 1312-44.

[9] Atkeson, Andrew and Ariel Burstein, 2010, "Innovation, Firm Dynamics, and International Trade," Journal of Political Economy, 118,(3) 433-484

[10] Baldwin, Richard, 1988, "Hysteresis in Import Prices: The Beachhead Effect," American Economic Review, 78(4), 773-785. 
[11] Baldwin, Richard, 2016, The Great Convergence. Information Technology and the New Globalization, Harvard University Press.

[12] Baldwin, Richard and Paul Krugman, 1989, "Persistent Trade Effects of Large Exchange Rate Shocks," Quarterly Journal of Economics, 104(4), 635-654

[13] Barajas, Adolfo, Sergio Restrepo, Roberto Steiner, Juan Medellín and César Pabón, 2016, "Balance Sheet Effects in Colombian Non-Financial Firms," Inter-American Development Bank Working Paper Series IDB-WP-740. Washington DC, October.

[14] Barattieri, Alessandro, Matteo Cacciatore, and Fabio Ghironi, 2018, "Protectionism and the Business Cycle,"NBER Working Paper No. 24353.

[15] Benigno, Gianluca, and Luca Fornaro, 2012, "Reserve Accumulation, Growth and Financial Crises," CEP Discussion Paper 1161.

[16] Benigno, Gianluca, Huigang Chen, Christopher Otrok, Alessandro Rebucci, and Eric Young, 2016, "Optimal Capital Controls and Real Exchange Rate Policies: A Pecuniary Externality Perspective," Journal of Monetary Economics, 84(C),147-165.

[17] Blaum, Joaquin, 2019 "Global Firms in Large Devaluations," working paper.

[18] Blaum, Joaquin, Claire LeLarge and Michael Peters, 2018, "The Gains from Input Trade with Heterogeneous Importers," American Economic Journal: Macroeconomics, 10(4), 77-127.

[19] Bøler, Esther, Andreas Moxnes, and Karen Ulltveit-Moe, 2015, "R\&D, International Sourcing, and the Joint Impact on Firm Performance," American Economic Review, 105(12), 3704-39.

[20] Bond, Eric W., James Tybout, and Hale Utar, 2015, "Credit Rationing, Risk Aversion, and Industrial Evolution in Developing Countries,"International Economic Review, 56 (3), 695-722.

[21] Brito, Steve, Nicolas E. Magud, and Sebastian Sosa, 2018, "Real Exchange Rates, Economic Complexity, and Investment," IMF Working Paper 18/107.

[22] Burstein, Ariel, Martin Eichenbaum and Sergio Rebelo 2005, "Large Devaluations and the Real Exchange Rate," Journal of Political Economy, 113 (4), 742-784.

[23] Burstein, Ariel, and Gita Gopinath, 2014, "International Prices and Exchange Rates," in Gopinath, G., Helpman, E., and Rogoff, K. (Eds.): Handbook of International Economics Volume 4, Amsterdam: Elsevier.

[24] Cavallo, Alberto, 2017 "Retail Prices and the Real Exchange Rate," working paper.

[25] Céspedes, Luis F., Roberto Chang and Andrés Velasco, 2004 "Balance Sheets and Exchange Rate Policy," American Economic Review 94(4), 1183-1193.

[26] Chaney, Thomas, 2016, "Liquidity Constrained Exporters," Journal of Economic Dynamics and Control, 72, 141-54.

[27] Chinn, Menzie D. and Hiro Ito, 2006, "What Matters for Financial Development? Capital Controls, Institutions, and Interactions," Journal of Development Economics, 81(1), 163-192.

[28] Cosar, Kerem, Nezih Guner and James Tybout, 2016 "Firm Dynamics, Job Turnover, and Wage Distributions in an Open Economy," American Economic Review, 106(3), 625-63.

[29] Costinot, Arnaud, and Andrés Rodríguez-Clare, 2014, "Trade Theory with Numbers: Quantifying the Consequences of Globalization" in Gopinath, G., Helpman, E., \& Rogoff, K. (Eds.): Handbook of International Economics Volume 4, Amsterdam: Elsevier

[30] Defever, Fabrice, and Alejandro Riaño, 2017 "Twin Peaks," CEP Discussion paper 1505.

[31] De Loecker, Jan, 2011, "Product Differentiation, Multi-Product Firms and Estimating the Impact of Trade Liberalization on Productivity," Econometrica, 79(5), 1407-1451.

[32] Diaz Alejandro, Carlos F., 1965, Exchange-rate Devaluation in a Semi-industrialized Country. The Experience of Argentina 1955-1961, MIT Press.

[33] Dix-Carneiro, Rafael, 2014, "Trade Liberalization and Labor Market Dynamics," Econometrica, $82(3)$.

[34] Dixit, Avinash, 1989, "Entry and Exit Decisions under Uncertainty," Journal of Political Economy, $97(3), 620-638$ 
[35] Eichengreen, Barry, 2008, "The Real Exchange Rate and Economic Growth," Commission on Growth and Development Working Paper No. 4, The World Bank

[36] Feenstra, Robert C., Robert Inklaar and Marcel P. Timmer, 2015. " The Next Generation of the Penn World Table," American Economic Review, 105(10), 3150-82.

[37] Fernandes, A., Freund, C. and M. Pierola, 2016. "Exporter Behavior, Country Size and Stage of Development: Evidence from the Exporter Dynamics Database," Journal of Development Economics, 119, 121-137.

[38] Gopinath, Gita and Brent Neimann, 2014, "Trade Adjustment and Productivity in Large Crises," American Economic Review, 2014, 104(3), 793-831.

[39] Gorodnichenko, Yuriy and Monika Schnitzer, 2013, "Financial Constraints and Innovation: Why Poor Countries Don't Catch Up," Journal of European Economic Association, 11, 1115-1152

[40] Gouriéroux, Christian, Montfort, Alain and Eric Renault, 1993, "Indirect Inference," Journal of Applied Econometrics, 8, 85-118.

[41] Halpern, László, Miklós Koren and Adam Szeidl, 2015, "Imported Inputs and Productivity," American Economic Review, 105(12), 3660-3703.

[42] Henry, Peter Blair, 2008, "Comment," Brookings Papers on Economic Activity, Fall, 413-420.

[43] Kasahara, Hiroyuki and Beverly Lapham, 2013 "Productivity and the Decision to Import and Export: Theory and Evidence," Journal of International Economics, 89(2), 297-316.

[44] Kohn, David, Fernando Leibovici, and Michal Szkup, 2019, "Financial Frictions and Export Dynamics in Large Devaluations," Journal of International Economics, forthcoming.

[45] Lerner, Josh, and Bronwyn H Hall, 2010, "The Financing of R\&D and Innovation." In Handbook of the Economics of Innovation. Vol. 1, edited by Bronwyn Hall and Nathan Rosenberg. Elsevier.

[46] Magud, Nicolas, Carmen Reinhart, and Kenneth Rogoff, 2018, "Capital Controls: Myth and Reality? A Portfolio Balance Approach," Annals of Economics and Finance, 19(1), May.

[47] Manova, Kalina, 2013, "Credit Constraints, Heterogeneous Firms, and International Trade," Review of Economic Studies 80, 711-744.

[48] Mendoza, Enrique and Viven Yue, 2012, "A General Equilibrium Model Of Sovereign Default and Business Cycles" Quarterly Journal of Economics, 127(2), 889-946.

[49] Midrigan, Virgiliu, and Daniel Yi Xu, 2014, "Finance and Misallocation: Evidence from Plant-Level Data," American Economic Review, 104(2), 422-458.

[50] Rodrik, Dani, 2008, "The Real Exchange Rate and Economic Growth," Brookings Papers on Economic Activity, Fall, 365-412.

[51] Salomão, Juliana, and Liliana Varela, 2018, "Exchange Rate Exposure and Firm Dynamics," CEPR Discussion Paper 12654.

[52] Shu, Pian and Claudia Steinwender, 2019, "The Impact of Trade Liberalization on Firm Productivity and Innovation" in Lerner, J. and Stern, S. (Eds.): NBER Book Series Innovation Policy and the Economy, Volume 19.

[53] Valle et al. 2017, "The Correlation Effect between Commodity Prices and Exchange Rate for Brazilian Firms' Balance Sheets," Inter-American Development Bank Technical Note IDB-TN-1168. Washington DC, January.

[54] Woodford, Michael, 2008, "Comment," Brookings Papers on Economic Activity, Fall, 420-437. 


\section{Appendix A}

\section{A-1.1 Model}

This Appendix presents the small-open-economy model that leads to a number of results we have used implicitly in section 3 .

\section{A-1.1.1 Preferences, Technologies and Market Environment}

Each country has a representative consumer who maximizes a Cobb-Douglas per-period utility:

$$
U_{t}=\left(\frac{C_{N T, t}}{\alpha_{N T}}\right)^{\alpha_{N T}}\left(\frac{D_{O, t}}{\alpha_{O}}\right)^{\alpha_{O}}\left(\frac{D_{T, t}}{\alpha_{T}}\right)^{\alpha_{T}},
$$

$\alpha_{j} \in(0,1)$ for all $j, \sum_{j} \alpha_{j}=1$. $C_{N T, t}, D_{O, t}$ and $D_{T, t}$ denote consumption of, respectively, a nontraded, a numéraire and a manufacturing good; $t$ denotes time. The non-traded and numéraire sectors are perfectly competitive. The manufacturing sector features differentiated varieties produced under monopolistic competition. The consumption-based price index associated to this utility function is $P_{t}=P_{N T, t}^{\alpha_{N T}} P_{O, t}^{\alpha_{O}} P_{T, t}^{\alpha_{T}}$. We take a small-open-economy approach whereby countries face given foreign prices and a given foreign price index $P_{t}^{*}$. Stars denote foreign variables. The RER is defined as $P_{t}^{*} / P_{t}$. Thus, given our assumptions, changes in $P_{t}$ also reflect changes in the real exchange rate.

\section{A-1.1.2 Numéraire and Non-traded Sectors}

The numéraire good is freely traded and produced with technology

$$
Y_{O, t}=e_{t}^{-1}\left(K_{O, t} / \beta_{k}\right)^{\beta_{k}}\left(L_{O, t} / \beta_{l}\right)^{\beta_{l}}\left(X_{O, t} / \beta_{m}\right)^{\beta_{m}},
$$

$\beta_{h}>0,\{h=k, l, m\}, \sum_{h} \beta_{h}=1 . K_{O, t}, L_{O, t}$, and $X_{O, t}$ respectively denote capital, labor and a domestically produced intermediate input employed by the numéraire sector. $e_{t}$ is a shifter inversely related to the sector's productivity. All countries produce the numéraire good. Since $P_{O, t}=1$, an increase in $e_{t}$ makes domestic production factors cheaper. The non-traded sector is produced with technology $Y_{N T, t}=\left(K_{N T, t} / \beta_{k}\right)^{\beta_{k}}\left(L_{N T, t} / \beta_{l}\right)^{\beta_{l}}\left(X_{N T, t} / \beta_{m}\right)^{\beta_{m}}$. We assume that non-tradables can be used for final non-traded consumption or as the domestic intermediate input $X_{t}$, which implies $P_{N T, t}=$ $P_{X, t}=w_{t}^{\beta_{l}} r^{\beta_{k}} P_{X, t}^{\beta_{m}}=e_{t}^{-1}$. Thus, the mininum cost bundle of non-importers in manufacturing is $e_{t}^{-1}$ and these firms charge a price $p_{i, t}\left(\omega_{i, t}, e_{t}\right)=e_{t}^{-1} \frac{\sigma}{\sigma-1} \exp \left(-\omega_{i t}\right)$. Similarly, the mininum cost bundle for importing manufacturing firms is $w_{t}^{\beta_{l}} r^{\beta_{k}} P_{X, t}^{\beta_{m}} \exp \left[-\tilde{a}_{t}\left(e_{t}\right)\right]^{\beta_{m}}=e_{t}^{-1} \exp \left[-\tilde{a}_{t}\left(e_{t}\right)\right]^{\beta_{m}}$ and so they charge $p_{i, t}\left(\omega_{i, t}, e_{t}\right)=e_{t}^{-1} \exp \left[-\tilde{a}_{t}\left(e_{t}\right)\right]^{\beta_{m}} \frac{\sigma}{\sigma-1} \exp \left(-\omega_{i t}\right)$.

\section{A-1.1.3 Aggregate Prices and the Real Exchange Rate}

The domestic consumption-based price of the manufacturing CES aggregator is

$$
P_{T}=\left[\int_{i \in \Omega_{T, N I}} p_{i}^{1-\sigma} d i+\int_{i \in \Omega_{T, I}} p_{i}^{1-\sigma} d i+\int_{i \in \Omega_{T}^{*}} p_{i}^{* 1-\sigma} d i\right]^{\frac{1}{1-\sigma}} .
$$


Define the price of imported goods $P_{T}^{*}=\left[\int_{i \in \Omega_{T}^{*}} p_{i}^{* 1-\sigma} d i\right]^{\frac{1}{1-\sigma}}$ and the price of domestic goods

$$
P_{T H}=P_{T, N I}\left[1+\left(P_{T, I} / P_{T, N I}\right)^{1-\sigma}\right]^{\frac{1}{1-\sigma}}
$$

where $P_{T, N I}=e^{-1} \Delta_{T, N I}, P_{T, I}=e^{-1}\left(P_{M} / P_{X}\right)^{\beta_{m}} \Delta_{T, I}, \Delta_{T, N I} \equiv \frac{\sigma}{\sigma-1}\left[\int_{i \in \Omega_{T, N I}} \exp \left[\omega_{i}(\sigma-1)\right] d i\right]^{\frac{1}{1-\sigma}}$ and $\Delta_{T, I} \equiv \frac{\sigma}{\sigma-1}\left[\int_{i \in \Omega_{T, I}} \exp \left[\omega_{i}(\sigma-1)\right] d i\right]^{\frac{1}{1-\sigma}}$. One can express $P_{T}$ as

$$
P_{T}=P_{T, N I}\left[1+\left(P_{T, I} / P_{T, N I}\right)^{1-\sigma}\right]^{\frac{1}{1-\sigma}}\left[1+\frac{P_{T}^{* 1-\sigma}}{\left(P_{T, N I}\right)^{1-\sigma}\left[1+\left(P_{T, I} / P_{T, N I}\right)^{1-\sigma}\right]}\right]^{\frac{1}{1-\sigma}} .
$$

Substituting from the definitions of $P_{T, N I}, P_{T, I}$, and $P_{T}^{*}$, imposing $\varepsilon=\sigma$ and manipulating the resulting expression yields $P_{T}=e^{-1} \Delta_{T, N I} \Gamma^{\frac{1}{1-\sigma}}$, where

$$
\Gamma \equiv\left[1+\left[1+\left(\frac{e}{A}\right)^{1-\sigma}\right]^{\beta_{m}}\left(\frac{\Delta_{T, I}}{\Delta_{T, N I}}\right)^{1-\sigma}+\left(\frac{e P_{T}^{*}}{\Delta_{T, N I}}\right)^{1-\sigma}\right] .
$$

$e$ has a direct negative effect on $P_{T}$ via $e^{-1}$, and a number of indirect effects that operate through (1) the prices of imported final goods, $e P_{T}^{*}$, and intermediate inputs, $\left[1+\left(A e^{-1}\right)^{\sigma-1}\right]$, and (2) the extensive margins of $\Delta_{T, N I}$ and $\Delta_{T, I}$. Changes in $\omega_{i}$ only have lagged effects on $P_{T}$, as they operate with a time lag via the innovation process.

Taking $\operatorname{logs}, \ln P_{T}=-\ln (e)+\ln \Delta_{T, N I}+\frac{1}{1-\sigma} \ln \Gamma$. Define $\widetilde{X}=\ln X-\ln \bar{X}$ as the $\log$ deviation of variable $X$ from its steady state $\bar{X}$ :

$$
\widetilde{P}_{T}=-\widetilde{e}+\widetilde{\Delta}_{T, N I}+\frac{1}{1-\sigma} \widetilde{\Gamma}
$$

Log-linearizing $\Gamma(\cdot)$,

$$
\widetilde{\Gamma} \approx(1-\sigma)\left[\left[\bar{\Gamma}_{2} \frac{\beta_{m}(\bar{e} / A)^{1-\sigma}}{1+(\bar{e} / A)^{1-\sigma}}+\bar{\Gamma}_{3}\right] \widetilde{e}+\bar{\Gamma}_{2} \widetilde{\Delta}_{T, I}-\left(\bar{\Gamma}_{2}+\bar{\Gamma}_{3}\right) \widetilde{\Delta}_{T, N I}\right],
$$

where

$$
\begin{aligned}
& \bar{\Gamma}_{2} \equiv\left[1+(\bar{e} / A)^{1-\sigma}\right]^{\beta_{m}}\left(\bar{\Delta}_{T, I} / \bar{\Delta}_{T, N I}\right)^{1-\sigma}=\left(\bar{P}_{T, I} / \bar{P}_{T, N I}\right)^{1-\sigma} \\
& \bar{\Gamma}_{3} \equiv\left(\bar{e} \bar{P}_{T}^{*} / \bar{\Delta}_{T, N I}\right)^{1-\sigma}=\left(\bar{P}_{T}^{*} / \bar{P}_{T, N I}\right)^{1-\sigma} \\
& \bar{\Gamma} \equiv 1+\bar{\Gamma}_{2}+\bar{\Gamma}_{3} .
\end{aligned}
$$

Plugging back into (A-1.7),

$$
\widetilde{P}_{T} \approx \bar{\Gamma}^{-1}\left[-\left[1+\bar{\Gamma}_{2}\left(1-\frac{\beta_{m}(\bar{e} / A)^{1-\sigma}}{1+(\bar{e} / A)^{1-\sigma}}\right)\right] \widetilde{e}+\widetilde{\Delta}_{T, N I}+\bar{\Gamma}_{2} \widetilde{\Delta}_{T, I}\right] .
$$

Notice that the direct effect $-\widetilde{e}$ is of a larger magnitude than the indirect effects provided changes in $e$ do not bring about large changes in the extensive margins of $\Delta_{T, N I}$ and $\Delta_{T, I}$. If we therefore ignore 
the last two terms of this equation and $1+\bar{\Gamma}_{2}$ is large relative to $\bar{\Gamma}_{3}$, then $\widetilde{P}_{T} \approx-\widetilde{e}$.

Finally, plugging the results obtained above for $P_{T}$ into aggregate consumption-based price index $P=P_{N T}^{\alpha_{N T}} P_{O}^{\alpha_{O}} P_{T}^{\alpha_{T}}$ yields

$$
\begin{gathered}
\ln P=-\left(\alpha_{N T}+\alpha_{T}\right) \ln e+\alpha_{T} \ln \Delta_{T, N I}+\alpha_{T} \frac{1}{1-\sigma} \ln \Gamma . \\
\widetilde{P}=-\left(\alpha_{N T}+\alpha_{T}\right) \widetilde{e}+\alpha_{T} \widetilde{\Delta}_{T, N I}+\alpha_{T} \frac{1}{1-\sigma} \widetilde{\Gamma}= \\
\approx-\left[\alpha_{N T}+\alpha_{T} \frac{\left[1+\bar{\Gamma}_{2}\left(1-\beta_{m} \frac{(\bar{e} / A)^{1-\sigma}}{1+(\bar{e} / A)^{1-\sigma}}\right)\right]}{\bar{\Gamma}}\right] \widetilde{e}+\alpha_{T} \frac{1}{\bar{\Gamma}} \widetilde{\Delta}_{T, N I}+\alpha_{T} \frac{\bar{\Gamma}_{2}}{\bar{\Gamma}} \widetilde{\Delta}_{T, I} .
\end{gathered}
$$

Notice that both $\alpha_{T} / \bar{\Gamma}$ and $\alpha_{T} \bar{\Gamma}_{2} / \bar{\Gamma}$ are close to zero. As for the coefficient of $\widetilde{e}$, it can be approximated

by $\alpha_{N T}+\alpha_{T}$, which we assume close to $1: \widetilde{P} \approx-\widetilde{e}$. We can therefore think of an increase in $e_{t}$ as a real depreciation.

\section{A-1.2 Closing the Model in General Equilibrium}

A proper general-equilibrium approach to our counterfactuals would entail specifying how expenditure (aggregate income minus the current account) reacts to changes in the RER. In the model, aggregate income consists of factor income (an immediate function of the RER $e$ and the given rate of return $r$ ) and the manufacturing sector's profits (that is, the aggregation of individual firms' profits). We can think of the current account as savings minus investment. Investment only comprises R\&D fixed costs. However, obtaining savings requires modeling the consumer's lifetime utility maximization problem, which depends on the expected time paths of $e$, productivity and profits, among other things. The current account is given by

$$
C A_{t}=S_{t}-I_{t}=w_{t}\left(e_{t}\right) L+r K+\int \Pi_{t}\left(\omega_{t}\right) d G\left(\omega_{t}\right)-P_{t} U_{t}-\int f_{R D, 0}\left(\omega_{t}\right) d G\left(\omega_{t}\right)-\int f_{R D}\left(\omega_{t}\right) d G\left(\omega_{t}\right),
$$

where $\mathrm{K}$ is the (given) capital stock owned by domestic consumers, which is not necessarily equal to the domestic capital stock due to capital mobility; $\int \Pi_{t}\left(\omega_{t}\right) d G\left(\omega_{t}\right)$ is total profits; $P_{t} U_{t}$ is aggregate consumption expenditure; the last two terms correspond to R\&D investment. Note that $P_{t} U_{t}-$ and therefore the current account - is not determined unless we define the consumer's lifetime utility maximization problem.

The following alternative approach bypasses the need for solving the consumer"s lifetime utility maximization problem. One could estimate the reduced-form response of the current account to changes in the RER. The corresponding estimate would determine a rule that - in combination with the model's implications for aggregate factor income, profits and R\&D decisions - would enable us to obtain the reaction of aggregate consumption expenditure to changes in the RER as a residual. 


\section{A-1.3 Model with Export Sunk Costs}

The setup is inspired by Aw et al., 2011. We assume that in each period the firm first observes values of the fixed import cost $f_{m}$, the fixed and sunk costs of exporting, $f_{x}$ and $f_{x, 0}$ and the fixed and sunk cost of R\&D investment, $f_{R D}$ and $f_{R D, 0}$. Subsequently, it makes its discrete decision to export in year t, $I_{i x, t}$ and afterwards the discrete decision to undertake R\&D $I_{i R D, t}$ subject to a credit constraint. The state vector is now given by $\left(\omega_{i, t}, e_{t}, I_{i R D, t-1} I_{i x, t-1}\right)$.

The firm's value function is given by:

$$
\begin{gathered}
V_{i, t}\left(s_{i, t}\right)=\mathbb{E}_{x}\left[\operatorname { m a x } _ { I _ { i x , t } } \left\{\Pi_{i, t}^{d}\left(I_{i x, t}=1\right)+\Pi_{i, t}^{x}-f_{x 0}\left(1-I_{i x, t-1}\right)-f_{x} I_{i x, t-1}+V_{i, t}^{x}\left(s_{i, t}\right),\right.\right. \\
\left.\left.\prod_{i, t}^{d}\left(I_{i x, t}=0\right)+V_{i, t}^{d}\left(s_{i, t}\right)\right\}\right]
\end{gathered}
$$

where the expectations operator $\mathbb{E}_{x}$ is with respect to the exporting fixed and sunk costs. In this equation, the value of investing in $\mathrm{R} \& \mathrm{D}$ is subsumed in $V_{i, t}^{x}$ and $V_{i, t}^{d}$, which are, respectively, the value of an exporting and a non-exporting firm. The value of an exporting firm $V_{i, t}^{x}$ is given by:

$$
\begin{gathered}
V_{i, t}^{x}\left(s_{i, t}\right)=\mathbb{E}_{R D}\left[\operatorname { m a x } _ { I _ { i R D , t } } \left\{\beta \mathbb{E}_{t} V_{i, t+1}\left(s_{i, t+1} \mid I_{i x, t}=I_{i R D, t}=1\right)-f_{R D 0}\left(1-I_{i R D, t-1}\right)-f_{R D} I_{i R D, t-1},\right.\right. \\
\left.\left.\beta \mathbb{E}_{t} V_{i, t+1}\left(s_{i, t+1} \mid I_{i x, t}=1, I_{i R D, t}=0\right)\right\}\right],
\end{gathered}
$$

where the expectations operator $\mathbb{E}_{R D}$ is with respect to the $\mathrm{R} \& \mathrm{D}$ fixed and sunk costs. The value is subject to the credit constraint:

$$
I_{i R D, t}\left[f_{R D, 0}\left(1-I_{i R D, t-1}\right)+f_{R D} I_{i R D, t-1}\right] \leq \theta \epsilon_{i, t}\left(\Pi_{i, t}^{d}\left(I_{i x, t}=1\right)+\Pi_{i, t}^{x}\right)
$$

The value of a non-exporting firm $V_{i, t}^{d}$ is given by:

$$
\begin{gathered}
V_{i, t}^{d}\left(s_{i, t}\right)=\mathbb{E}_{R D}\left[\operatorname { m a x } _ { I _ { i R D , t } } \left\{\beta \mathbb{E}_{t} V_{i, t+1}\left(s_{i, t+1} \mid I_{i x, t}=0, I_{i R D, t}=1\right)-f_{R D 0}\left(1-I_{i R D, t-1}\right)-f_{R D} I_{i R D, t-1},\right.\right. \\
\left.\left.\beta \mathbb{E}_{t} V_{i, t+1}\left(s_{i, t+1} \mid I_{i x, t}=I_{i R D, t}=0\right)\right\}\right]
\end{gathered}
$$

and is subject to the credit constraint:

$$
I_{i R D, t}\left[f_{R D, 0}\left(1-I_{i R D, t-1}\right)+f_{R D} I_{i R D, t-1}\right] \leq \theta \epsilon_{i, t} \Pi_{t i}^{d}\left(I_{i x, t}=0\right)
$$

In comparison with Aw, Robert and Xu (2011), firms also face a static import decision. The optimal import choice of an exporter is given by:

$$
\begin{gathered}
\Pi_{i, t}^{d}\left(I_{i x, t}=1\right)+\Pi_{i, t}^{x}=\max _{I_{i m, t}}\left\{\Pi_{i, t}^{d}\left(I_{i x, t}=I_{i m, t}=1\right)+\Pi_{i, t}^{x}\left(I_{i m, t}=1\right)-f_{m},\right. \\
\left.\Pi_{i, t}^{d}\left(I_{i x, t}=1, I_{i m, t}=0\right)+\Pi_{i, t}^{x}\left(I_{i m, t}=0\right)\right\}
\end{gathered}
$$

The optimal import choice of a non-exporter is given by:

$$
\Pi_{i, t}^{d}\left(I_{i x, t}=0\right)=\max _{I_{i m, t}}\left\{\Pi_{i, t}^{d}\left(I_{i x, t}=0, I_{i m, t}=1\right)-f_{m}, \Pi_{i, t}^{d}\left(I_{i x, t}=I_{i m, t}=0\right)\right\}
$$




\section{A-1.4 Production-function Estimation}

In this Appendix we explain the details of the production-function estimation procedure we use to construct the gross-output-based and the value-added based revenue-productivity measures. In the exposition we focus on the model consistent gross-output-based measure. For the case of value added, we subtract material expenditure from gross output and use it as the dependent variable. Most steps are analogous to the case of gross output.

\section{A-1.4.1 Firm-level Revenue-Productivity Measures}

Rewriting the demand function (7) as $d_{i}=\left(\frac{p_{i}}{P_{T}}\right)^{-\sigma} D_{T}$, we get the inverse demand function $p_{i}=$ $d_{i}^{\frac{-1}{\sigma}} D_{T}^{\frac{1}{\sigma}} P_{T}$. Using optimal pricing $p_{i}=\frac{\sigma}{\sigma-1} M C_{i}$, it is easy to show that the fraction of domestic sales is given by $\nu_{i}(e) \equiv \frac{d_{i}}{d_{i}+d_{i}^{*}}$. Since $d_{i}=\nu_{i} Y_{i}$, we have that $d_{i}^{\frac{\sigma-1}{\sigma}}=\nu_{i}^{\frac{\sigma-1}{\sigma}} Y_{i}^{\frac{\sigma-1}{\sigma}}$. For the case of an exporting firm, we can then write total revenue $R_{i}=p_{i t} d_{i t}+p_{i t} d_{i t}^{*}$ as $R_{i}=Y_{i}^{\frac{\sigma-1}{\sigma}}\left[\nu(e)^{\frac{\sigma-1}{\sigma}} D_{T}^{\frac{1}{\sigma}} P_{T}+(1-\nu(e))^{\frac{\sigma-1}{\sigma}}\left(D_{T}^{*}\right)^{\frac{1}{\sigma}}\left(P_{T}^{*}\right)\right] \equiv$ $Y_{i}^{\frac{\sigma-1}{\sigma}} G_{i}\left(D_{T}, D_{T}^{*}, e\right)$. Total revenue can be expressed as:

$$
R_{i, t}=p_{i, t} d_{i, t}+I_{i X, t} p_{i, t} d_{i, t}^{*}=\left(Y_{i, t}\right)^{\frac{\sigma-1}{\sigma}} G_{i, t}\left(D_{T, t}, D_{T, t}^{*}, e_{t}\right)
$$

where $Y_{i, t}$ is physical output and $G_{i, t}$ captures the state of aggregate demand, which depends on the RER $e_{t}$. $G_{i, t}$ varies by firm through $I_{i X, t}$, which is an indicator that equals one if the firm exports, while conditional on exporting, the export share $(1-\nu(e))$ is not firm-specific. Taking logs and plugging in production function (6),

$r_{i, t}=\frac{\sigma-1}{\sigma}\left[\beta_{0}+\beta_{k} k_{i, t}+\beta_{l} l_{i, t}+\beta_{m} \tilde{m}_{i, t}-\beta_{m} \log \left(P_{X, t}\right)+I_{i m, t} \beta_{m} \tilde{a}_{t}\left(e_{t}\right)+\omega_{i t}+\epsilon_{i, t}\right]+g_{i, t}\left(D_{T, t}, D_{T, t}^{*}, e_{t}\right)$.

\section{A-1.4.2 First Stage}

Materials are chosen conditional on observing $\omega_{i t}$, the capital stock $k_{i t}$, the export and import status $I_{i x, t}, I_{i m, t}$, the RER $e_{t}$ and aggregate demand $D_{T, t}, D_{T, t}^{*}$. Since material expenditure $\tilde{m}_{i, t}=$ $\tilde{m}_{i, t}\left(\omega_{i, t}, k_{i, t}, D_{T, t}, D_{T, t}^{*}, e_{t}\right)$ is strictly increasing in $\omega_{i, t},{ }^{72}$ we can express $\omega_{i, t}$ as a function of capital $k_{i, t}$, material expenditure $\tilde{m}_{i, t}$ and aggregate demand $\left(D_{T, t}, D_{T, t}^{*}, e_{t}\right)$.

$$
\begin{aligned}
r_{i, t} & =\tilde{\beta}_{l} l_{i, t}+\tilde{\beta}_{0}+\tilde{\beta}_{k} k_{i, t}+\tilde{\beta}_{m} \tilde{m}_{i, t}+I_{i m, t} \tilde{\beta}_{m} \tilde{a}_{t}\left(e_{t}\right)-\tilde{\beta}_{m} \log \left(P_{X, t}\right)+\tilde{\omega}_{i, t}\left(k_{i, t}, \tilde{m}_{i, t}, D_{T, t}, D_{T, t}^{*}, e_{t}\right)+g_{i, t}\left(D_{T, t}, D_{T, t}^{*}, e_{t}\right)+\epsilon_{i, t}= \\
& =\tilde{\beta}_{l} l_{i, t}+\Phi\left(k_{i, t}, \tilde{m}_{i, t}, D_{T, t}, D_{T, t}^{*}, e_{t}\right)+\epsilon_{i, t},
\end{aligned}
$$

where $\tilde{\beta}=\frac{\sigma-1}{\sigma} \beta$ and $\tilde{\omega}=\frac{\sigma-1}{\sigma} \omega . \Phi\left(k_{i, t}, \tilde{m}_{i, t}, D_{T, t}, D_{T, t}^{*}, e_{t}\right)$ is a function that captures a combination of $\tilde{\omega}_{i, t}$, the import channel $I_{i, m t} \tilde{a}_{t}$ and the export demand channel $g_{i, t}$. It is approximated using a flexible

\footnotetext{
${ }^{72}$ The dependence on the export and import status is indicated by making the function $m_{i, t}$ firm specific. Strictly speaking, the production function estimation procedure requires material choices to be made after the other input choices are made. In our theoretical model we assume for convenience that all inputs are chosen simultaneously so that firms operate on their long-run marginal cost curve. We have also experimented with material choices to be made after the other inputs are chosen, leading to very similar results.
} 
polynomial:

$$
\begin{aligned}
\Phi\left(k_{i, t}, \tilde{m}_{i, t}, D_{T, t}, D_{T, t}^{*}, e_{t}\right)= & \lambda_{0}+\lambda_{1} k_{i, t}+\lambda_{2} \tilde{m}_{i, t}+\lambda_{3} k_{i, t} \tilde{m}_{i, t}+\lambda_{4} k_{i, t}^{2}+\ldots+\lambda_{9} \tilde{m}_{i, t}^{3}+ \\
& +\sum_{j=1}^{J} \lambda_{j}^{E X P} \log \left(e_{s, t}^{E X P}\right)+\sum_{j=1}^{J} \lambda_{j}^{I M P} \log \left(e_{s, t}^{I M P}\right)+D_{c, t}+D_{s}
\end{aligned}
$$

Here, $D_{c, t}$ are country-time dummies that absorb aggregate demand shocks, the price of domestic materials, $P_{X, t}$, and also correct for the fact that output and inputs are measured in nominal terms, while $D_{s}$ are sector dummies. The terms $\sum_{j=1}^{J} \lambda_{j}^{E X P} \log \left(e_{s, t}^{E X P}\right)$ and $\sum_{j=1}^{J} \lambda_{j}^{I M P} \log \left(e_{s, t}^{I M P}\right)$ are interactions of sector-specific export and import-weighted RERs with dummies for firm-size bins $\lambda_{j}^{E X P}, \lambda_{j}^{I M P}$. They control for the impact of firms' export and import decisions on their demand and productivity. By interacting RERs with dummies for firm size, we allow the impact of RER changes to affect firms differentially depending on their size. ${ }^{73}$ Larger firms are much more likely to export and/or import and should thus be more affected by RER changes. We prefer these firm-size-bin interactions with the RERs to interactions with export and import status, since the firm-level trade status is not available for around $60 \%$ of the observations. ${ }^{74}$ Since $\epsilon_{i, t}$ is uncorrelated with the covariates given our timing assumptions, OLS estimation of (A-1.17) allows us to recover a consistent estimate for the labor coefficient $\widehat{\beta}_{l}$ and predicted values for $\widehat{\Phi}\left(k_{i, t}, \tilde{m}_{i, t}, D_{T, t}, D_{T, t}^{*}, e_{t}\right)$ from the first stage.

\section{A-1.4.3 Second Stage}

In the second stage we obtain consistent estimates for the capital and material coefficients $\tilde{\beta}_{k}$ and $\tilde{\beta}_{m}$, the return to $\mathrm{R} \& \mathrm{D} \tilde{\alpha}_{2}$ and for the stochastic process of TFP. To obtain a better fit, we allow the Markov-process to be a second-order polynomial of lagged TFP, with parameters $\alpha_{0}, \alpha_{1}$ and $\alpha_{3}$. To do this, we plug our estimates $\widehat{\beta}_{l}$ and $\widehat{\Phi}\left(k_{i, t}, \tilde{m}_{i, t}, D_{T, t}, D_{T, t}^{*}, e_{t}\right)$ into the equation resulting from combining the stochastic process for TFP (14) with (A-1.17).

$$
\begin{aligned}
& r_{i, t}-\widehat{\beta}_{l} l_{i, t}=\tilde{\beta}_{0}+\tilde{\beta}_{k} k_{i, t}+\tilde{\beta}_{m} \tilde{m}_{i, t}+\tilde{\alpha}_{0}+ \\
& +\alpha_{1}\left[\widehat{\Phi}\left(k_{i, t-1}, \tilde{m}_{i, t-1}, D_{T, t}, D_{T, t}^{*}, e_{t-1}\right)-\tilde{\beta}_{k} k_{i, t-1}-\tilde{\beta}_{m} \tilde{m}_{i, t-1}\right] \\
& +\alpha_{3}\left[\widehat{\Phi}\left(k_{i, t-1}, \tilde{m}_{i, t-1}, D_{T, t}, D_{T, t}^{*}, e_{t-1}\right)-\tilde{\beta}_{k} k_{i, t-1}-\tilde{\beta}_{m} \tilde{m}_{i, t-1}\right]^{2}+\tilde{\alpha}_{2} I_{i R D, t-1}+\epsilon_{i, t}+\tilde{u}_{i, t} .
\end{aligned}
$$

Since $\mathbb{E}\left(\tilde{m}_{i, t} \tilde{u}_{i, t}\right) \neq 0$ we need to instrument for $\tilde{m}_{i, t}$ using the 2-period lag of materials. The moment conditions are given by $\mathbb{E}\left(Z_{i, t}^{\prime}\left(\varepsilon_{i, t}+\tilde{u}_{i t}\right)\right)=0$, where $Z_{i, t}=\left(\tilde{m}_{i, t-1}, \tilde{m}_{i, t-2}, k_{i, t-1}, I_{i R D, t-1}\right)$. We use a 2-step GMM estimator to obtain consistent estimates of $\tilde{\beta}_{k}, \tilde{\beta}_{m}, \tilde{\alpha}_{0}, \alpha_{1}, \alpha_{3}$ and $\tilde{\alpha}_{2} \cdot{ }^{75}$ We obtain standard errors using a bootstrap. In some specifications we impose constant returns to scale in the second stage of the estimation procedure (i.e., given $\sigma=4$, the input coefficients need to sum to $3 / 4$ ). Results of the production-function estimation are reported in Table B-4. TFPR is then constructed using equation (25) and estimates from Table B-4, columns (1) and (2). In the baseline results (all

\footnotetext{
${ }^{73}$ In the estimation we use 4 firm-size bins: $\leq 20$ employees; $20-50$ employees; $50-200$ employees; $\geq 200$ employees. ${ }^{74}$ We obtain similar results for the first-stage coefficients when instead interacting RERs with export and import status.

${ }^{75}$ For the case of the value added production function materials do not appear on the right-hand side, so the equation can be consistently estimated by non-linear least squares.
} 
Tables except Table A-3) we do not impose constant returns to scale (we use estimates from columns (1) and (2) of Table B-4) and we do not correct for the markup term. We report results for the impact of RER on firm-level TFPR growth imposing constant returns in Table A-3, columns (3) and (6). We report results imposing constant returns and multiplying $\tilde{\beta}$ with $(\sigma-1) / \sigma$ in Table A-3, columns (4) and (7).

\section{A-1.5 Reduced-form Evidence}

In this section, we present detailed reduced-form regression evidence for the relationships between RER changes and firm-level TFPR growth; innovation activity; and cash flow. We also present separate estimates of these relationships for exporters and importers. In addition, we provide evidence for the relation between innovation and cash flow. We use the coefficients of interest from these regressions either to obtain statistics to be matched in the structural estimation procedure or as untargeted moments that speak to the specific economic mechanisms that are emphasized in the model. These can be used to evaluate the model's external validity.

\section{A-1.5.1 Firm-level outcomes and the RER - Regional Heterogeneity}

We regress a number of firm-level variables on the growth rate of the RER, allowing the effect of the RER to vary by region. Since the aggregate RER is the relative price of the foreign vs. domestic aggregate goods basket, endogeneity to aggregate shocks may be a concern. Our analysis considers RER fluctuations as exogenous demand shocks that impact on firms' export, import and innovation decisions. The fact that we investigate how firm-level outcomes of manufacturing firms are affected by RER movements makes reverse causality unlikely. Omitted-variable bias is perhaps more of a concern. In particular, positive aggregate supply shocks should be positively correlated with the RER, while positive demand shocks should negatively correlate with it. Therefore, we always control for the aggregate growth rate of the economy. Alternatively, we (i) pursue an instrumental-variable strategy and (ii) use tradeweighted exchange rates, which allows us to control for country-year fixed effects that absorb aggregate shocks. The baseline regression specification is given by:

$$
\Delta \log \left(Y_{i c, t}\right)=\beta_{0}+\sum_{r \in R} \beta_{r} \Delta \log \left(e_{c, t}\right) I_{r}+\beta_{2} X_{c, t}+\delta_{s c}+\delta_{t}+u_{i c, t},
$$

where $I_{r}$ is a dummy for country $c$ belonging to region $r, \delta_{s c}$ is a 3-digit-sector-country fixed effect (controlling for the average growth rate in a given sector-country pair) and $\delta_{t}$ is a time fixed effect. The vector $X_{c, t}$ consists of business-cycle controls and includes the real GDP growth rate and the inflation rate. Controlling for inflation corrects for the fact that our dependent variables are measured in nominal value of domestic currency. ${ }^{76}$ We cluster standard errors at the country level since all firms in a given country are exposed to the same RER shock and RERs are auto-correlated. This choice of clustering implies that standard errors are robust to arbitrary correlation of the error terms across firms within a given country-year and over time within a given country.

\footnotetext{
${ }^{76}$ We use domestic currency values. Section 7.1 analyzes valuation effects.
} 
We consider five different firm-level dependent variables $\left.\Delta \log \left(Y_{i c, t}\right): 1\right)$ the revenue-based TFP (TFPR) growth rate, constructed from value added; 2) the revenue-based TFP growth rate, constructed from gross output [used as a targeted moment]; 3) the growth rate of sales; 4) the growth rate of cash flow; 5) the change of an indicator variable for R\&D. ${ }^{77}$ We also consider the (log) entry rate into exporting at the country-time level, defined as the number of new exporters relative to the number of total exporters, from the World Bank's Exporter Dynamics Database.

Table A-1 reports results based on yearly data and aggregate RERs. In emerging Asia, a one-percent depreciation of the RER increases value-added TFPR growth by 0.24 percentage points, gross-output TFPR growth by 0.12 percentage points, sales growth by 0.2 percentage points, and cash flow growth by 0.78 percentage points. The probability of $\mathrm{R} \& \mathrm{D}$ increases by 0.19 percentage points and the export entry rate increases by 0.55 percentage points. In the other emerging economies, real depreciations are associated instead with significantly slower TFPR and sales growth, while there is no significant effect on cash flow, R\&D probabilities and export entry. Finally, in industrialized countries, a real depreciation has no significant effect on firm-level TFPR, sales, R\&D probabilities and export entry rates, while the impact on cash flow is negative. These results are robust to excluding the years of the global financial crisis from our sample and to using alternative productivity measures. (See Tables A-2 and A-3.)

Table A-1: The aggregate RER and firm-level outcomes by region

\begin{tabular}{|c|c|c|c|c|c|c|}
\hline & $\begin{array}{c}(1) \\
\Delta \log \operatorname{TFPR}_{V A, i t}\end{array}$ & $\begin{array}{c}(2) \\
\Delta \log \operatorname{TFPR}_{G O, i t}\end{array}$ & $\begin{array}{c}(3) \\
\Delta \log \text { sales }_{i t}\end{array}$ & $\begin{array}{c}(4) \\
\Delta \log \text { c. f. } \cdot i t\end{array}$ & $\begin{array}{c}(5) \\
\Delta \mathrm{R} \& \mathrm{D} \text { prob.it }\end{array}$ & $\begin{array}{c}(6) \\
\Delta \text { log exp. } \\
\text { entry rate } c t\end{array}$ \\
\hline$\Delta \log e_{c t} \times$ & $0.239^{* * *}$ & $0.120^{* * *}$ & 0.195 & $0.783^{* * *}$ & $0.191^{*}$ & $0.552^{* * *}$ \\
\hline emerging Asia $_{c}$ & $(0.089)$ & $(0.019)$ & $(0.216)$ & $(0.114)$ & $(0.095)$ & $(0.207)$ \\
\hline$\Delta \log e_{c t} \times$ & $-0.546^{* * *}$ & $-0.105^{* *}$ & $-0.762^{* * *}$ & -0.557 & 0.16 & 0.063 \\
\hline other emerging $_{c}$ & $(0.185)$ & $(0.0426)$ & $(0.274)$ & $(0.414)$ & $(0.125)$ & $(0.059)$ \\
\hline$\Delta \log e_{c t} \times$ & 0.0196 & -0.031 & -0.282 & $-0.319^{* *}$ & -0.168 & -0.275 \\
\hline industrialized $_{c}$ & $(0.103)$ & $(0.0309)$ & $(0.217)$ & $(0.126)$ & $(0.149)$ & $(0.274)$ \\
\hline Observations & $1,333,986$ & $1,333,986$ & $1,275,606$ & 772,970 & 148,367 & 392 \\
\hline R-squared & 0.057 & 0.038 & 0.103 & 0.024 & 0.016 & 0.107 \\
\hline Country-sector FE & YES & YES & YES & YES & YES & $\mathrm{NO}$ \\
\hline Time FE & YES & YES & YES & YES & YES & YES \\
\hline Business cycle controls & YES & YES & YES & YES & YES & YES \\
\hline Cluster & Country & Country & Country & Country & Country & Country \\
\hline
\end{tabular}

Notes: The dependent variable in columns (1)-(5) is the annual log difference in the following firm-level outcomes computed from Orbis for manufacturing firms for the years 2001-2010: revenue-based TFP computed from value-added (column 1), revenuebased TFP computed from gross output (column 2), nominal sales (column 3), cash flow (column 4), an indicator for R\&D status (column 5). The construction of TFP is explained in section 4 of the paper. In column (6) the dependent variable is the log annual change in the export entry rate compute from the Worldbank's export dynamics database. The main explanatory variable of interest is the annual log difference in the real exchange rate from the PWT 8.0 interacted with dummies for: emerging Asia; other emerging economy; industrialized economy. The regressions also control for the real growth rate of GDP in PPP (from PWT8.0) and the inflation rate (from IMF). Standard errors are clustered at the country level. *, ** and *** indicate statistical significance at the $10 \%, 5 \%$ and $1 \%$ levels.

Alternatively, we also consider an instrumental-variable strategy that exploits exogenous fluctuations in world commodity prices and world capital flows. Both higher commodity prices and larger world-level capital flows are plausibly exogenous to domestic shocks and policies and tend to appreciate the RER through their impact on domestic inflation. Moreover, the domestic effects of these external shocks are

\footnotetext{
${ }^{77}$ That is, in the case of R\&D status we estimate a linear probability model.
} 
Table A-2: The aggregate RER and firm-level outcomes: excluding crisis years

\begin{tabular}{lccccc}
\hline \hline & $(1)$ & $(2)$ & $(3)$ & $(4)$ & $(5)$ \\
& $\Delta \log$ TFPR $_{V A, i t}$ & $\Delta \log$ TFPR $_{G O, i t}$ & $\Delta \log \operatorname{sales}_{i t}$ & $\Delta \log$ c. f. $i t$ & $\Delta$ R\&D prob.it \\
\hline$\Delta \log e_{c t} \times$ & $0.209^{* * *}$ & $0.124^{* * *}$ & $0.410^{* *}$ & $0.660^{* * *}$ & $0.164^{* * *}$ \\
emerging Asia $_{c}$ & $(0.062)$ & $(0.017)$ & $(0.164)$ & $(0.246)$ & $(0.058)$ \\
$\Delta \log e_{c t} \times$ & $-0.217^{*}$ & -0.0438 & -0.0828 & 0.173 & 0.00822 \\
other emerging $_{c}$ & $(0.130)$ & $(0.048)$ & $(0.207)$ & $(0.336)$ & $(0.007)$ \\
$\Delta \log e_{c t} \times$ & $0.094^{*}$ & 0.0105 & 0.162 & -0.258 & 0.0104 \\
industrialized & $(0.055)$ & $(0.022)$ & $(0.105)$ & $(0.326)$ & $(0.023)$ \\
\hline Observations $_{\text {R-squared }}$ & 871,672 & 871,672 & 816,686 & 528,152 & 86,859 \\
Country-sector FE & 0.053 & 0.031 & 0.076 & 0.022 & 0.012 \\
Time FE & YES & YES & YES & YES & YES \\
Business cycle controls & YES & YES & YES & YES & YES \\
Cluster & YES & YES & YES & YES & YES \\
\hline \hline
\end{tabular}

Notes: The dependent variable in columns (1)-(5) is the annual log difference in the following firm-level outcomes computed from Orbis for manufacturing firms for the years 2001-2008: revenue-based TFP computed from value-added (column 1), revenuebased TFP computed from gross output (column 2), nominal sales (column 3), cash flow (column 4), an indicator for R\&D status (column 5). The construction of TFP is explained in section 4 of the paper. The main explanatory variable of interest is the annual $\log$ difference in the real exchange rate from the PWT 8.0 interacted with dummies for: emerging Asia; other emerging economy; industrialized economy. The regressions also control for the real growth rate of GDP in PPP (from PWT8.0) and the inflation rate (from IMF). Standard errors are clustered at the country level. *, ** and *** indicate statistical significance at the $10 \%, 5 \%$ and $1 \%$ levels.

Table A-3: The aggregate RER and firm-level productivity growth: alternative productivity measures

\begin{tabular}{|c|c|c|c|c|c|c|c|}
\hline & $\begin{array}{c} \\
\Delta \log \text { lab. prod.it }\end{array}$ & $\begin{array}{c}(2) \\
\Delta \log \operatorname{TFPR}_{V A, i t}\end{array}$ & $\begin{array}{c}\Delta \log \mathrm{TFPR}_{V A, i t} \\
\text { CRS } \\
\end{array}$ & $\begin{array}{c}(4) \\
\Delta \log \mathrm{TFPR}_{V A, i t} \\
\text { CRS, markup }\end{array}$ & $\begin{array}{c}(5) \\
\Delta \log \operatorname{TFPR}_{G O, i t}\end{array}$ & $\begin{array}{c}(6) \\
\Delta \text { TFPR }_{G O, i t} \\
\text { CRS } \\
\end{array}$ & $\begin{array}{c}(7) \\
\Delta \text { TFPR }_{G O, i t} \\
\text { CRS, markup }\end{array}$ \\
\hline$\Delta \log e_{c t} \times$ & $0.245^{*}$ & $0.239^{* * *}$ & $0.242^{* * *}$ & $0.835^{* *}$ & $0.120^{* * *}$ & 0.106 & $0.152^{* *}$ \\
\hline emerging Asia $_{c}$ & $(0.144)$ & $(0.090)$ & $(0.087)$ & $(0.366)$ & $(0.020)$ & $(0.113)$ & $(0.060)$ \\
\hline$\Delta \log e_{c t} \times$ & $-0.483^{* *}$ & $-0.546^{* * *}$ & $-0.542^{* * *}$ & 0.277 & $-0.105^{* *}$ & $-0.376^{* * *}$ & $-0.234^{* * *}$ \\
\hline other emerging ${ }_{c}$ & $(0.190)$ & $(0.185)$ & $(0.185)$ & $(0.390)$ & $(0.043)$ & $(0.126)$ & $(0.083)$ \\
\hline$\Delta \log e_{c t} \times$ & -0.13 & 0.0196 & 0.021 & 0.304 & -0.031 & -0.118 & -0.0773 \\
\hline industrialized $_{c}$ & $(0.139)$ & $(0.103)$ & $(0.102)$ & $(0.245)$ & $(0.031)$ & $(0.109)$ & $(0.063)$ \\
\hline Observations & $1,275,606$ & $1,333,986$ & $1,333,986$ & $1,333,986$ & $1,333,986$ & $1,333,986$ & $1,333,986$ \\
\hline R-squared & 0.052 & 0.057 & 0.056 & 0.012 & 0.038 & 0.066 & 0.058 \\
\hline Country-sector FE & YES & YES & YES & YES & YES & YES & YES \\
\hline Time FE & YES & YES & YES & YES & YES & YES & YES \\
\hline Business cycle controls & YES & YES & YES & YES & YES & YES & YES \\
\hline Cluster & Country & Country & Country & Country & Country & Country & Country \\
\hline
\end{tabular}

Notes: The dependent variable in columns (1)-(7) is the annual log difference in the following firm-level productivity measures computed from Orbis for manufacturing firms for the years 2001-2010: labor productivity (sales/employment) (column 1), revenuebased TFP computed from value-added (column 2), revenue-based TFP computed from value added, imposing constant returns to scale (column 3), revenue-based TFP computed from value added, imposing constant returns to scale and correcting for markups (column 4), revenue-based TFP computed from gross output (column 5), revenue-based TFP computed from gross output, imposing constant returns to scales (column 6), revenue-based TFP computed from gross output, imposing constant returns to scale and correcting for markups (column 7). The construction of TFP is explained in section 4 of the paper and in Appendix A-1.2. The main explanatory variable of interest is the annual log difference in the real exchange rate from the PWT 8.0 interacted with dummies for: emerging Asia; other emerging economy; industrialized economy. The regressions also control for the real growth rate of GDP in PPP (from PWT 8.0) and the inflation rate (from IMF). Standard errors are clustered at the country level. $*, * *$ and $* * *$ indicate statistical significance at the $10 \%, 5 \%$ and $1 \%$ levels. 
larger for countries that rely more on commodity trade or have more open financial accounts. In Table A-4 we show that our results are robust to instrumenting for RER changes with (i) trade-weighted world commodity prices (using pre-sample trade weights) and (ii) interactions of world gross financial flows with pre-sample values of the Chinn-Ito index for financial account openness. We construct two instruments for the RER. The first one is based on a trade-weighted average of world commodity prices (a fixed set of agricultural commodities, metals, oil). For each country and commodity we compute exports and imports (using trade data from WITS) in the pre-sample year 2000 to construct trade weights. We then compute the instrument as a country-specific trade-weighed average of world commodity prices (using price information from the Worldbank). Our second instrument is based on world capital flows. We compute world capital flows as the sum of equity and debt inflows across countries (from IMF). We then interact this variable (which has only time variation), with the value of the Chinn-Ito index (Chinn and Ito, 2006) for financial openness in the pre-sample year 2000. World commodity prices interacted with commodity-country-specific trade weights are strongly negatively correlated with RER changes, in particular for emerging economies. The rationale for the second instrument is that world gross financial flows should also be independent of local economic conditions and act as a push factor for the RER, in particular for countries with an open financial account, as measured by the Chinn-Ito index.

Table A-4: The aggregate RER and firm-level outcomes: IV estimates

\begin{tabular}{lccccc}
\hline \hline & $(1)$ & $(2)$ & $(3)$ & $(4)$ & $(5)$ \\
& $\Delta \log$ TFPR $_{V A, i t}$ & $\Delta \log \operatorname{TFPR}_{G O, i t}$ & $\Delta \log \operatorname{sales}_{i t}$ & $\Delta \log \mathrm{c}$. f.it & $\Delta$ R\&D prob.it \\
\hline$\Delta \log e_{c t} \times$ & $0.286^{* * *}$ & $0.140^{* * *}$ & 0.267 & $0.895^{* * *}$ & $0.668^{* * *}$ \\
emerging Asia & $(0.078)$ & $(0.023)$ & $(0.190)$ & $(0.060)$ & $(0.245)$ \\
$\Delta \log e_{c t} \times$ & $-0.922^{* * *}$ & $-0.337^{* *}$ & $-2.114^{*}$ & -0.906 & -4.076 \\
other emerging & $(0.354)$ & $(0.137)$ & $(1.241)$ & $(0.560)$ & $(2.836)$ \\
$\Delta \log e_{c t} \times$ & -0.009 & -0.054 & -0.353 & -0.105 & -5.169 \\
industrialized $c$ & $(0.258)$ & $(0.099)$ & $(0.686)$ & $(0.520)$ & $(5.424)$ \\
\hline Observations & $1,310,509$ & $1,310,509$ & $1,252,483$ & 758,623 & 142,093 \\
R-squared & 0.011 & 0.011 & 0.028 & 0.014 & -0.006 \\
Country-sector FE & YES & YES & YES & YES & YES \\
Time FE & YES & YES & YES & YES & YES \\
Business cycle controls & YES & YES & YES & YES & YES \\
Cluster & Country & Country & Country & Country & Country \\
Kleibergen-Paap F-Statistic & 9.146 & 9.146 & 9.919 & 4.759 & 8.304 \\
Over-identification test & 3.333 & 1.88 & 3.951 & 2.625 & 2.642 \\
(P-value) & $(0.343)$ & $(0.597)$ & $(0.267)$ & $(0.453)$ & $(0.452)$ \\
\hline \hline
\end{tabular}

Notes: The dependent variable in columns (1)-(5) is the annual log difference in the following firm-level outcomes computed from Orbis for manufacturing firms for the years 2001-2010: revenue-based TFP computed from value-added (column 1), revenuebased TFP computed from gross output (column 2), nominal sales (column 3), cash flow (column 4), an indicator for R\&D status (column 5). The construction of TFP is explained in section 4 of the paper. The main explanatory variable of interest is the annual log difference in the real exchange rate from the PWT 8.0 interacted with dummies for: emerging Asia; other emerging economy; industrialized economy. The regressions also control for the real growth rate of GDP in PPP (from PWT8.0) and the inflation rate (from IMF). The set of excluded instruments consists of: regional dummies interacted with (i) initial-period trade-weighted world commodity prices and (ii) world capital flows interacted with the initial-period Chinn-Ito index for financial account openness. Standard errors are clustered at the country level. *,** and *** indicate statistical significance at the $10 \%$, $5 \%$ and $1 \%$ levels.

Finally, we identify the causal impact of RER fluctuations by using trade-weighted exchange rates. In this case, we can control for country-time fixed effects, which eliminate any spurious correlation 
due to aggregate shocks to the manufacturing sector. We find that our results are robust to using this alternative RER measures. These results are available in the working paper version (Alfaro et al., 2018). Moreover, we have also found very similar results using specifications in 3-year annualized differences. These results are available on request.

\section{A-1.5.2 Firm-level outcomes and the RER - Trade Status}

We now provide direct evidence that the effect of RER changes on firm-level outcomes depends on the firms' trade status. We run firm-level outcomes on changes in the RER, allowing for differential effects for exporters (for which we expect the effects of RER depreciations to be positive) and importers (for which we expect the effects to be negative). Since the interaction of trade status with the RER varies at the firm-country-time level, this specification allows us to include country-sector-time fixed effects. In this way we can control for any unobserved shocks to a given country-sector-pair. These fixed effects absorb the impact on the baseline category (domestic firms which neither export nor import). We also control for an interaction of RER with a dummy for the multinational status of the firm, which is highly correlated with trade participation. ${ }^{78}$ Again, we cluster standard errors at the country level.

$$
\Delta \log \left(Y_{i c, t}\right)=\beta_{0}+\sum_{r \in R, T \in \exp , i m p} \beta_{T r} \Delta \log \left(e_{c, t}\right) I_{T} I_{r}+\sum_{r \in R,} \sum_{T \in \exp , i m p} I_{T} I_{r}+\delta_{s c t}+u_{i c, t}
$$

Table A-5 reports the corresponding results. As expected, in emerging Asia the interaction term of RER changes with export status is positive, highly significant and large, while the interaction with import status is negative and strongly significant. Similarly, for firms in other emerging countries the interaction effect with export status is positive and significant and the interaction effect with import status is negative. ${ }^{79}$ Finally, for firms in industrialized countries the interaction effects with export status and import status are small and mostly statistically insignificant. ${ }^{80}$

\section{A-1.5.3 R\&D and Financial Constraints}

In order to understand the effect of financial constraints on R\&D decisions, we check if the probability to engage in $R \& D$ is affected by the availability of internal cash flow. We run the following regression for the firms in the Orbis dataset:

$I_{i R D, t}=\beta_{0} \sum_{i=1}^{4} \beta_{1 i} \log (\text { cashflow })_{i, t} \times$ size $_{i}+\sum_{i=1}^{4} \beta_{2 i} \log \left({\text { cashflow })_{i, t} \times \text { size }_{i} \times \text { fin.dev } \cdot c}_{\cdot c}+\beta_{4} X_{i c, t}+\nu_{i, t}\right.$,

where $I_{i R D, t}$ is an indicator that equals one if firm $i$ performs $\mathrm{R} \& \mathrm{D}$ in year $t$. $\log (\text { cash flow })_{i, t}$ is the firm's cash flow (in logs), size $_{i}$ is a dummy indicator for the firm-size quartile (measured in terms of $\log ($ employment)) and financial dev is a measure of the country's financial development (private

\footnotetext{
${ }^{78}$ To avoid endogeneity of firms' status, we keep the firms' trade and multinational status fixed over the sample period and equal to the status in the first period we observe it.

${ }^{79}$ For related evidence see Brito et al., 2018.

${ }^{80}$ Note that in our sample the average firm engaging in international trade in industrialized countries is much smaller compared to the other regions and thus we likely observe firms that export and import only a small amount relative to their sales and change their trade status frequently, which exacerbates measurement error in trade status (we only observe an indicator for exporting and importing for a small number of years). This makes it harder to detect a significant impact of exporting or importing on firm-level outcomes.
} 
Table A-5: The aggregate RER and firm-level outcomes by firm's trade participation status and region

\begin{tabular}{|c|c|c|c|c|c|}
\hline & $\begin{array}{c}(1) \\
\Delta \log \operatorname{TFPR}_{V A, i t}\end{array}$ & $\begin{array}{c}(2) \\
\Delta \log \operatorname{TFPR}_{G O, i t}\end{array}$ & $\begin{array}{c}(3) \\
\Delta \log \text { sales }_{i t}\end{array}$ & $\begin{array}{c}(4) \\
\Delta \log \text { c. } f_{\cdot i t}\end{array}$ & $\begin{array}{c}(5) \\
\Delta R^{\prime} \& \text { prob. }_{i t}\end{array}$ \\
\hline$\Delta \log e_{c t} \times$ & $0.197^{* *}$ & 0.030 & $0.135^{* * *}$ & $0.243^{* * *}$ & $0.065^{* * *}$ \\
\hline emerging Asia $_{c} \times \operatorname{exporter}_{f}$ & $(0.075)$ & $(0.019)$ & $(0.036)$ & $(0.035)$ & $(0.011)$ \\
\hline$\Delta \log e_{c t} \times$ & $-0.157^{* * *}$ & $-0.016^{* *}$ & $-0.099^{* * *}$ & $-0.123^{* *}$ & $-0.101^{* * *}$ \\
\hline emerging Asia $_{c} \times$ importer $_{f}$ & $(0.041)$ & $(0.008)$ & $(0.024)$ & $(0.049)$ & $(0.012)$ \\
\hline$\Delta \log e_{c t} \times$ & -0.005 & 0.019 & $-0.088^{* * *}$ & -0.096 & $-0.049^{*}$ \\
\hline 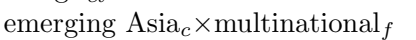 & $(0.045)$ & $(0.019)$ & $(0.015)$ & $(0.059)$ & $(0.024)$ \\
\hline$\Delta \log e_{c t} \times$ & $0.394^{* *}$ & $0.087^{* *}$ & $0.333^{* * *}$ & $1.162^{* * *}$ & $0.167^{* * *}$ \\
\hline other emerging ${ }_{c} \times$ exporter $_{f}$ & $(0.159)$ & $(0.036)$ & $(0.079)$ & $(0.281)$ & $(0.029)$ \\
\hline$\Delta \log e_{c t} \times$ & -0.251 & -0.074 & 0.005 & $-0.803^{* * *}$ & -0.119 \\
\hline other emerging ${ }_{c} \times$ importer $_{f}$ & $(0.177)$ & $(0.046)$ & $(0.102)$ & $(0.203)$ & $(0.072)$ \\
\hline$\Delta \log e_{c t} \times$ & -0.027 & $-0.083^{* *}$ & 0.382 & $0.502^{*}$ & 0.036 \\
\hline other emerging ${ }_{c} \times$ multinational $_{f}$ & $(0.127)$ & $(0.040)$ & $(0.248)$ & $(0.292)$ & $(0.024)$ \\
\hline$\Delta \log e_{c t} \times$ & 0.006 & -0.004 & 0.025 & $0.272^{* * *}$ & -0.004 \\
\hline industrialized $_{c} \times \operatorname{exporter}_{f}$ & $(0.021)$ & $(0.009)$ & $(0.033)$ & $(0.085)$ & $(0.018)$ \\
\hline$\Delta \log e_{c t} \times$ & 0.046 & $0.012^{* * *}$ & $0.068^{* * *}$ & -0.052 & $-0.042^{* *}$ \\
\hline industrialized $_{c} \times$ importer $_{f}$ & $(0.028)$ & $(0.004)$ & $(0.014)$ & $(0.078)$ & $(0.016)$ \\
\hline$\Delta \log e_{c t} \times$ & 0.033 & $0.020^{*}$ & 0.045 & 0.144 & -0.040 \\
\hline industrialized $_{c} \times$ multinational $_{f}$ & $(0.034)$ & $(0.011)$ & $(0.043)$ & $(0.088)$ & $(0.028)$ \\
\hline Observations & 511,061 & 511,061 & 481,733 & 313,856 & 35,151 \\
\hline R-squared & 0.094 & 0.076 & 0.16 & 0.063 & 0.116 \\
\hline Country-sector-time FE & YES & YES & YES & YES & YES \\
\hline Firm status controls & YES & YES & YES & YES & YES \\
\hline Cluster & Country & Country & Country & Country & Country \\
\hline
\end{tabular}

Notes: The dependent variable in columns (1)-(5) is the annual log difference in the following firm-level outcomes computed from Orbis for manufacturing firms for the years 2001-2010: revenue-based TFP computed from value-added (column 1), revenuebased TFP computed from gross output (column 2), nominal sales (column 3), cash flow (column 4), an indicator for R\&D status (column 5). The construction of TFP is explained in section 4 of the paper. The main explanatory variable of interest is the triple interaction between the annual log difference in the real exchange rate from the PWT 8.0; firm-level indicators for exporting, importing and multinational status; and dummies for: emerging Asia; other emerging economy; industrialized economy. The regressions also control for the firms' exporter, importer and multinational status. Standard errors are clustered at the country level. *,** and $* * *$ indicate statistical significance at the $10 \%, 5 \%$ and $1 \%$ levels. 
credit/GDP). We always include the following set of additional controls: firm-size-bin dummies, capital stock (in logs), the inflation rate and the real growth rate of GDP. Depending on the specification, we include different fixed effects (country and sector, or country-sector). Since we are regressing firm-level variables on each other, endogeneity is of course a concern here; we thus emphasize that these are just conditional correlations that we replicate with our structural model. ${ }^{81}$

We report results for these specifications in Table A-6. The coefficient on (log) cash flow interacted with the dummy for the smallest firm-size quartile is insignificant, suggesting that for these firms R\&D status is insensitive to cash flow. For medium-size to large firms, cash flow is robustly positively related to $R \& D$, as indicated by the significantly positive coefficients on the interaction between $(\log )$ cash flow and the dummies for the 3rd and 4th firm-size quartiles. Finally, the triple interaction term between (log) cash flow, the firm-size-bin dummies and the country's financial development is negative and statistically significant for the 3rd and 4th firm-size bin: for these firms the relevance of internal cash flow for R\&D is smaller in countries with more developed capital markets.

Table A-6: R\&D sensitivity to cash flow by firm-size quartiles and level of financial development

\begin{tabular}{|c|c|c|}
\hline & $\begin{array}{c}(1) \\
\text { R\&D prob.it }\end{array}$ & $\begin{array}{c}(2) \\
\text { R\&D prob.it }\end{array}$ \\
\hline $\log (\text { cash flow })_{f t} \times$ & 0.015 & 0.008 \\
\hline size quartile $1_{f}$ & $(0.019)$ & $(0.019)$ \\
\hline $\log (\text { cash flow })_{f t} \times$ & $0.035^{* *}$ & 0.018 \\
\hline size quartile $2_{f}$ & $(0.0153)$ & $(0.014)$ \\
\hline $\log (\text { cash flow })_{f t} \times$ & $0.052^{* * *}$ & $0.048^{* * *}$ \\
\hline size quartile $3 f$ & $(0.005)$ & $(0.006)$ \\
\hline $\log (\text { cash flow })_{f t} \times$ & $0.056 * * *$ & $0.059 * * *$ \\
\hline size quartile $4_{f}$ & $(0.003)$ & $(0.003)$ \\
\hline $\log (\operatorname{cash} \text { flow })_{f t} \times$ & -0.0001 & -0.0001 \\
\hline size quartile $1_{f} \times$ credit $_{c}$ & $(0.0001)$ & $(0.0001)$ \\
\hline $\log (\text { cash flow })_{f t} \times$ & $-0.0002^{*}$ & -0.0001 \\
\hline size quartile $2_{f} \times$ credit $_{c}$ & $(0.0001)$ & $(0.0001)$ \\
\hline $\log (\text { cash flow })_{f t} \times$ & $-0.0002^{* * *}$ & $-0.0002^{* * *}$ \\
\hline size quartile $3_{f} \times$ credit $_{c}$ & $(0.00004)$ & $(0.00004)$ \\
\hline $\log (\text { cash flow })_{f t} \times$ & $-0.0002^{* * *}$ & $-0.0002 * * *$ \\
\hline size quartile $4_{f} \times$ credit $_{c}$ & $(0.00002)$ & $(0.00002)$ \\
\hline R-squared & 0.347 & 0.383 \\
\hline Observations & 117,394 & 117,142 \\
\hline Time FE & YES & YES \\
\hline Sector FE & YES & $\mathrm{NO}$ \\
\hline Country FE & YES & $\mathrm{NO}$ \\
\hline Sector-country FE & $\mathrm{NO}$ & YES \\
\hline Firm controls & YES & YES \\
\hline Business cycle controls & YES & YES \\
\hline Cluster & Firm & Firm \\
\hline
\end{tabular}

Notes: The dependent variable is an indicator for the firm's R\&D status. Explanatory variables are firm-level cash flow (in logs) interacted with 4 dummies for the quartiles of $(\log )$ firm employment and triple interactions of these variables with financial development (measured as private credit/GDP). Further controls include (coefficients not reported): dummies for quartiles of (log) firm employment, capital (in logs), the real GDP growth rate (from PWT 8.0) and the inflation rate (from IMF). Standard errors are clustered at the firm level. $*{ }^{* *}$ and $* * *$ indicate statistical significance at the $10 \%, 5 \%$ and $1 \%$ levels.

${ }^{81}$ Using lagged cash flow instead of current cash flow mitigates endogeneity concerns and gives very similar results. More generally, as documented by Lerner and Hall, 2010, there is substantial evidence on the role of internal funds and cash flowing financing R\&D. 


\section{A-1.6 Dataset Construction}

We have compiled our dataset by combining data from a number of sources. We use firm-level information from Orbis (Bureau Van Dijk) and Worldbase (Dunn \& Bradstreet). In terms of information from Orbis, we use data from two CDs (2007 and 2014) and the web version. Orbis provides firm-level balance sheet data of listed and unlisted firms.

We drop firm-year observations without firm identifiers, company names, information on revenue or sales, total assets, employees and observations with missing accounting units. We replace as missing any negative reported values for sales, revenue, number of employees, total assets, current liabilities, total liabilities, long-term debt, tangible fixed assets, intangible fixed assets, current assets, material costs, $\mathrm{R} \& \mathrm{D}$ expenditure. We convert variables into common units (thousands of current local currency). We compute the capital stock as the sum of tangible fixed assets and intangible fixed assets. We compute value added as revenue minus material costs. We keep firms with a primary activity in the manufacturing sector (US SIC 1997 codes 200-399). See Alfaro and Chen, 2018, for further description of the data.

Dun \& Bradstreet's WorldBase is a database covering millions of public and private companies in more than 200 countries and territories. The unit of observation in Worldbase is the establishment/plant. Among other variables, Worldbase reports for each plant the full name of the company, location information (country, state, city, and street address) basic operational information (sales and employment), and most importantly, information on the plant's trade status (exporting/not exporting/importing/not importing). See Alfaro et al., 2016, for a detailed description.

For those manufacturing firms in Orbis that report revenue, number of employees, capital stock and material costs, we merge by names with the Worldbase datasets for the years 2000, 2005, 2007 and 2009. When common ids are not provided in the datasets, we use the Jaro-Winkler string distance algorithm to match the datasets by company names. We condition on the firms being located in the same country and then match by names and require a match score of at least 0.93 , which turns out to provide a very good match in manual checks. For our main analysis we disregard the year information of the trade status to maximize sample coverage. We thus assign a fixed trade status to each firm, giving priority to earlier years.

We drop outliers, by removing the top and bottom one percent of observations in terms of (log) capital stock, materials, value added, sales, employment in the TFP estimation. After the production function coefficients have been estimated on this restricted sample, we expand sample size and compute TFP also for observations with missing material costs, by proxying for the material cost as (median material share in revenue) $\times$ revenue. Finally, we drop the top and bottom one percent of observations in terms of TFP growth before running the reduced-form regressions reported in the paper.

Appendix Table A-1 (Panel B) reports descriptive statistics of firm-level variables (for comparability across countries in thousands of 2004 US-Dollars). 


\section{A-1.7 Numerical Solution Algorithm}

This Appendix describes the computational details of the algorithm used in the estimation. Denote $\Theta$ as the vector of parameters to be estimated. The estimation follows the following routine:

(1) For a given value of $\Theta$, solve the dynamic problem of firms, captured by the Bellman equation described in Section 2.7. This step yields the value functions for the firms.

(2) Simulate the decisions (for a panel of 8000 firms for 80 periods) for a set of firms. Calculate the desired moments from the simulated data.

(3) Update $\Theta$ to minimize the (weighted) distance between the simulated statistics and the data statistics.

Step 1 Solving the Bellman equation.

First we use Tauchen's method to discretize the state space for the continuous state variables that include productivity $\omega_{i t}$ and the RER $e_{t}$. We choose 50 grids for each state variable. The transition matrix of productivity conditional on doing or not doing $R \& D$ is calculated accordingly.

We first derive the per-period revenue, profit, static export and import choices at each state in the grid, as described in Section 3. The discrete R\&D choice is the only dynamic decision. Each firm maximizes the sum of its current and discounted future profits. We iterate on the value function until numerical convergence. We do not get a deterministic $R \& D$ decision since only the mean $R \& D$ costs are known to the firms when solving the Bellman equation. However, we can calculate the value of doing $R \& D$ at any given state. In step 2, after firms observe their cost draws, they can then make deterministic R\&D investment decisions.

Step 2 Simulating firms' decisions.

We then simulate the decisions for a panel of 8000 firms and 80 periods. For 20 countries, we simulate decisions of 400 firms over 80 periods. Each country gets a unique series of exchange rates shocks simulated following the same $\mathrm{AR}(1)$ process and mapped to the grids of the state space. The shocks in the initial period are drawn from the steady-state distribution implied by the AR(1) process. All the cost shocks are drawn from their respective distributions.

With respect to firms' idiosyncratic productivity shocks, we assume that no firm does R\&D in period 1 , and draw the initial-period productivity shocks from the steady-state distribution without R\&D. In each subsequent period, given the beginning-of-period productivity and other shocks, each firm then makes the static export and import decisions, and also the dynamic R\&D decisions by comparing their associated fixed or sunk cost draws with the value of doing $R \& D$ computed in step 1 (taking into account the credit constraint). After knowing each firm's R\&D decision, we simulate its end-of-period productivity shock following the respective AR(1) process. The moments of interest are then calculated from the simulated data on exporting, importing, sales, cash flow, etc. The first 10 periods are considered as burn-in periods and not used to calculate the data moments.

Step 3 Indirect Inference.

Steps 1 and 2 together generate the moments of interest for any given $\Theta$. In step $3, \Theta$ is updated to minimize a weighted distance between the data statistics and the simulated statistics (see below). After 
each optimization step, we return to steps 1 and 2 using the updated guess of $\Theta$. The minimization is performed using the genetic algorithm.

Let $\nu$ be the $p \times 1$ vector of data statistics and let $\nu(\Theta)$ denote the synthetic counterpart of $\nu$ with the statistics computed from artificial data generated by the structural model. Then the indirect-inference estimator of the $q \times 1$ vector $\Theta, \tilde{\Theta}$ is the value that solves: $\min _{\beta}(\nu-\nu(\Theta))^{\prime} V(\nu-\nu(\Theta))$, where $V$ is the $p \times p$ optimal weighting matrix (the inverse of the variance-covariance matrix of the data statistics $\nu)$. Since the data statistics are computed from different datasets, we set the off-diagonal elements of the variance-covariance matrix to zero. (See Cosar et al., 2016, and Dix-Carneiro, 2014, for a similar approach.) One can show that under certain regularity conditions, the estimates are consistent and asymptotically normal. (See Gouriéroux et al., 1993, for details.)

\section{Appendix B: Additional Figures and Tables}

Figure B-1: Aggregate effect of an unexpected real depreciation $(25 \%, 12.5 \%)$ and appreciation $(25 \%)$ for emerging Asia.
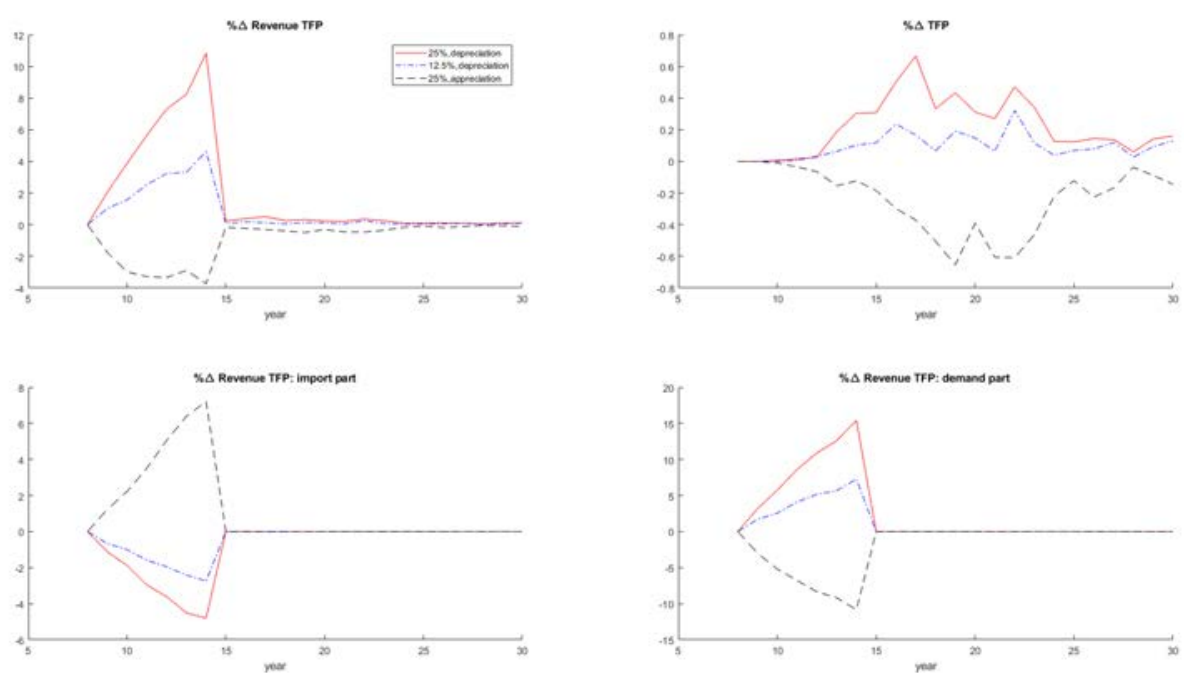
Figure B-2: Aggregate effect of an unexpected real depreciation $(25 \%, 12.5 \%)$ and appreciation $(25 \%)$ for other emerging economies.
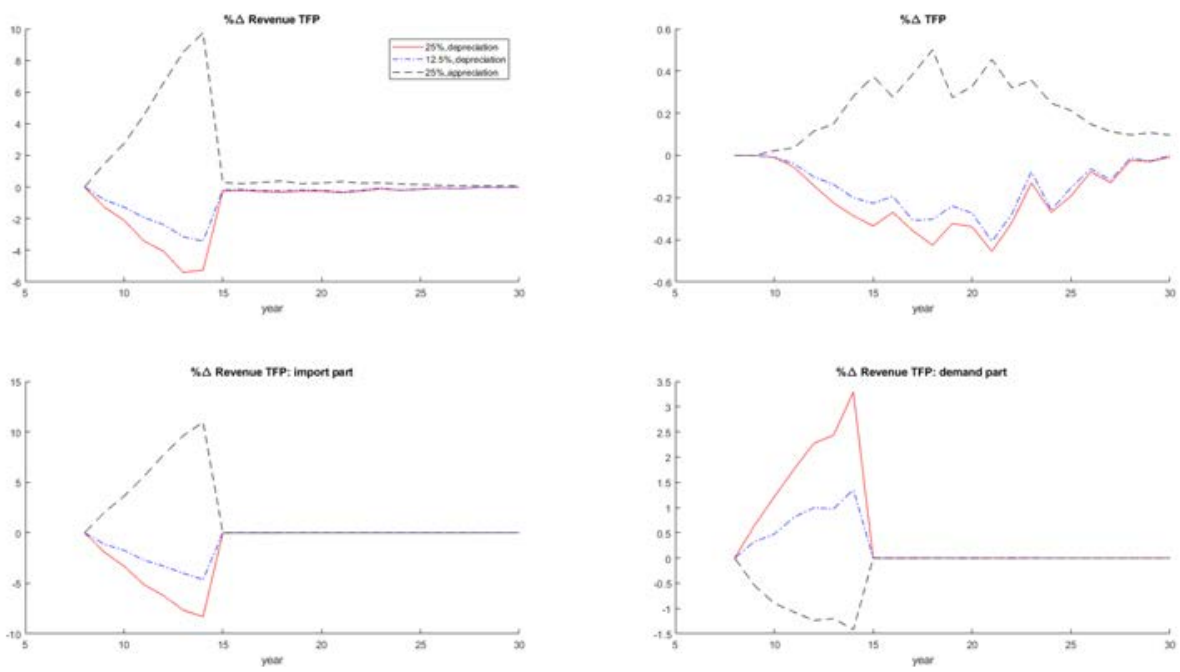

Figure B-3: Aggregate effect of an unexpected real depreciation $(25 \%, 12.5 \%)$ and appreciation $(25 \%)$ for industrialized economies.
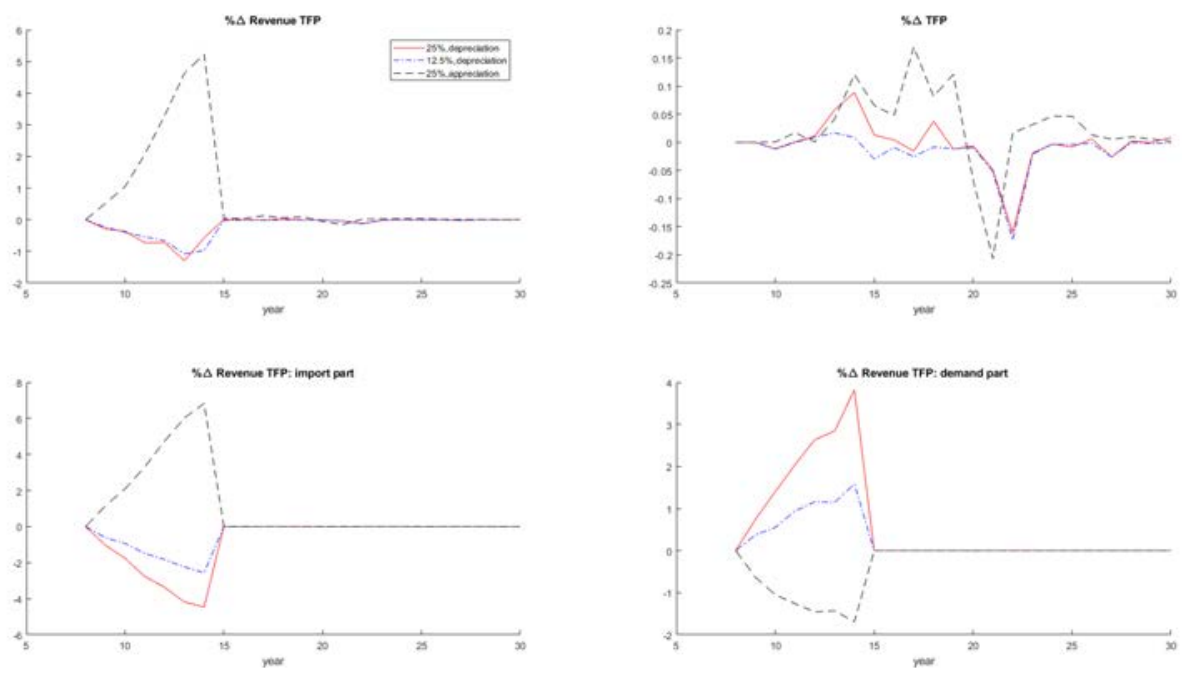
Table B-1: Panel A - Sample Frame

\begin{tabular}{|c|c|c|c|c|c|c|c|}
\hline Country & Freq. & Percent & Cum. & Country & Freq. & Percent & Cum \\
\hline $\mathrm{ARG}^{*}$ & 98 & 0.01 & 0.01 & KEN* & 13 & 0 & 88.28 \\
\hline AUS+ & 1,004 & 0.08 & 0.08 & KOR- & 101,267 & 7.63 & 95.91 \\
\hline AUT+ & 5,895 & 0.44 & 0.53 & KWT* & 33 & 0 & 95.91 \\
\hline BEL+ & 25,908 & 1.95 & 2.48 & $\mathrm{LBN}^{*}$ & 1 & 0 & 95.91 \\
\hline BGD- & 36 & 0 & 2.48 & LKA- & 126 & 0.01 & 95.92 \\
\hline BGR* & 24,114 & 1.82 & 4.3 & LTU* & 64 & 0 & 95.92 \\
\hline BHR* & 6 & 0 & 4.3 & LUX+ & 38 & 0 & 95.93 \\
\hline $\mathrm{BIH}^{*}$ & 15,580 & 1.17 & 5.47 & LVA* & 64 & 0 & 95.93 \\
\hline BOL* & 32 & 0 & 5.48 & MAR* & 15 & 0 & 95.93 \\
\hline BRA* & 2,030 & 0.15 & 5.63 & MEX* & 152 & 0.01 & 95.94 \\
\hline BRB* & 1 & 0 & 5.63 & MKD* & 73 & 0.01 & 95.95 \\
\hline BWA* & 1 & 0 & 5.63 & MLT* & 3 & 0 & 95.95 \\
\hline CAN+ & 30 & 0 & 5.63 & MUS+ & 8 & 0 & 95.95 \\
\hline CHE+ & 538 & 0.04 & 5.67 & MWI* & 1 & 0 & 95.95 \\
\hline CHL* & 5 & 0 & 5.67 & MYS+ & 3,210 & 0.24 & 96.19 \\
\hline CHN- & 213,230 & 16.07 & 21.74 & NAM $^{*}$ & 4 & 0 & 96.19 \\
\hline $\mathrm{COL}^{*}$ & 125 & 0.01 & 21.75 & NGA* & 168 & 0.01 & 96.21 \\
\hline $\mathrm{CPV}^{*}$ & 4 & 0 & 21.75 & NLD+ & 4,111 & 0.31 & 96.52 \\
\hline CRI* & 8 & 0 & 21.75 & NOR+ & 11,227 & 0.85 & 97.36 \\
\hline CYP* & 204 & 0.02 & 21.76 & NZL+ & 41 & 0 & 97.36 \\
\hline CZE* & 5,216 & 0.39 & 22.16 & OMN* & 158 & 0.01 & 97.38 \\
\hline DEU+ & 100,801 & 7.59 & 29.75 & PAK* & 134 & 0.01 & 97.39 \\
\hline DMA* & 4 & 0 & 29.75 & $\mathrm{PAN}^{*}$ & 14 & 0 & 97.39 \\
\hline DNK+ & 915 & 0.07 & 29.82 & $\mathrm{PER}^{*}$ & 151 & 0.01 & 97.4 \\
\hline DOM $^{*}$ & 6 & 0 & 29.82 & PHL- & 216 & 0.02 & 97.41 \\
\hline ECU* & 18 & 0 & 29.82 & $\mathrm{POL}^{*}$ & 11,174 & 0.84 & 98.26 \\
\hline EGY* & 70 & 0.01 & 29.83 & PRT+ & 137 & 0.01 & 98.27 \\
\hline $\mathrm{ESP}+$ & 291,219 & 21.94 & 51.77 & PRY* & 8 & 0 & 98.27 \\
\hline $\mathrm{EST}^{*}$ & 16,559 & 1.25 & 53.02 & QAT* & 10 & 0 & 98.27 \\
\hline FIN+ & 30,996 & 2.34 & 55.35 & ROU* & 27 & 0 & 98.27 \\
\hline FJI* & 3 & 0 & 55.35 & SAU* & 33 & 0 & 98.27 \\
\hline FRA+ & 168,756 & 12.71 & 68.07 & SGP- & 1,462 & 0.11 & 98.38 \\
\hline GBR+ & 37,491 & 2.82 & 70.89 & $\mathrm{SLV}^{*}$ & 4 & 0 & 98.38 \\
\hline GHA* & 4 & 0 & 70.89 & SRB* & 3 & 0 & 98.38 \\
\hline GRC+ & 24,076 & 1.81 & 72.7 & SVK* & 9 & 0 & 98.38 \\
\hline GRD* & 1 & 0 & 72.71 & SVN* & 21 & 0 & 98.39 \\
\hline GTM* & 7 & 0 & 72.71 & SWE+ & 9,262 & 0.7 & 99.08 \\
\hline HKG- & 351 & 0.03 & 72.73 & THA- & 3,677 & 0.28 & 99.36 \\
\hline $\mathrm{HRV}^{*}$ & 35,905 & 2.71 & 75.44 & TTO* & 1 & 0 & 99.36 \\
\hline HUN* & 28 & 0 & 75.44 & TUN* & 3 & 0 & 99.36 \\
\hline IDN- & 1,055 & 0.08 & 75.52 & TUR* & 81 & 0.01 & 99.37 \\
\hline IND- & 303 & 0.02 & 75.54 & TWN- & 7,369 & 0.56 & 99.92 \\
\hline IRL+ & 2,120 & 0.16 & 75.7 & TZA* & 4 & 0 & 99.92 \\
\hline IRN* & 126 & 0.01 & 75.71 & UGA* & 1 & 0 & 99.92 \\
\hline $\mathrm{IRQ}^{*}$ & 15 & 0 & 75.71 & $\mathrm{UKR}^{*}$ & 307 & 0.02 & 99.95 \\
\hline ISL+ & 25 & 0 & 75.71 & URY* & 5 & 0 & 99.95 \\
\hline $\mathrm{ISR}^{*}$ & 696 & 0.05 & 75.77 & VEN* & 2 & 0 & 99.95 \\
\hline ITA+ & 107,685 & 8.11 & 83.88 & VNM- & 528 & 0.04 & 99.99 \\
\hline $\mathrm{JAM}^{*}$ & 4 & 0 & 83.88 & $\mathrm{ZAF}^{*}$ & 174 & 0.01 & 100 \\
\hline JOR* & 229 & 0.02 & 83.9 & ZMB* & 8 & 0 & 100 \\
\hline JPN+ & 58,096 & 4.38 & 88.27 & ZWE* & 3 & 0 & 100 \\
\hline KAZ* & 25 & 0 & 88.28 & Total & $1,333,986$ & 100 & \\
\hline
\end{tabular}

Notes: + indicates industrialized economies, - indicates emerging Asia, * indicates other emerging economies. The number of observations for each country correspond to those of Table 1, columns (1) and (2). These numbers correspond to those observations included in the estimation that are not absorbed by the fixed effects. 
Table B-1: Panel B - Firm-level descriptive statistics. Mean values of firm-level variables by trade status (in thousands of constant 2004 Dollars)

\begin{tabular}{|c|c|c|c|c|c|c|c|c|c|c|}
\hline & sales & evalue added & capital & mat. & empl. & TFPR & R\&D prob. & ex. prob. & im. prob. & Firms \\
\hline full sample & 18.015 & 5.871 & 5.960 & 7.082 & 110.685 & 0.406 & 0.341 & n.a. & n.a. & 494,652 \\
\hline with trade data & 24.688 & 8.675 & 7.889 & 8.954 & 123.687 & 0.540 & 0.423 & 0.290 & 0.221 & 177,358 \\
\hline domestic firms & 15.439 & 5.924 & 4.691 & 5.842 & 81.437 & 0.428 & 0.327 & 0.000 & 0.000 & 127,943 \\
\hline exporters & 46.459 & 14.984 & 15.407 & 15.948 & 223.573 & 0.806 & 0.551 & 1.000 & 0.644 & 43,766 \\
\hline importers & 47.162 & 13.534 & 15.452 & 15.337 & 223.240 & 0.803 & 0.543 & 0.847 & 1.000 & 32,935 \\
\hline
\end{tabular}

Table B-1: Panel C - Firm-level descriptive statistics. Growth rates of firm-level outcomes.

\begin{tabular}{lcccccc}
\hline \hline & Mean & Median & S.D. & Pct. 10 & Pct. 90 & Observations \\
\hline$\Delta$ log TFPR \\
VA,it & 0.062 & 0.032 & 0.401 & -0.323 & 0.459 & $1,333,986$ \\
$\Delta \log$ TFPR $_{G O, i t}$ & 0.014 & 0.009 & 0.149 & -0.127 & 0.155 & $1,333,986$ \\
$\Delta \log$ sales $_{i t}$ & 0.083 & 0.045 & 0.421 & -0.280 & 0.458 & $1,275,606$ \\
$\Delta \log$ c. f.it $_{\Delta}$ R\&D prob.it & 0.032 & 0.033 & 0.810 & -0.770 & 0.835 & 772,970 \\
\hline \hline
\end{tabular}

Table B-1: Panel D - Percentage changes in aggregate/trade-weighted real exchange rates (computed from PWT 8.0).

\begin{tabular}{lcccccc}
\hline \hline & Mean & Median & S.D. & Pct.10 & Pct. 90 & Observations \\
\hline$\Delta \log \left(e_{c t}\right)$ (sample weights) & -0.022 & -0.026 & 0.077 & -0.106 & 0.069 & $1,333,986$ \\
$\Delta \log \left(e_{s c t}^{e x p}\right)$ (sample weights) & -0.009 & -0.001 & 0.037 & -0.054 & 0.036 & $1,285,833$ \\
$\Delta \log \left(e_{s c t}^{i m p}\right)$ (sample weights) & -0.010 & -0.001 & 0.038 & $-0-061$ & 0.028 & $1,286,033$ \\
$\Delta \log \left(e_{c t}\right)$ (unweighted) & -0.034 & -0.040 & 0.119 & -0.160 & 0.086 & 1,832 \\
$\Delta \log \left(e_{c t}\right)$ (5-year differences) & -0.189 & -0.211 & 0.248 & -0.478 & -0.196 & 333 \\
\hline \hline
\end{tabular}

Table B-2: Import and export propensity/intensity, manufacturing plants (WB Enterprise Survey 2016)

\begin{tabular}{lcc}
\hline \hline & emerging Asia & other emerging \\
\hline Export prob. & 0.20 & 0.26 \\
Import prob. & 0.19 & 0.33 \\
$\begin{array}{l}\text { Avg. export intensity } \\
\text { (exporters) }\end{array}$ & 0.58 & 0.25 \\
$\begin{array}{l}\text { Avg. import intensity } \\
\text { (importers) }\end{array}$ & 0.13 & 0.14 \\
\hline \hline
\end{tabular}

Notes: Emerging Asia is defined as emerging East Asia and South Asia; other emerging economies are defined as Eastern Europe and Latin America.

Table B-3: Estimation of log RER, AR (1) process

\begin{tabular}{lcc}
\hline \hline & $(1)$ & $(2)$ \\
\hline $\log e_{c, t-1}$ & $0.930^{* * *}$ & $0.935^{* * *}$ \\
& $(0.015)$ & $(0.015)$ \\
\hline Observations & 1,832 & 1,832 \\
R-squared & 0.931 & 0.947 \\
S.D. residuals & 0.105 & 0.0924 \\
Country FE & YES & YES \\
Time FE & NO & YES \\
Cluster & Country & Country \\
\hline \hline
\end{tabular}

Notes: AR (1) process of log RER. The explanatory variable of interest is the 1-year lag of the log RER from the PWT 8.0. Standard errors are clustered at the country level. ${ }^{*},{ }^{* *}$ and ${ }^{* * *}$ indicate statistical significance at the $10 \%, 5 \%$ and $1 \%$ levels. 
Table B-4: Production function: coefficient estimates

\begin{tabular}{|c|c|c|c|c|}
\hline & $\begin{array}{l}\text { (1) } \\
\text { GO }\end{array}$ & $\begin{array}{l}(2) \\
\text { VA }\end{array}$ & $\begin{array}{c}(3) \\
\text { GO } \\
\text { CRS }\end{array}$ & $\begin{array}{c}(4) \\
\text { VA } \\
\text { CRS }\end{array}$ \\
\hline labor $\tilde{\beta}_{l}$ & $\begin{array}{c}0.336^{* * *} \\
(0.002)\end{array}$ & $\begin{array}{c}0.533^{* * *} \\
(0.002)\end{array}$ & $\begin{array}{c}0.336^{* * *} \\
(0.002)\end{array}$ & $\begin{array}{c}0.533^{* * *} \\
(0.002)\end{array}$ \\
\hline capital $\tilde{\beta}_{k}$ & $\begin{array}{c}0.093^{* * *} \\
(0.018)\end{array}$ & $\begin{array}{c}0.210^{* * *} \\
(0.010)\end{array}$ & $\begin{array}{c}0.051^{* * *} \\
(0.008)\end{array}$ & $\begin{array}{c}0.217^{* * *} \\
(0.002)\end{array}$ \\
\hline materials $\tilde{\beta}_{m}$ & $\begin{array}{c}0.682^{* * *} \\
(0.022)\end{array}$ & & $\begin{array}{c}0.363^{* * *} \\
(0.008)\end{array}$ & \\
\hline $\mathrm{R} \& \mathrm{D}$ return $\tilde{\alpha}_{2}$ & $\begin{array}{c}0.079^{* * *} \\
(0.013)\end{array}$ & $\begin{array}{c}0.033^{* *} \\
(0.016)\end{array}$ & $\begin{array}{c}0.060^{* * *} \\
(0.009)\end{array}$ & $\begin{array}{c}0.033^{* *} \\
(0.016)\end{array}$ \\
\hline $\begin{array}{l}\log \left(e_{s c t}^{E X P}\right) \times \\
\lambda_{1}^{E X P}\end{array}$ & $\begin{array}{c}0.001 \\
(0.021)\end{array}$ & $\begin{array}{c}-0.149 * * * \\
(0.034)\end{array}$ & $\begin{array}{c}0.001 \\
(0.021)\end{array}$ & $\begin{array}{c}-0.149 * * * \\
(0.034)\end{array}$ \\
\hline$\lambda_{2}^{\log \left(e_{S c t}^{E X P}\right) \times}$ & $\begin{array}{c}0.426^{* * *} \\
(0.025)\end{array}$ & $\begin{array}{c}0.729^{* * *} \\
(0.039)\end{array}$ & $\begin{array}{c}0.426^{* * *} \\
(0.025)\end{array}$ & $\begin{array}{c}0.729^{* * *} \\
(0.039)\end{array}$ \\
\hline $\log _{E X P}\left(e_{s c t}^{E X P}\right) \times$ & $0.345^{* * *}$ & $0.755^{* * *}$ & $0.345^{* * *}$ & $0.755^{* * *}$ \\
\hline$\hat{l}_{3}\left(e_{s c t}^{E X P}\right) \times$ & $0.178^{* * *}$ & $0.445^{* * *}$ & $0.178^{* * *}$ & $0.445^{* * *}$ \\
\hline$\lambda_{4}^{E X P}$ & $(0.068)$ & $(0.117)$ & $(0.068)$ & $(0.117)$ \\
\hline $\begin{array}{l}\log \left(e_{s c t}^{I M P}\right) \times \\
\lambda_{1}^{I M P}\end{array}$ & $\begin{array}{c}-0.073^{* * *} \\
(0.020)\end{array}$ & $\begin{array}{c}0.110^{* * *} \\
(0.032)\end{array}$ & $\begin{array}{c}-0.073^{* * *} \\
(0.020)\end{array}$ & $\begin{array}{c}0.110^{* * *} \\
(0.032)\end{array}$ \\
\hline $\begin{array}{l}\log \left(e_{s c t}^{I M P}\right) \times \\
\lambda_{2}^{I M P}\end{array}$ & $\begin{array}{c}-0.561^{* * *} \\
(0.025)\end{array}$ & $\begin{array}{c}-0.838^{* * * *} \\
(0.034)\end{array}$ & $\begin{array}{c}-0.561^{* * *} \\
(0.025)\end{array}$ & $\begin{array}{c}-0.838 * * * \\
(0.034)\end{array}$ \\
\hline$\lambda_{3}^{I M P} \log \left(e_{s c t}^{I M P}\right) \times$ & $\begin{array}{c}-0.700^{* * *} \\
(0.027)\end{array}$ & $\begin{array}{c}-1.142^{* * *} \\
(0.045)\end{array}$ & $\begin{array}{c}-0.700^{* *} \\
(0.027)\end{array}$ & $\begin{array}{c}-1.142^{* * *} \\
(0.045)\end{array}$ \\
\hline $\begin{array}{l}\log \left(e_{s c t}^{I M P}\right) \times \\
\lambda_{4}^{I M P}\end{array}$ & $\begin{array}{c}-0.827^{* * *} \\
(0.066)\end{array}$ & $\begin{array}{c}-1.240^{* * *} \\
(0.117)\end{array}$ & $\begin{array}{c}-0.827^{* * *} \\
(0.066)\end{array}$ & $\begin{array}{c}-1.240^{* * *} \\
(0.117)\end{array}$ \\
\hline Country-time FE & YES & YES & YES & YES \\
\hline Sector FE & YES & YES & YES & YES \\
\hline Cluster & Firm & Firm & Firm & Firm \\
\hline
\end{tabular}

Notes: Gross-output (GO) and value-added (VA) production-function estimates. Details of the production-function estimation are explained in Appendix A-1.4. The terms $\lambda_{j}^{E X P} \times \log \left(e_{s, t}^{E X P}\right)$ and $\lambda_{j}^{I M P} \times \log \left(e_{s, t}^{I M P}\right)$ are interactions of sector-specific export and import-weighted RERs with dummies for firm-size bins for $\leq 20$ employees; $20-50$ employees; $50-200$ employees; $\geq 200$ employees. Bootstrapped standard errors clustered at the firm level reported in parentheses. *,** and *** indicate statistical significance at the $10 \%, 5 \%$ and $1 \%$ levels. 
Table B-5: The aggregate RER and firm-level outcomes: separating depreciations and appreciations

\begin{tabular}{lcccc}
\hline \hline & $(1)$ & $(2)$ & $(3)$ & $(4)$ \\
& $\Delta \log$ TFPR $_{V A, i t}$ & $\Delta \log$ TFPR $_{G O, i t}$ & $\Delta \log$ sales $_{i t}$ & $\Delta \log$ c. $_{\text {. }}$ \\
\hline$\left|\Delta \log e_{c t}\right| \times I_{c t}^{+} \times$ & $0.740^{* * *}$ & $0.243^{* * *}$ & $1.209^{* * *}$ & $1.580^{* * *}$ \\
emerging Asia & $(0.152)$ & $(0.077)$ & $(0.285)$ & $(0.238)$ \\
$\left|\Delta \log e_{c t}\right| \times I_{c t}^{-} \times$ & 0.159 & -0.020 & $0.657^{* *}$ & 0.153 \\
emerging Asia & $(0.124)$ & $(0.057)$ & $(0.323)$ & $(0.310)$ \\
$\left|\Delta \log e_{c t}\right| \times I_{c t}^{+} \times$ & -0.231 & 0.020 & -0.739 & 0.136 \\
other emerging & $(0.402)$ & $(0.128)$ & $(0.449)$ & $(0.299)$ \\
$\left|\Delta \log e_{c t}\right| \times I_{c t}^{-} \times$ & $0.864^{* * *}$ & $0.219^{* * *}$ & $1.039^{* *}$ & $1.124^{* *}$ \\
other emerging & $(0.234)$ & $(0.077)$ & $(0.427)$ & $(0.528)$ \\
$\left|\Delta \log e_{c t}\right| \times I_{c t}^{+} \times$ & -0.056 & -0.072 & -0.790 & -0.225 \\
industrialized & $(0.198)$ & $(0.094)$ & $(0.544)$ & $(0.313)$ \\
$\left|\Delta \log e_{c t}\right| \times I_{c t}^{-} \times$ & -0.026 & 0.011 & -0.062 & 0.430 \\
industrialized & $(0.143)$ & $(0.048)$ & $(0.251)$ & $(0.290)$ \\
\hline Observations & $1,333,986$ & $1,333,986$ & $1,275,606$ & 772,970 \\
R-squared & 0.057 & 0.038 & 0.104 & 0.024 \\
Country-sector FE & YES & YES & YES & YES \\
Time FE & YES & YES & YES & YES \\
Business cycle controls & YES & YES & YES & YES \\
Cluster & Country & Country & Country & Country \\
\hline \hline
\end{tabular}

Notes: The dependent variable in columns (1)-(4) is the annual log difference in the following firm-level outcomes computed from Orbis for manufacturing firms for the years 2001-2010: revenue-based TFP computed from value-added (column 1), revenue-based TFP computed from gross output (column 2), nominal sales (column 3), cash flow (column 4). We do not present results for R\&D status, which are not statistically significant. The construction of TFP is explained in section 4 of the paper. The main explanatory variable of interest is the absolute value of the annual log difference in the real exchange rate from the PWT 8.0 interacted with dummies for depreciation $\left(I_{c t}^{+}\right)$and appreciation $\left(I_{c t}^{-}\right)$and dummies for emerging Asia; other emerging economy; industrialized economy. The regressions also control for the real growth rate of GDP in PPP (from PWT8.0) and the inflation rate (from IMF). Standard errors are clustered at the country level. *, ** and *** indicate statistical significance at the $10 \%, 5 \%$ and $1 \%$ levels. 


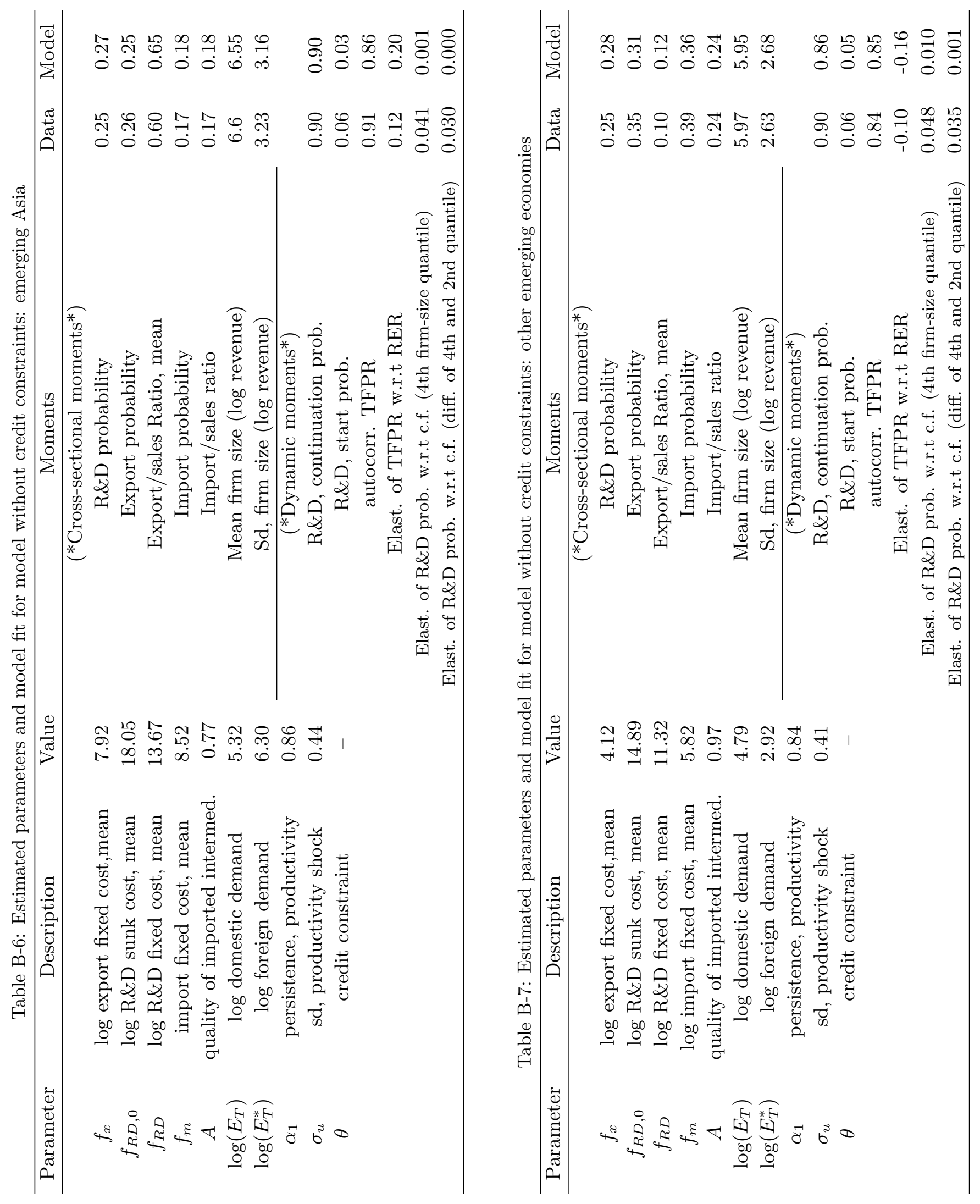




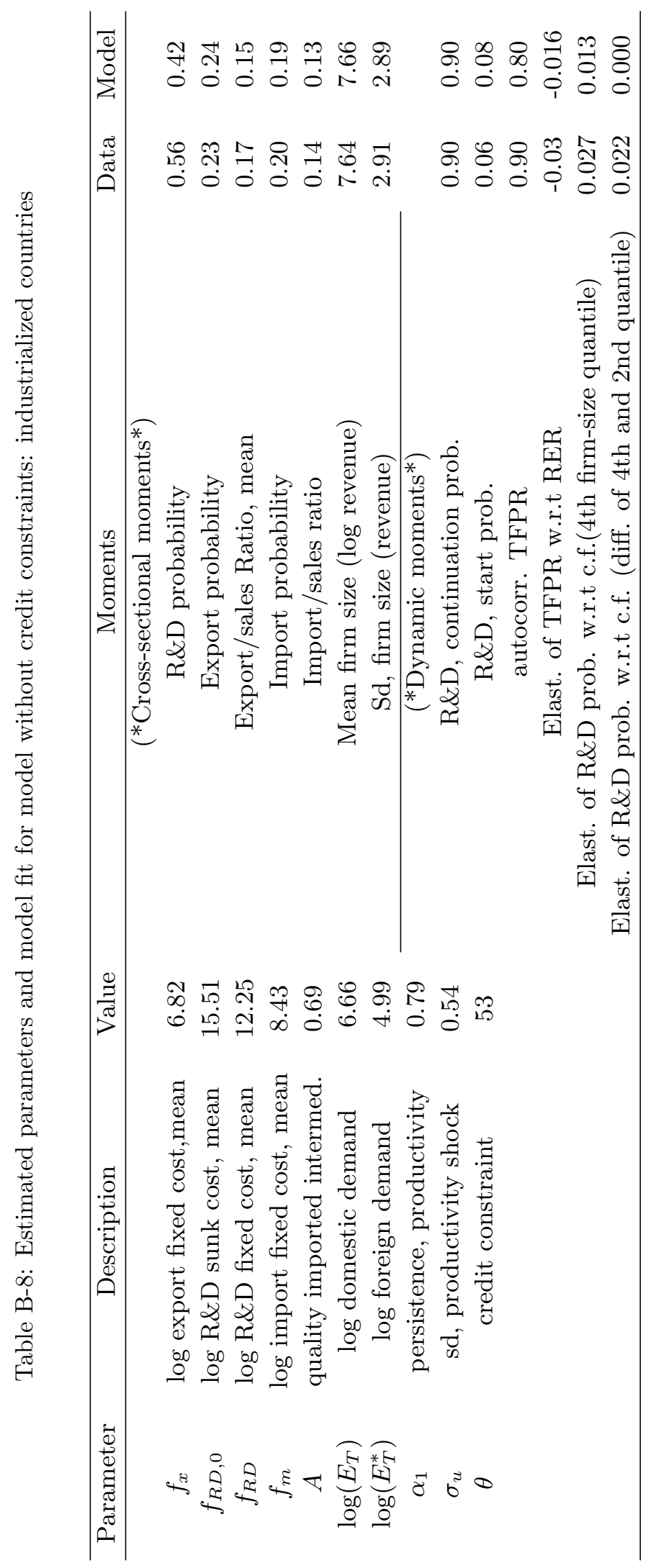



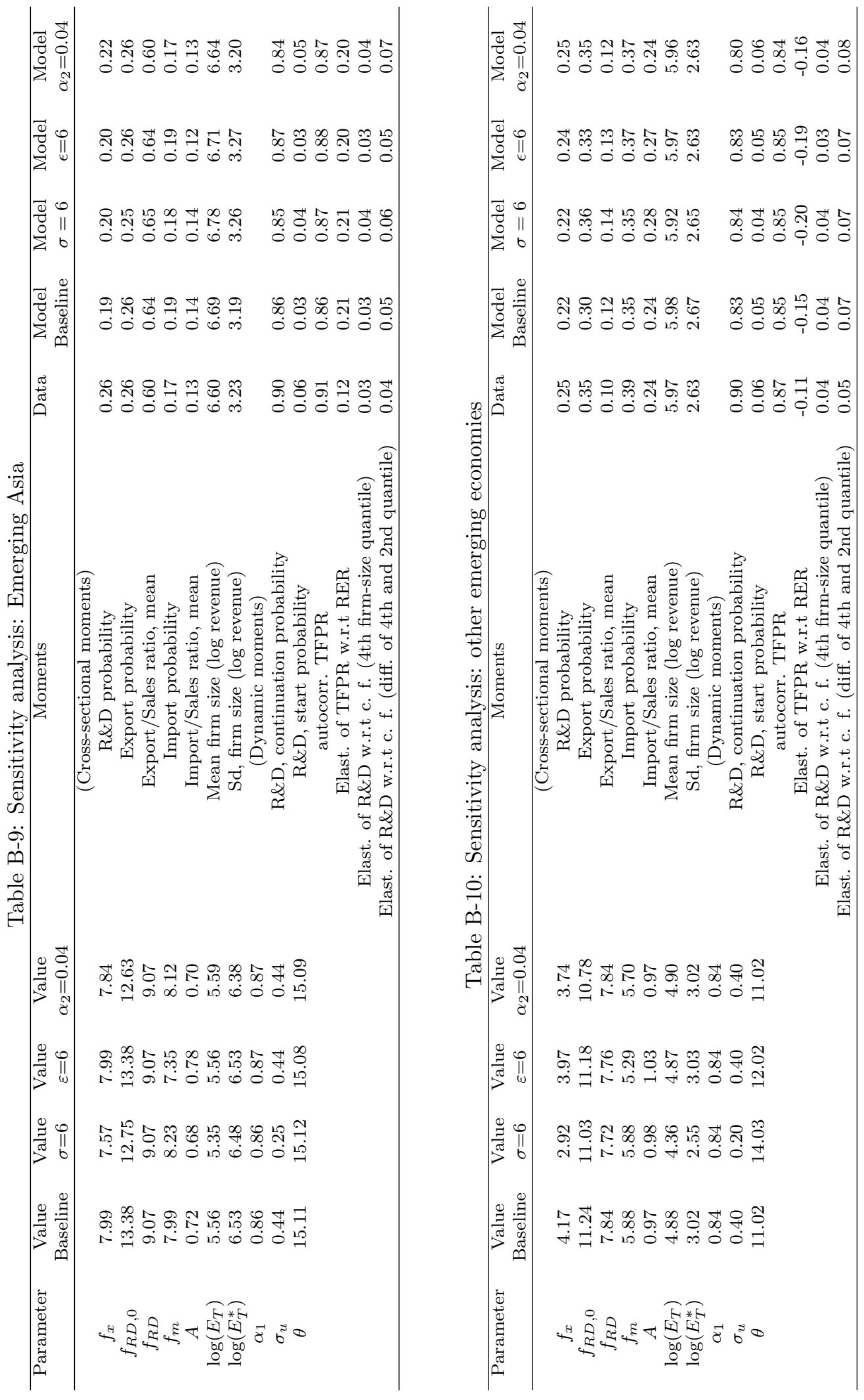


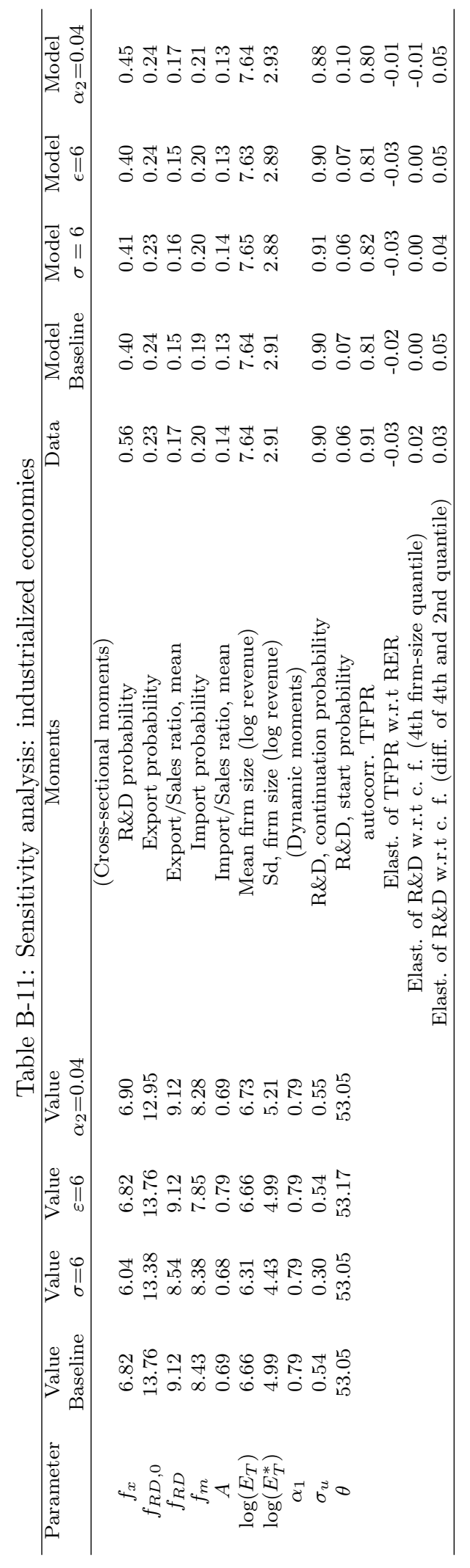

